Universidade de São Paulo

Programa de Pós-Graduação em Física

Instituto de Física

\title{
ESTUDO DAS PROPRIEDADES DE TRANSPORTE ELETRÔNICO DE OLIGOANILINAS E OLIGOTIOFENOS CONECTADOS A ELETRODOS DE OURO
}

\author{
Jeconias Rocha Guimarães \\ Orientadora: Profa. Dra. Maria Cristina dos Santos
}

Tese de doutorado apresentada ao

Instituto de Física para a obtenção

do título de Doutor em Ciências

Comissão examinadora:

Profa. Dra. Maria Cristina dos Santos-IFUSP

Prof. Dr. Alexandre Reily Rocha-IFUSP

Profa. Dra. Euzi Conceição Fernandes da Silva-IFUSP

Prof. Dr. Geraldo Magela e Silva-UNB

Prof. Dr. Marcio Henrique Franco Bettega-UFPR 
FICHA CATALOGRÁFICA

Preparada pelo Serviço de Biblioteca e Informação do Instituto de Física da Universidade de São Paulo

Guimarães, Jeconias Rocha

Estudo das propriedades de transporte eletrônico de oligoanilinas e oligotiofenos conectados a eletrodos de ouro. - São Paulo, 2012.

Tese (Doutorado) - Universidade de São Paulo. Instituto de Física, Depto. Física dos Materiais e Mecânica.

Orientador: Profa. Dra. Maria Cristina dos Santos

Área de Concentração: Física da Matéria Condensada

Unitermos: 1.Física da Matéria Condensada;

2. Nanopartículas; 3. Fenômenos de transporte; 4.

Física computacional; 5. Física teórica. 


\section{Sumário}

Agradecimentos 1

$\begin{array}{ll}\text { Resumo } & 3\end{array}$

$\begin{array}{ll}\text { Abstract } & 5\end{array}$

1 Introdução $\quad 6$

2 Metodologia 18

2.1 Transmitância via função de Green . . . . . . . . . . . . . . . . . . . . 19

2.2 Métodos de Química Quântica e Teoria do Funcional da Densidade . . . . 23

2.2.1 Método de Hartree-Fock . . . . . . . . . . . . . . . . . . . . . 24

2.2.2 Teoria do Funcional da Densidade-DFT . . . . . . . . . . . . . . 25

2.3 Método de Renormalização . . . . . . . . . . . . . . . . . 27

2.4 Funções de Base . . . . . . . . . . . . . . . . . . . . . . . . 30

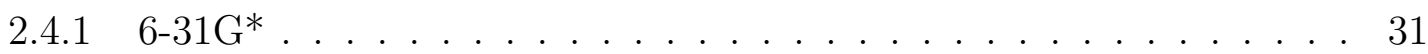

2.4.2 Método do Pseudopotencial . . . . . . . . . . . . . . 32

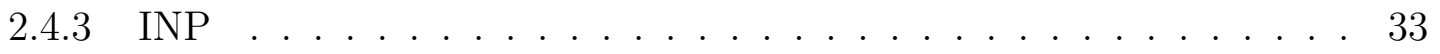

2.4.4 Densidade de Estados Projetada(PDOS) . . . . . . . . . . . . 33

3 Análise dos oligômeros de Anilina e Tiofeno 35

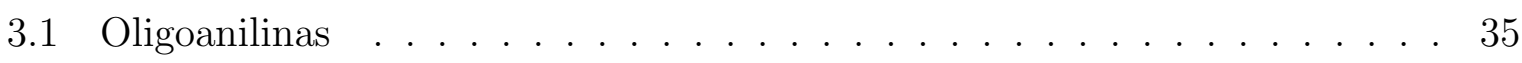

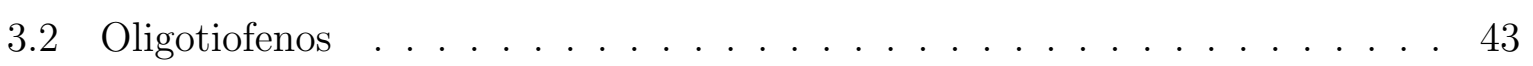


3.3 Eletrodos . . . . . . . . . . . . . . . . . . . . . . . . . 43

4 Resultados I: Análise estrutural e eletrônica das cadeias orgânicas conectadas aos eletrodos metálicos. 50

4.1 Leucoesmeraldina . . . . . . . . . . . . . . . . . . . 52

4.1 .1 Análise dos níveis . . . . . . . . . . . . . . . . . 56

4.2 Cadeias sob ação de um campo elétrico externo . . . . . . . . . . . . . . 58

4.3 Cadeias sob estiramento . . . . . . . . . . . . . . . . . 61

4.4 A origem das diferenças entre as conexões bridge e atop e o caso da conexão com o eletrodo $1 \ldots \ldots \ldots \ldots$

4.5 Aspectos estruturais e eletrônicos das formas oxidadas das oligoanilinas e dos oligotiofenos conectados aos eletrodos . . . . . . . . . . . . . . . 64

5 Resultados II: Transmitância dos Oligômeros Orgânicos $\quad 67$

5.1 Oligoanilinas . . . . . . . . . . . . . . . . . . 67

5.1.1 Método tight-binding de primeiros vizinhos . . . . . . . . . . 68

5.1 .2 Transmitância calculada via DFT . . . . . . . . . . . . . . . . 71

5.1.3 Transmitância alta e baixa obtidas com o método tight-binding . . . 77

5.1.4 Transmitância das diversas formas de oligoanilinas obtidas com o método tight-binding . . . . . . . . . . . . . . 78

5.2 Oligoanilinas sob Estiramento . . . . . . . . . . . . . . . . . 78

5.2.1 Leucoesmeraldinas e Esmeraldinas . . . . . . . . . . . . . . . . 79

5.2 .2 Pernigranilinas . . . . . . . . . . . . . . . . . . . 81

5.3 Oligoanilinas sob ação de um Campo Elétrico . . . . . . . . . . . . . . . . 84

5.3.1 Leucoesmeraldinas e Esmeraldinas . . . . . . . . . . . . . . . . 84

5.3 .2 Pernigranilinas . . . . . . . . . . . . . . . . 85

5.4 Oligotiofenos . . . . . . . . . . . . . . . . . 85

5.5 Oligotiofenos sob estiramento . . . . . . . . . . . . . . . . 89

6 Conclusão $\quad 92$ 
$\begin{array}{ll}\text { A Método DFT } & 96\end{array}$

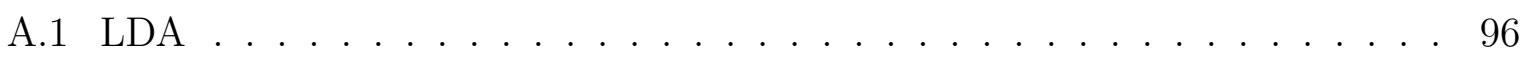

A.2 Funcionais GGA f . . . . . . . . . . . . . . . . . . . 99

A.2.1 O termo de Exchange . . . . . . . . . . . . . . . . . 100

A.2.2 O termo de correlação . . . . . . . . . . . . . . . . . 101

A.2.3 O funcional PBE . . . . . . . . . . . . . . . . . . . 102

B Função de Green 103

B.1 Teste com o poliacetileno . . . . . . . . . . . . . . . . . . . 103 


\section{Agradecimentos}

Agradeço ao CNPQ, pelo apoio financeiro, aos professores do Instituto de Física da USP principalmente à Prof. Maria Cristina dos Santos pelo incentivo, discussões e pelo imenso aprendizado científico. 


\section{Resumo}

Apresentamos cálculos de estrutura eletrônica de oligotiofenos e oligoanilinas conectados a contatos metálicos. Diversos aglomerados de ouro e acoplamentos com as moléculas orgânicas foram testados. Expressões analíticas para a função de transmissão, de acordo com a teoria de Landauer, foram obtidas por meio de um modelo tight-binding, juntamente com resultados numéricos da teoria do funcional da densidade (DFT). O pacote computacional Gaussian 03 foi empregado para realizar os cálculos DFT com o funcional híbrido B3LYP. Um conjunto de base misto foi escolhido: LANL2DZ para os átomo de ouro e 6-31G* para os átomos leves $\mathrm{S}, \mathrm{C}, \mathrm{N}$ e $\mathrm{H}$.

A geometria das cadeias orgânicas conectadas a eletrodos metálicos depende fortemente do tipo de conexão e fracamente do número de átomos representando o eletrodo. Em nossos modelos o átomo de enxofre conecta-se ao eletrodo nas geometrias bridge e atop. A principal diferença entre estes acoplamentos é uma significativa transferência de elétrons nos oligômeros ligados na forma atop. A redistribuição de carga resulta numa cadeia orgânica carregada positivamente acompanhada por uma mudança estrutural. Oligotiofenos apresentam uma distorção quinóide, enquanto que nas pernigranilinas $(\mathrm{PE})$ sua alternância entre anéis quinóides e aromáticos é invertida. Um campo elétrico externo foi aplicado nos sistemas. A resposta da transmissão eletrônica é correlacionada com o estado de oxidação das cadeias e acoplamento com os eletrodos. Nos sistemas de leucoesmeraldina(LE) e esmeraldina(EM) conectados de forma atop, o campo elétrico induz a localização dos orbitais de fronteira levando à diminuição da transmitância. Cadeias de LE e EM conectadas de forma bridge e as PE apresentam um aumento na transmissão em função do campo elétrico. Nas cadeias de PE as propriedades são menos dependentes da conexão com o eletrodo.

Aplicamos uma tensão nas cadeias orgânicas forçando um alongamento, similarmente ao que acontece nos experimentos de quebra de junção. Cadeias de LE e EM conectadas de forma bridge bem como PE em ambas conexões com os eletrodos, apresentam a mesma dependência do transporte em função do estiramento. O aumento inicial da transmissão 
é associado à planarização da cadeia, que induz a deslocalização dos orbitais. Entretanto, o subsequente alongamento localiza os orbitais por aumentar os comprimentos de ligação, o que leva a uma baixa transmitância. Cadeias de LE e EM conectadas de forma atop são fracamente afetadas pelo alongamento. Em oligotiofenos nos dois tipos de conexão com os eletrodos, o estiramento provoca uma significativa redução da transmissão. Por este mecanismo, oligômeros mais longos apresentam valores de condutância similares aos mais curtos. 


\section{Abstract}

We present electronic structure and transport calculations of oligothiophenes and oligoanilines bonded to metallic contacts. Several gold clusters and couplings to the organic molecule were tested. Analytical expressions for the transmission function, within Landauer theory, were obtained by means of a tight-binding model, along with numerical results from density functional theory (DFT). The software Gaussian 03 was employed to perform DFT calculations with the hybrid functional B3LYP. A mixed basis set was chosen: LANL2DZ for gold atoms and 6-31G* for light atoms S, C, N and H.

The geometry of organic chains bonded to metallic electrodes depend strongly on the type of connection with the metallic electrode and weakly on the number of atoms representing the electrode. In our models the sulfur atom connects to the electrodes in either atop or bridge geometries. The main diference between these two couplings is a significant electronic transfer on the atop bonded oligomers. The charge reorganization results in a positively charged organic part accompained by a structural change. Oligothiophenes present a quinoidal distortion, while in pernigranilines the alternation between aromatic and quinoid ring is reversed.

An external electric field was applied to the systems. The electronic transmission response is correlated to the oxidation state and coupling to electrodes. On the atop bonded systems leucoemeraldine(LE) and emeraldine (EM), the electric field induces a localization of the frontier orbitals leading to a decreased transmission. Pernigranilines(PE) and bridge-bonded LE and EM present an increase of transmission as a function of the electric field. In the PE chains the properties are less dependent on the connection to the electrodes.

We applied a tension on the organic chains by forcing an elongation, similarly to what happens in break-junction experiments. Bridge-bonded LE and EM, as well as PE in both types of connection to electrodes, present the same dependence of transport as function of stress. The initial increasing transmission is associated to a planarization of the chain that induces an orbital delocalization. However, the subsequent elongation localize orbitals by 
increasing the bond lengths and leads to a low transmission. Atop bonded LE and EM are weakly sensitive to elongation. On oligothiophenes in both types of connection to the electrodes, the stretching induces a significant decrease of transmission. By this mechanism longer oligomers present conductance values similar to small ones. 


\section{Capítulo 1}

\section{Introdução}

Há um interesse na ciência que estuda os materiais no entendimento do mecanismo de transporte através de uma única cadeia conectada à eletrodos metálicos $[1,2,3,4]$. São grandes as dificuldades experimentais para acessar esta propriedade, evidenciado pela discrepância nos resultados experimentais $[5,6]$ e pela fraca correspondência das medidas com a teoria $[7,8]$.

Os sistemas eletrodo-molécula-eletrodo (cadeias estendidas) podem apresentar periodicidade se a cadeia espalhadora for equivalente à célula unitária do eletrodo (Fig. 1.1 (a)). Quando ocorre essa situação, o resultado da probabilidade de transmissão é dado por um numero inteiro (Fig. 1.1 (b)), igual à quantidade de bandas do sistema periódico $[9,10,11,12]$. Estamos interessados, entretanto, nos sistemas que o eletrodo é um metal e a cadeia uma molécula orgânica (Fig. 1.2). Neste caso, o resultado da transmitância indica o quanto a cadeia diminui a probabilidade de transmissão através do metal [13]. O sistema eletrodo-cadeia-eletrodo é um sistema eletrônico aberto, por estar em contato com um contínuo de estados do reservatório de elétrons. Estes sistemas não apresentam, de modo geral, a característica molecular ou condições periódicas de contorno. Deste modo, não podem ser completamente estudados pelos métodos tradicionais de estrutura eletrônica. Escolhemos a teoria de Landauer neste estudo, por ser amplamente utilizada neste tipo de sistemas $[14,15,16,17]$.

No que se refere à propriedade eletrônica, os materiais macroscópicos são discriminados em 3 grandes grupos: isolantes, semicondutores e condutores. A grandeza que determina 


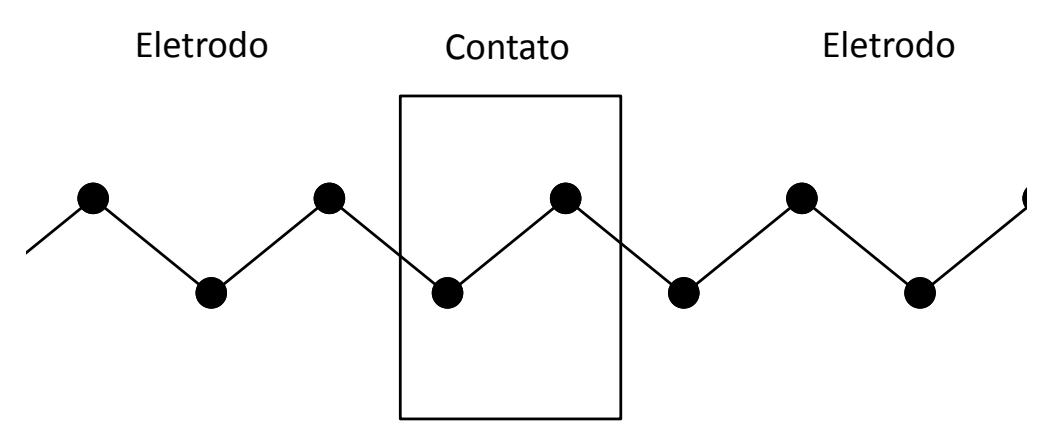

(a)

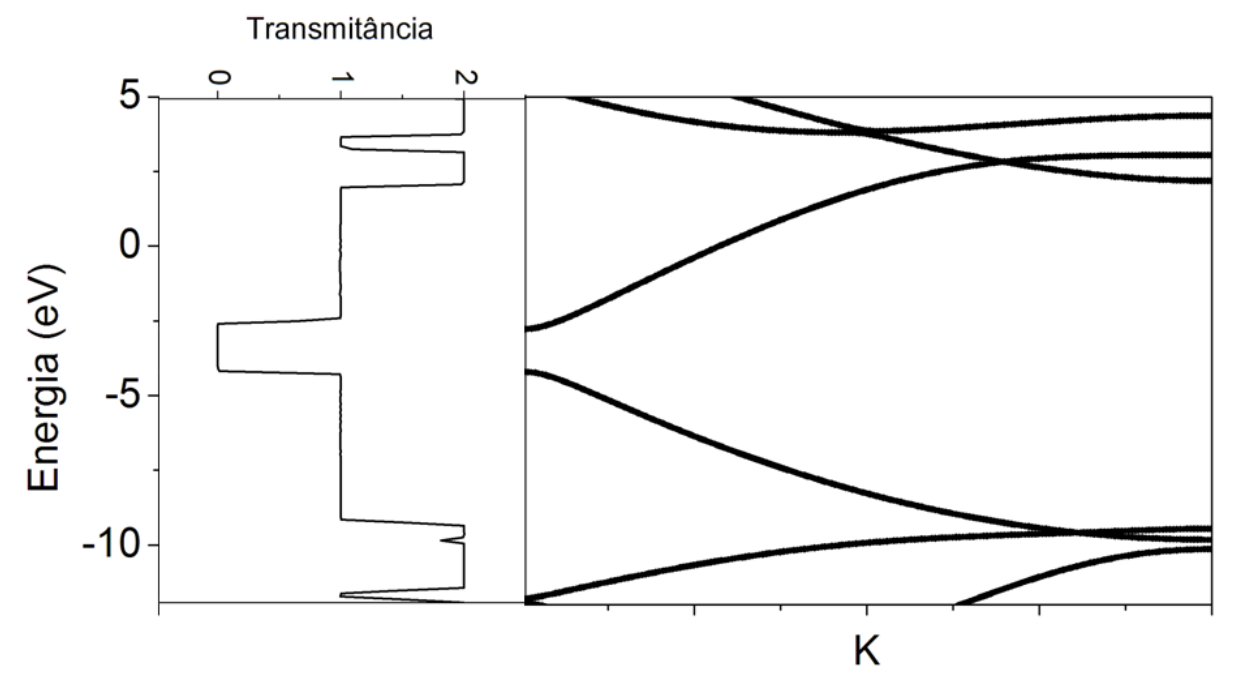

(b)

Figura 1.1: (a) Exemplo de uma cadeia conectada a eletrodos que possuem como célula unitária a mesma estrutura da cadeia espalhadora. (b) Resultado da transmitância e estrutura de bandas (ver Apêndice B). 


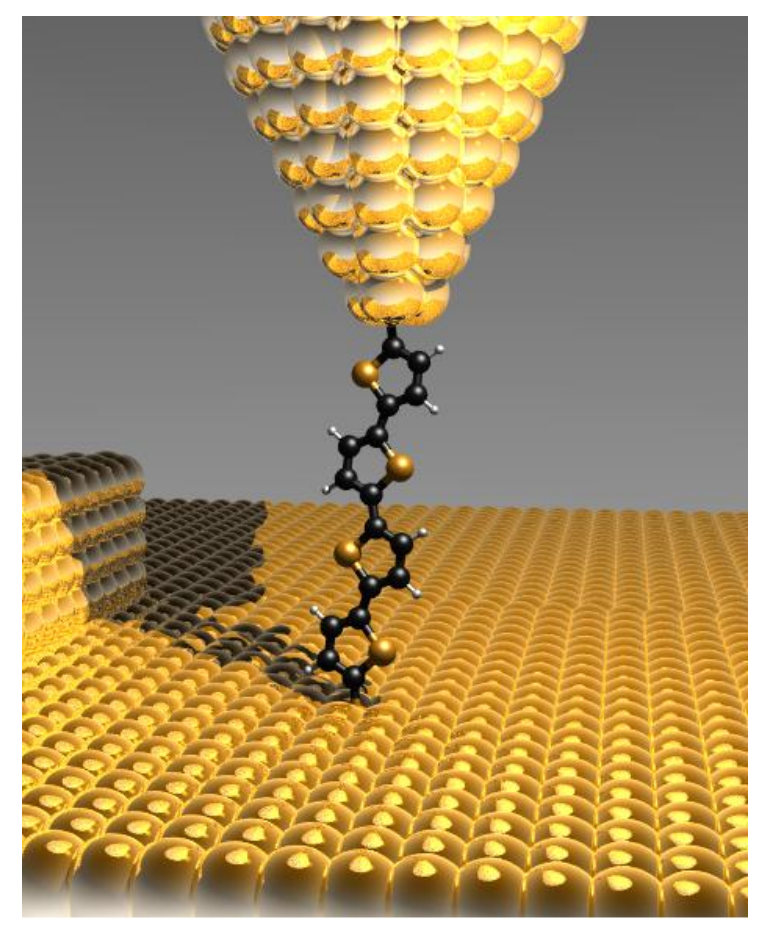

Figura 1.2: Estrutura padrão do sistema metal-molécula-metal.

esta classificação é a condutividade, que é obtida com a relação $\sigma=\frac{d I}{d V} \times \frac{L}{A}$, que depende do material e dos aspectos estruturais, especificamente área $(A)$ e comprimento $(L)$, onde $I$ e $V$ são a corrente e o potencial eletrônicos, respectivamente. Para o estudo dos sistemas moleculares utilizamos a condutância $G=d I / d V$, que pode ser obtida a partir da relação $G=\frac{2 e^{2}}{h} T\left(E_{f}\right)$, onde $T\left(E_{f}\right)$ é a transmitância calculada para o valor de energia igual a energia de Fermi e $\frac{2 e^{2}}{h}$ é o chamado quantum de condutância. A grandeza $T\left(E_{f}\right)$ é central na teoria de Landauer [13] e será discutida em mais detalhes no capítulo seguinte.

O entendimento do mecanismo de transporte em moléculas orgânicas é bastante importante em nível de fundamento científico, mas além disso pode levar ao desenvolvimento de dispositivos moleculares, que poderão substituir os atuais baseados em silício. O transístor, desenvolvido por Bardeen [18], desde sua invenção teve seu tamanho diminuido devido a novas técnicas de fabricação [19], entretanto há um limite para esta redução. Os dispositivos baseados em silício são fabricados utilizando a dopagem por átomos cuja camada de valência apresenta um número de elétrons diferente de 4 , dado 
que o silício possui 4 elétrons na camada de valência. Quando o dopante possui 5 ou mais elétrons na camada de valência, a dopagem é do tipo N, pois quando este substitui algum átomo de silício, após fazer as quatro ligações usuais restará um elétron sobrando. Os maiores problemas na redução do tamanho dos dispositivos atuais são dois: (I) menor capacidade de bloquear a corrente, devido a diminuição da barreira ao deslocamento eletrônico, que leva a um comprometimento da capacidade de chaveamento; (II) Quanto menor a área, menor será a homogeneidade da distribuição dos dopantes, que tornaria cada dispositivo com uma característica de retificação própria [20].

A possibilidade de construir dispositivos com materiais orgânicos vem sendo bastante estudada apartir da descoberta da condutividade em poliacetileno através do processo de dopagem [21]. Estes materiais, entretanto, foram inicialmente estudados na forma de filmes e são interessantes por juntarem em um só dispositivo, além da condutividade, a transparência e a flexibilidade.

Apesar de citarmos os materiais orgânicos (constituídos por carbono e hidrogênio) como promissores candidatos a dispositivos eletrônicos, há um enorme potencial nos materiais constituídos apenas de átomos de carbono, tais como nanotubos, grafenos e fulerenos. O uso de nanotubos de carbono permite a fabricação de dispositivos flexíveis [22] e transparentes [23], podendo ser utilizado como eletrodo [24] em aplicações de optoeletrônica. Os polímeros orgânicos podem ser empregados na fabricação de células solares [25], transístores [26] e dispositivos eletrocrômicos [27]. Um circuito integrado utilizando grafeno como transístor foi construído [28] e demonstrou bastante estabilidade a temperatura ambiente. Outro aspecto interessante do grafeno reside nas suas notáveis propriedades mecânicas, que são comprovadas com o papel de grafeno que apresenta dureza duas vezes maior que a do aço [29]. Uma vez estabelecido que os materiais baseados na química do carbono apresentam notáveis propriedades eletrônicas, a questão seguinte é se estes possuem estas mesmas características quando há apenas uma cadeia envolvida no dispositivo.

Existem diversos métodos que são empregados para realizar a medida de condutância de uma única cadeia orgânica, que podem ser dividos em dois tipos: (1) Através de varre- 


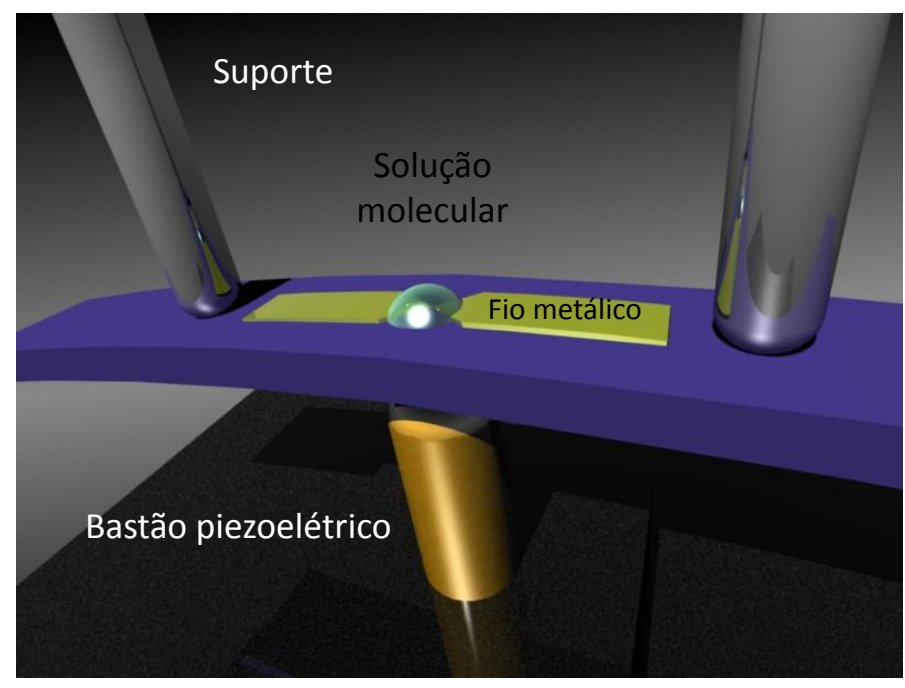

Figura 1.3: Representação esquemática do aparato de medida de condutância que emprega o método MCJB.

dura com uma ponta de STM (Scanning Tunneling Microscope) ou AFM (Atomic Force Microscope), que utilizam filmes moleculares adsorvidos no substrato metálico [30, 31, 32]. Este conjunto de métodos, apesar de empregar uma grande quantidade de cadeias, revela a condutância de apenas algumas por usar uma ponta metálica em nanoescala. Outro modo de melhorar a resolução é inserir a cadeia de interesse na matriz de outra menos condutiva. (2) Através de quebra de junção de um contato metálico, os quais citamos: O método MCJB (Mechanically controlable Break Junction) [33] e o STM (AFM)-BJ (BJBreak Junction) [34, 35]. Estes métodos, que são baseados na quebra da ligação química entre dois átomos metálicos, geram regiões mais reativas que atraem as cadeias. O procedimento de medida nos casos STM, AFM-BJ resulta em cadeias covalentemente ligadas aos eletrodos metálicos. O arranjo experimental do método MCJB é mostrado na figura 1.3, e consiste de um bastão piezoelétrico, que pressiona um substrato isolante que apoia um fio metálico. O bastão piezoelétrico, que é regulado por uma corrente elétrica, força o substrato a ser dobrado para romper a ligação entre os átomos do metal. Após a quebra do fio, cadeias orgânicas preenchem a posição entre os dois eletrodos. 
Um esquema do método de medida STM (AFM)-BJ é mostrado na figura 1.4, que dividimos em 4 etapas: (I) Inicialmente cadeias são depositadas sobre um substrato metálico, com a ponta de STM e o substrato mantendo uma diferença de potencial. (II) A ponta é descida até formar uma ligação com o substrato. (III) A ponta é erguida até quebrar a ligação formando dois eletrodos. (IV) Após a quebra da ligação, uma ou várias cadeias orgânicas ligam-se simultaneamente ao eletrodo e a ponta de STM, enquanto esta continua a ser erguida. O processo é repetido diversas vezes, propiciando uma grande quantidade de dados e tornando este o método com a análise estatística mais robusta.

Uma discussão interessante sobre as medidas de condutividade é descobrir se o elétron utiliza os estados da cadeia para ir de um eletrodo a outro, ou se o que ocorre é um tunelamento. Para elucidar esta questão, a experiência feita por Slowinsk e colaboradores $[36,37]$ compara o decaimento da condutância em duas configurações: (1) filmes compostos de oligômeros de comprimentos diferentes e (2) oligômeros de mesmo tamanho, mas com diferentes ângulos de inclinação da cadeia com relação ao plano do substrato metálico. No primeiro caso, a constante de decaimento $\beta$, presente na expressão $G=G_{0} e^{-\beta L}$, onde $G$ é a condutância, e $G_{0}$ a condutância do metal, apresenta o valor de $0,96 \AA^{-1}$ e no segundo $0,12 \AA^{-1}$, indicando que o decaimento depende mais fortemente do tamanho das cadeias. Em sistemas com anéis, a torção entre estes afeta a condutância, sendo que evidências experimentais e teóricas apontam para uma relação linear entre $G$ e $\cos \phi^{2}$, onde $\phi$ é o ângulo de torção entre os anéis [38]. Nesta referência, a relação entre a condutância e $\cos \phi^{2}$ é demonstrada utilizando o fato que a barreira de potêncial da molécula é proporcional a $\cos \phi$.

Dispositivos moleculares são promissores por utilizarem um elétron para criar o efeito de chaveamento de um dispositivo, por comparação um MOSFET (Metal Oxide Semiconductor Field Effect Transistor) precisa em torno de 1000-10000 elétrons [39]. O uso destes materiais ainda permitirá construir circuitos integrados muito eficientes, pois com menos elétrons, menor será a quantidade de potência dissipada e o número de componentes poderá ser imenso [40]. As primeiras propostas teóricas de dispositivos moleculares foram reportadas por Aviram e Ratner [41, 42]. O primeiro dispositivo é um diodo e o 

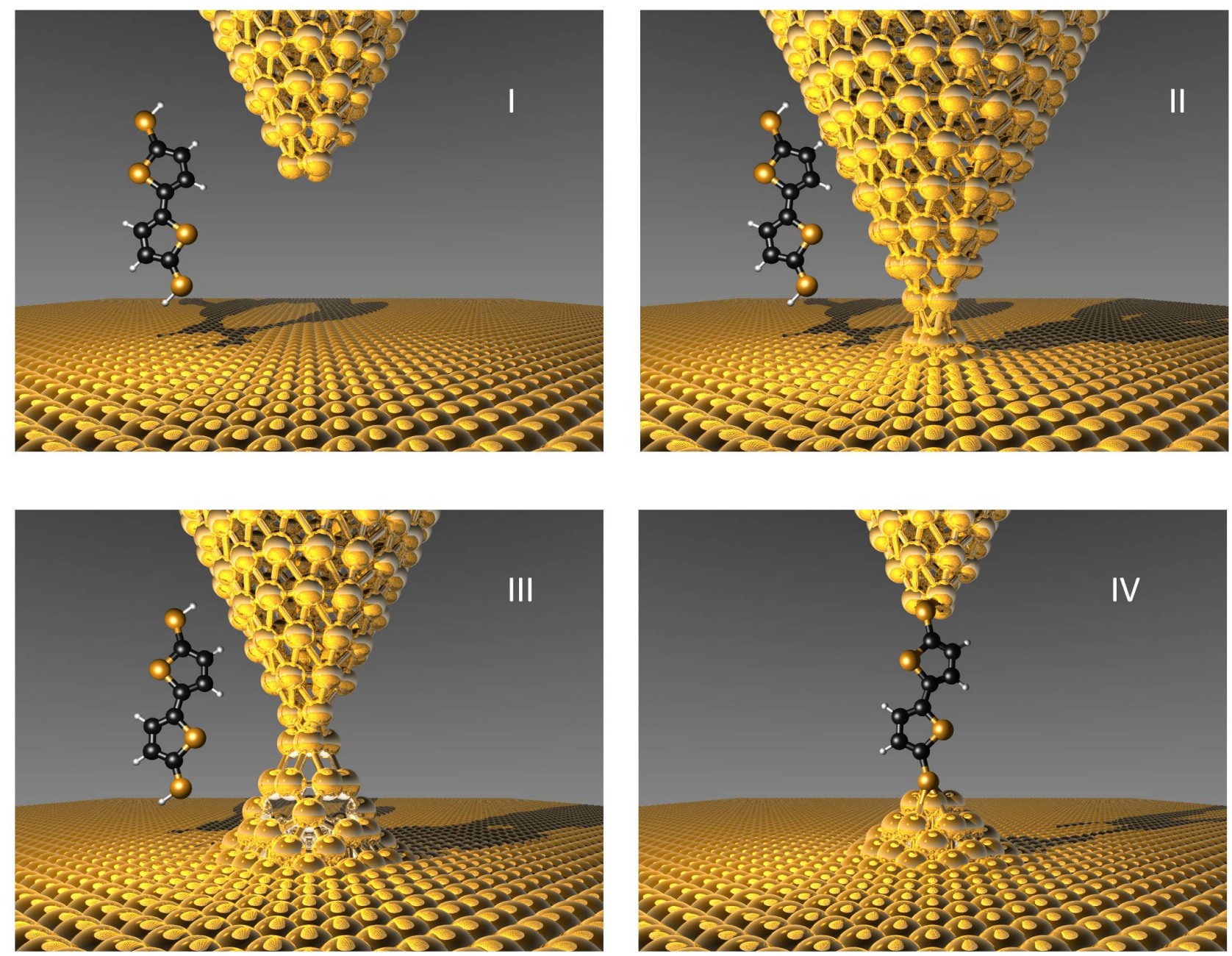

Figura 1.4: Representação esquemática da medida de condutância baseada no método STM(AFM)-BJ. Brevemente, em cada etapa temos: (I) as moléculas estão depositadas sobre o substrato metálico, enquanto a ponta encontra-se distante da superfície metálica, (II) a seguir a ponta de STM é descida até formar uma ligação com a superfície, (III) que é erguida até romper a ligação Au-Au. (IV) Eventualmente cadeias orgânicas podem ocupar a região recém quebrada entre os metáis. 
segundo um sistema com memória, e ambos foram projetados com base nas propriedades dos elétrons $\pi$ e $\sigma$. Os elétrons $\pi$, entre outras propriedades, possuem a característica de serem menos profundos energeticamente que os $\sigma$. Isto faz com que sejam os principais responsáveis pela mobilidade eletrônica de uma cadeia, mais detalhes sobre estes elétrons serão discutidos no capítulo a seguir. No diodo proposto por Aviram (parte inferior da Fig. 1.5) a cadeia orgânica é constituída por um grupo aceitador de elétrons e outro doador de elétrons separados por uma região isolante. Os grupos(doador e aceitador de elétrons) são anexados, cada um, nas extremidades da cadeia, que também são as regiões escolhidas para apresentar predominância de elétrons $\pi$ e são separados pela região da cadeia com predominância de elétrons $\sigma$, essa parte isolante previne o contato das regiões doadoras e aceitadoras, que levaria a um sistema unicamente doador. O arranjo do dispositivo molecular de Aviram é bastante similar a um diodo de junção P-N. O grupo aceitador, que reduz a densidade de elétrons e apresenta uma grande eletroafinidade, é similar a região do diodo com dopagem tipo $\mathrm{P}$, de modo análogo o grupo doador diminui a eletroafinidade, como na região $\mathrm{N}$ do diodo de silício. A região $\sigma$ entre as regiões doadoras e aceitadoras é similar a zona de depleção, onde os elétrons e buracos recombinam-se no diodo.

Um dispositivo com a alternância de um estado ligado-desligado, através do uso de luz, é reportado tanto experimentalmente [43] quanto teoricamente [44]. Embora seja um sistema com apenas um ciclo, indica a possibilidade do uso de uma cadeia como dispositivo eletrônico.

A condutância de moléculas derivadas de polianilinas e politiofenos foi medida recentemente através da técnica de quebra de junção $[45,46]$. Em oligoanilinas são reportados dois sinais de condutância, que são denominados de alto e baixo [46]. O sinal denominado alto apresenta um decaimento quase linear da condutância com o tamanho da cadeia, dado que a constante de decaimento $\beta$ na equação $G=G_{0} e^{-\beta L}$ apresenta um valor muito pequeno. Sistemas de dimensões nanoscópicas usualmente apresentam um decaimento exponencial com o tamanho, pois possuem um mecanismo de tunelamento no transporte eletrônico. A condutância baixa apresenta o comportamento usual de decaimento expo- 


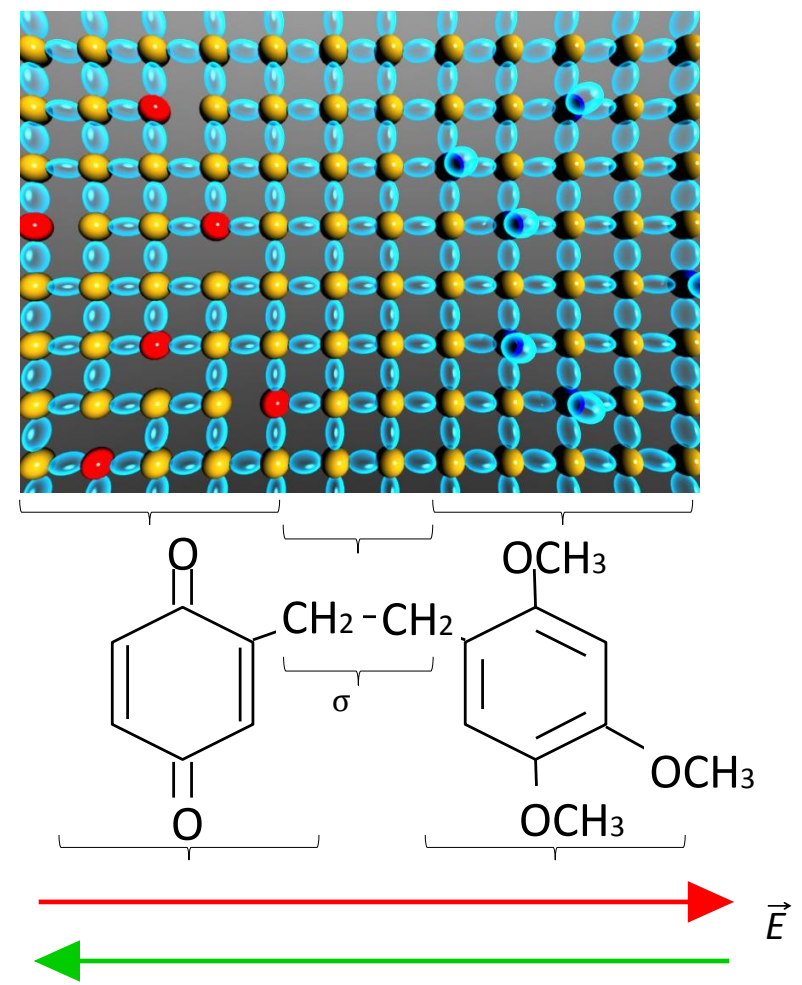

Figura 1.5: Diodo usual em comparação com o modelo molecular proposto por Aviram. O diodo está representado na parte superior, com os átomos de silício indicados pela cor amarela e os dopantes com as cores vermelha $(\mathrm{P})$ e azul (N). À esquerda está a região P (com excesso de buracos), no centro a região de depleção (igual quantidade de buracos e elétrons) e à direita a região $\mathrm{N}$ (com mais elétrons que buracos). Na parte inferior está o modelo molecular, com a região com maior eletroafinidade à esquerda, no centro a região isolante, com átomos de carbono que ligam-se de forma $\sigma$, e à direita a região com pouca eletroafinidade. As setas abaixo da cadeia orgânica indicam a direção de um campo elétrico aplicado, onde apenas na direção indicada de verde ocorre o transporte de elétrons, pois quando estes chegam ao diodo pelo lado N "empurram" os elétrons em excesso para o lado P, fechando circuito. Note que quando a direção do campo está indicada pela seta vermelha os elétrons que chegam pelo lado P param na região de depleção, devido a uma barreira criada pelo excesso de elétrons. 
nencial em função do tamanho da cadeia, que é obtido teoricamente [47], e será discutido nos capítulos de resultados.

Oligotiofenos apresentam uma anomalia na condutividade eletrônica em função do tamanho da cadeia quando se trata do trímero e do tetrâmero [48]. Discutimos anteriormente que o comportamento esperado é o decrescimento exponencial da condutância em função do aumento da cadeia. Entretanto, observa-se que os tetrâmeros de tiofeno são mais condutores que os trímeros.

Outras medidas incomuns da condutância são relatadas na literatura, como a alternância aleatória entre dois estados de condutância, ligado e desligado, em alcanoditióis [32] e oligotiofenos [30]. Nas medidas em alcanoditióis, o arranjo experimental consiste de uma partícula de ouro conectada na extremidade da cadeia orgânica. Sendo a condutância obtida por uma ponta de STM quando toca a partícula. Em oligotiofenos e oligofenileno-etinileno, as medidas são feitas sem a partícula metálica [31].

Como já mencionado, sistemas de quebra de junção possuem 3 componentes principais: o eletrodo extenso, um aglomerado de metal na superfície do substrato e a molécula, que é a região espalhadora de elétrons. Destes três componentes, o aglomerado de ouro, na interface entre o bulk metálico e a molécula, é o único que possui geometria desconhecida. Os três modelos mais estudados para conectar de forma covalente uma molécula ao eletrodo de ouro são: atop, bridge e hollow, conforme ilustrado na figura 1.6. A superfície de um eletrodo de ouro é cheia de imperfeições, com isso não há um controle sobre o tipo de ligação que será formada com uma cadeia que seja depositada nessa superfície [49]. Além disso, quando a cadeia é puxada, pode experimentar diversos tipos de conexões com o aglomerado de ouro, como indica o cálculo de dinâmica molecular Car-Parrinelo [50]. Ressaltamos também que não há um controle experimental da forma do contato entre as cadeias e os eletrodos, podendo ser diferente para cada medida. Uma suposição razoável, e que guiará o curso deste trabalho, é que as mudanças de geometria do aglomerado podem induzir alterações das propriedades eletrônicas da molécula ao longo do processo de "puxa e quebra", suficientes para causar mudanças perceptíveis na condutância.

Para um entendimento mais profundo destes experimentos precisamos investigar os 
efeitos dos seguintes parâmetros sobre as propriedades do sistema: (I) o potencial elétrico entre o eletrodo e a ponta do STM; (II) o estado de oxidação da molécula orgânica; (III) o comprimento da molécula e a (IV) a forma do contato. Para isso, realizamos cálculos de otimização de geometria para oligômeros de vários tamanhos de cadeias de polianilinas em diversos estados de oxidação e de oligotiofenos. Essas moléculas foram submetidas a diferentes campos elétricos aplicados e conectadas a diferentes tipos de geometrias de contato e estiradas, como ocorre nestas medidas [51]. Os cálculos foram feitos com o programa Gaussian 03 [52], utilizando o método DFT (Density functional theory)com o funcional B3LYP [53] e conjunto de bases 6-31G* para os átomos C, S, N e H. Os átomos de ouro foram tratados com um pseudopotencial e função de base LANL2DZ [54].

Nesta tese, estruturamos os próximos capítulos da seguinte maneira: (1) no capítulo 2 abordamos os métodos de cálculo quântico, que incluem a probabilidade de transmissão eletrônica e os métodos para resolver a equação de Schroedinger multieletrônica, como a teoria do funcional da densidade (DFT) e o método de Hartree-Fock (HF). (2) No capítulo 3 discutimos os resultados dos sistemas eletrodo-molécula-eletrodo no âmbito de sua estrutura eletrônica e geométrica como moléculas isoladas, avaliando o efeito na parte orgânica após a ligação com um eletrodo metálico. (3) No capítulo 4 os resultados da transmitância dos sistemas são apresentados, e fornecem informações sobre o efeito da conexão das cadeias em termos do tamanho dos oligômeros, da conexão com os eletrodos, de um campo elétrico externo e do estiramento. (4) No capítulo 5 fazemos um resumo das conclusões obtidas ao longo da tese. 

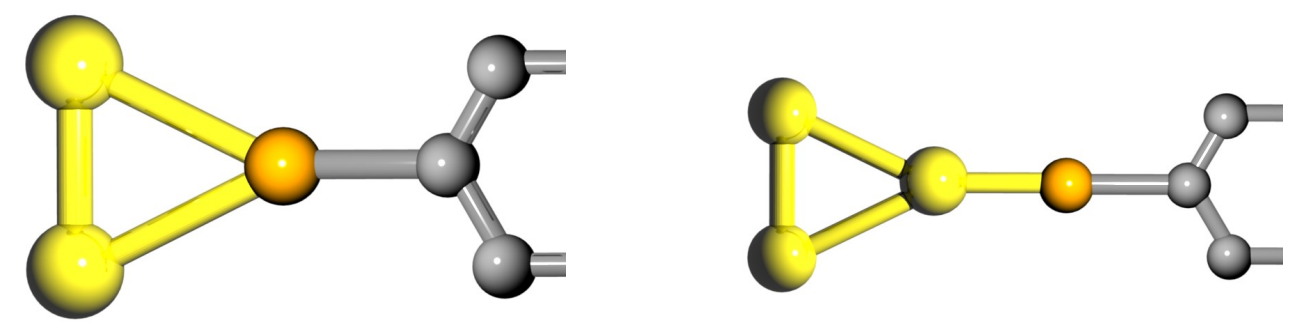

(Bridge)

(Atop)

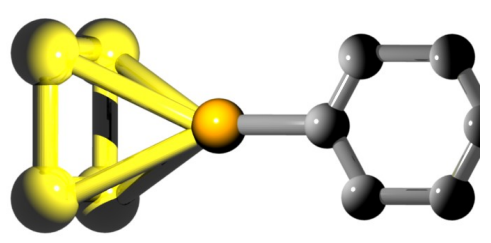

(Hollow)

Figura 1.6: Tipos de ligações que podem ser feitas entre os eletrodos metálicos e as moléculas orgânicas. Em amarelo estão representados os átomos do eletrodo, em laranja o átomo de enxofre e em cinza os átomos da molécula orgânica. 


\section{Capítulo 2}

\section{Metodologia}

Estamos interessados em estudar o transporte eletrônico através de cadeias orgânicas conectadas a eletrodos metálicos. Para isso utilizaremos diversos métodos de cálculo quântico, que serão discutidos neste capítulo.

Empregamos o método da função de Green fora do equilíbrio(NEGF-Non Equilibrium Green Function) para obter as características do transporte eletrônico. Esta metodologia fornece a probabilidade de transmissão de um elétron através do sistema molecular. A transmitância, que fornece a condutância, é obtida a partir do hamiltoniano de um cálculo de estrutura eletrônica, como Hartree-Fock(HF) e DFT (Density Functional Theory), que serão mostrados após uma breve introdução dos métodos de química quântica.

Mostraremos o método de renormalização, que nos permite calcular a transmitância de forma analítica dos sistemas que estamos interessados. A renormalização é aplicada quando o hamiltoniano eletrônico está escrito na aproximação tight-binding de primeiros vizinhos.

Discutiremos, brevemente, o método do pseudopotencial, que simplifica a resolução de um átomo com um número grande de elétrons, através da substituição dos elétrons mais internos por um potencial efetivo.

Ao final do capítulo mostraremos como se obtém o inverso do número de participação (INP) e a densidade de estados projetada (PDOS). O INP fornece de modo quantitativo 
o grau de extensão/deslocalização de um orbital e a PDOS fornece a contribuição de um subconjunto de vetores da base em que o hamiltoniano é escrito para a densidade de estados total.

\subsection{Transmitância via função de Green}

Landauer introduziu a interpretação do transporte de carga entre dois eletrodos como sendo uma propriedade resultante da probabilidade de transmissão de um elétron através de uma barreira, o contato. Assim, formulou a seguinte relação:

$$
I=\frac{2 e}{h} \int_{-\infty}^{+\infty} d E T(E, V)\left[f\left(E-\mu_{1}\right)-f\left(E-\mu_{2}\right)\right]
$$

Os termos $T(E)$ e $f\left(E-\mu_{1,2}\right)$ indicam, respectivamente, a probabilidade de transmissão e a distribuição de Fermi-Dirac. As constantes $\frac{2 e^{2}}{h}$ fornecem o valor da condutância do metal por banda (canal). Nesta equação a corrente elétrica é obtida para diferentes valores de potencial elétrico através da integral da probabilidade de transmissão em todos os valores de energia. Resultam imediatamente da fórmula de Landauer, a inexistência de corrente elétrica quando os eletrodos apresentam o mesmo potencial químico e, quando o transporte é $100 \%$ balístico $(T=1.0)$, a dependência da corrente apenas nas propriedades dos eletrodos $\left(\mu_{1}, \mu_{2}\right)$. Estamos interessados, simultâneamente, no quanto o contato diminui a característica balística dos eletrodos e em suas propriedades de transporte intrínsecas, ou seja, quando o campo elétrico é zero. Com isto em mente, recorremos a uma expressão derivada da fórmula de Landauer[15] que fornece a condutância, que não depende diretamente das características dos metais, através da relação:

$$
g_{0}(V)=\frac{2 e^{2}}{h} T\left(E_{f}\right)
$$

Os sistemas moleculares conectados a um eletrodo extenso apresentam seus níveis discretos em contato com o contínuo de estados do reservatório de elétrons. Neste arranjo a cadeia molecular é um sistema denominado "aberto", que pode ser tratado com o forma- 
lismo de função de Green. A cadeia entre os contatos elimina a simetria de translação do volume de metal e esta espalha os elétrons que vão de um eletrodo ao outro. Os elétrons utilizam os estados da cadeia como "canais", que sofrem um alargamento e um deslocamento devido à conexão com o eletrodo. A probabilidade de um elétron ser transmitido [55] de um eletrodo ao outro é dada por:

$$
T(E)=\operatorname{tr} \Gamma_{L}(E) G(E) \Gamma_{R}(E) G^{\dagger}(E)
$$

onde $t r$ é o traço do produto das matrizes $\Gamma_{L}(E), \Gamma_{R}(E), G(E)$ e $G^{\dagger}(E)$, que indicam, respectivamente, a intensidade da conexão a direita e à esquerda e a função de Green da cadeia entre os eletrodos e seu transposto conjugado.

Para obter os termos desta equação precisamos escrever o hamiltoniano total do sistema eletrodo-molécula-eletrodo em uma base, e discriminar as partes do hamiltoniano dos eletrodos e da molécula. Para exemplificar, utilizaremos o sistema mostrado na figura 2.1, que é bem geral para o caso que estamos interessados, cujo hamiltoniano é dado a seguir:

$$
H=\left(\begin{array}{ccc}
H_{L} & H_{L M} & 0 \\
H_{M L} & H_{M} & H_{M R} \\
0 & H_{R M} & H_{R}
\end{array}\right)
$$

os elementos $H_{L}, H_{M}, H_{L M}$ indicam, respectivamente, a parte do hamiltoniano eletrônico associado ao eletrodo esquerdo, ao contato e a interação entre estes. De modo análogo existem os blocos associados à conexão do lado direito, indicadas com o índice $R$. Para o caso de funções de base não ortogonais os termos $S_{L}, S_{M}$, e $S_{L M}$, fornecem o overlap entre as funções de base. A seguir, os termos da equação 2.3 são obtidos:

$$
\begin{gathered}
G_{M}(E)=\left[E S_{M}-H_{M}-\Sigma_{L}(E)-\Sigma_{R}(E)\right]^{-1} \\
\Gamma_{L, R}(E)=i\left[\Sigma_{L, R}(E)-\left(\Sigma_{L, R}(E)\right)^{\dagger}\right]
\end{gathered}
$$




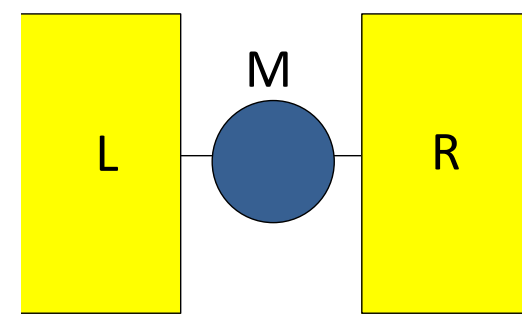

Figura 2.1: Esquema de um sistema molecular conectado a eletrodos metálicos. Os índices $\mathrm{L}, \mathrm{M}$ e $\mathrm{R}$ indicam o eletrodo esquerdo, a cadeia central e o eletrodo direito, respectivamente.

$\Sigma_{L, R}(E)$ possui a informação da interação da cadeia com os eletrodos, e é obtido através da equação:

$$
\Sigma_{L, R}(E)=\left(E S_{M L, M R}-H_{M L, M R}\right) g_{L, R}\left(E S_{L M, R M}-H_{L M, R M}\right)
$$

O termo $g_{L, R}$ é a função de Green do eletrodo, e é obtido como mostrado a seguir:

$$
g_{L, R}=\left(E+i \eta-H_{L, R}\right)^{-1}
$$

onde $\eta \rightarrow 0$ é utilizado para contornar o polo da função de Green. De forma equivalente, a função de Green é escrita como:

$$
g_{L, R}=\sum_{j} \frac{C_{j} C_{j}^{*}}{E+i \eta-\lambda_{j}}
$$

onde $C$ e $\lambda$ são, respectivamente, os autovetores e autovalores do hamiltoniano $H_{L, R}$. Separando as partes real e imaginária de $g_{L, R}$ temos:

$$
g_{L, R}=\sum_{j} \frac{\left(E-\lambda_{j}\right) C_{j} C_{j}^{*}}{\left(E-\lambda_{j}\right)^{2}+\eta^{2}}-i \frac{\eta C_{j} C_{j}^{*}}{\left(E-\lambda_{j}\right)^{2}+\eta^{2}}
$$

é útil escrever a função de Green neste formato para visualizar que a parte imaginária é proporcional à densidade de estados:

$$
\operatorname{dos}_{L, R}=-\frac{1}{\pi} \operatorname{imag}\left(g_{L, R}\right)=\frac{1}{\pi} \sum_{j} \frac{\eta C_{j} C_{j}^{*}}{\left(E-\lambda_{j}\right)^{2}+\eta^{2}}
$$


a constante $\frac{1}{\pi}$ surge do fato que a densidade de estados integrada em todos estados ocupados deve ser igual a $N / 2$, sendo $N$ o número de elétrons.

Existe uma situação em que os estados do eletrodo estão muito próximos entre si, de modo que podemos transformar a somatória numa integral:

$$
g_{L, R}=\int d \lambda \frac{\left(E-\lambda_{j}\right) C_{j} C_{j}^{*}}{\left(E-\lambda_{j}\right)^{2}+\eta^{2}}-\int d \lambda i \frac{\eta C_{j} C_{j}^{*}}{\left(E-\lambda_{j}\right)^{2}+\eta^{2}}
$$

utilizando a definição da delta de Dirac,

$$
\delta(x)=\lim _{\eta \rightarrow 0} \frac{1}{\pi} \frac{\eta}{x^{2}+\eta^{2}}
$$

e inserindo na equação 2.12, obtemos:

$$
g_{L, R}=\int d \lambda \frac{\left(E-\lambda_{j}\right) \delta(E-\lambda) C_{j} C_{j}^{*}}{\eta}-\int d \lambda i \pi \delta(E-\lambda) C_{j} C_{j}^{*}
$$

ao aplicarmos as propriedades da delta de Dirac anulamos a parte real da função de Green, assim:

$$
g_{L, R}=-i \pi D O S
$$

que é a aproximação denominada WBL (Wide Band Limit)[56], utilizada quando a densidade de estados do eletrodo é independente da energia. No Apêndice B discutimos com mais detalhes o cálculo da função de Green dos eletrodos.

Vimos nesta seção o modo geral de calcular da probabilidade de transmissão eletrônica através de uma cadeia molecular conectada a dois eletrodos, utilizando o hamiltoniano do sistema total escrito em uma base atômica. Assim, para obter o hamiltoniano temos que utilizar um método de cálculo quântico. Dentre os métodos atuais utilizamos a DFT, que será discutida a seguir, juntamente com outros métodos. 


\subsection{Métodos de Química Quântica e Teoria do Funcional da Densidade 23}

\subsection{Métodos de Química Quântica e Teoria do Fun- cional da Densidade}

O problema central da química quântica consiste em obter as propriedades eletrônicas

e geométricas de sistemas moleculares. Utiliza-se, como ponto de partida a equação de Schrödinger não-relativística, útil para sistemas onde os efeitos relativísticos podem ser desprezados. Em metais, onde os efeitos relativísticos devem ser levados em conta, utilizamos o método do pseudopotencial, que será discutido ao final do capítulo.

O hamiltoniano (em unidades atômicas) do sistema multieletrônico que desejamos resolver é:

$$
H=-\sum_{i=1}^{N} \frac{1}{2} \nabla_{i}^{2}-\sum_{A=1}^{N} \frac{1}{2 M_{A}} \nabla_{A}^{2}-\sum_{i=1}^{N} \sum_{A=1}^{M} \frac{Z_{A}}{r_{i A}}+\sum_{i=1}^{N} \sum_{j>i}^{N} \frac{1}{r_{i j}}+\sum_{A=1}^{M} \sum_{B>A}^{M} \frac{Z_{A} Z_{B}}{r_{A B}}
$$

Os termos do hamiltoniano, na ordem em que estão escritos, são: energia cinética dos elétrons, energia cinética dos núcleos, energia potencial eletrostática entre os núcleos e os elétrons, energia potencial eletrostática entre os elétrons e a energia potencial eletrostática entre os núcleos. O hamiltoniano 2.16 pode ser resolvido através da aproximação de Born-Oppenheimer, que se vale do fato dos núcleos serem muito mais massivos que os elétrons, para desprezar suas energias cinéticas. Com isso, a contribuição dos núcleos, no hamiltoniano, é dada apenas pela energia potencial eletrostática. Podemos resolver separadamente apenas a parte eletrônica e incluir a energia potencial dos núcleos como uma constante. Como consequência, a função de onda eletrônica, na aproximação de BornOppenheimer, possui a contribuição das posições nucleares $\left(R_{A}\right)$ como um parâmetro:

$$
\Psi_{e}=\Psi_{e}\left(\left\{r_{i}\right\} ;\left\{R_{A}\right\}\right)
$$

A solução do hamiltoniano 2.16 pode ser obtida através da aproximação de HartreeFock [57], que será discutida a seguir. 


\subsection{Métodos de Química Quântica e Teoria do Funcional da Densidade 24}

\subsubsection{Método de Hartree-Fock}

Na aproximação de Hartree-Fock o princípio da exclusão de Pauli é imposto na forma da função de onda total, que é dada por um produto antisimétrico das funções de onda individuais de cada elétron. Para dois elétrons a função de onda total normalizada, $\Psi$, é escrita como:

$$
\Psi\left(x_{1}, x_{2}\right)=2^{-1 / 2}\left(\chi_{i}\left(x_{1}\right) \chi_{j}\left(x_{2}\right)-\chi_{j}\left(x_{1}\right) \chi_{i}\left(x_{2}\right)\right)
$$

onde $\chi_{i}\left(x_{k}\right)$ é o orbital monoeletrônico de número quântico $i$ e posição $k$. A escolha do produto antisimétrico leva a proibição de qualquer um dos elétrons (1 ou 2) possuir o mesmo número quântico, representados por $i$ e $j$, quando na mesma posição. Para $N$ elétrons, a forma geral da função de onda total é obtida através do determinante de Slater.

$$
\Psi\left(x_{1}, x_{2}, \ldots, x_{N}\right)=(N !)^{-1 / 2}\left|\begin{array}{cccc}
\chi_{i}\left(x_{1}\right) & \chi_{j}\left(x_{1}\right) & \cdots & \chi_{k}\left(x_{1}\right) \\
\chi_{i}\left(x_{2}\right) & \chi_{j}\left(x_{2}\right) & \cdots & \chi_{k}\left(x_{2}\right) \\
\vdots & \vdots & \vdots & \vdots \\
\chi_{i}\left(x_{N}\right) & \chi_{j}\left(x_{N}\right) & \cdots & \chi_{k}\left(x_{N}\right)
\end{array}\right|
$$

Aplicando o determinante de Slater no hamiltoniano eletrônico, que denominaremos apenas de hamiltoniano, obtemos a equação que fornece a energia do estado fundamental de HF:

$$
\langle\Psi|H| \Psi\rangle=\sum_{i=1}^{N} h_{i}+\sum_{i}^{N} \sum_{j>i}^{N}\left(J_{i j}-K_{i j}\right)
$$

com:

$$
\begin{array}{r}
h_{i}=\int \chi_{i}^{*}\left(x_{1}\right) h(1) \chi_{i}\left(x_{1}\right) d x_{1} \\
J_{i j}=\int d x_{1} d x_{2} \chi_{i}^{*}\left(x_{1}\right) \chi_{j}^{*}\left(x_{2}\right)\left(r_{i j}\right)^{-1} \chi_{i}\left(x_{1}\right) \chi_{j}\left(x_{2}\right) \\
K_{i j}=\int d x_{1} d x_{2} \chi_{i}^{*}\left(x_{1}\right) \chi_{j}^{*}\left(x_{2}\right)\left(r_{i j}\right)^{-1} \chi_{i}\left(x_{2}\right) \chi_{j}\left(x_{1}\right)
\end{array}
$$

onde $h_{i}, J_{i j}$ e $K_{i j}$ são, respectivamente: o valor médio do termo monoeletrônico, do operador de Coulomb e do operador de Troca (Exchange). O termo $h_{i}$ contém a contribuição da 


\subsection{Métodos de Química Quântica e Teoria do Funcional da Densidade 25}

energia cinética de cada elétron e a interação com o núcleo, $J_{i j}$ fornece a contribuição do potencial de repulsão elétron-elétron e $K_{i j}$ a interação que impede os elétrons de mesmo número quântico ocuparem a mesma posição.

O método de HF apresenta um erro intrínseco que surge do fato da função de onda total ser dada por um produto antisimétrico das funções de onda de cada elétron. A solução verdadeira não necessariamente apresentará este tipo de separabilidade. Os detalhes da teoria de Hartree-Fock podem ser encontrados na referência [57].

\subsubsection{Teoria do Funcional da Densidade-DFT}

A DFT é uma metodologia alternativa à função de onda no cálculo de sistemas quânticos multieletrônicos. A diferença fundamental entre as duas abordagens recai no uso da densidade eletrônica $\rho$ como variável central na $\operatorname{DFT}[58,59]$, que é obtida através da função de onda total: $\rho=\Psi^{*} \Psi$. A formulação geral da DFT foi desenvolvida por Hohemberg e Kohn através de 2 teoremas, os quais garantem que: (1) O potencial exato sentido pelos elétrons possui como única variável a densidade eletrônica; (2) A energia é mínima quando calculada com a densidade eletrônica exata.

De modo geral, o funcional obtido por Kohn-Sham é dado por:

$$
E[\rho]=\int \nu(r) \rho(r) d^{3} r+\frac{1}{2} \iint \frac{\rho(r) \rho\left(r^{\prime}\right)}{\left|r-r^{\prime}\right|} d^{3} r d^{3} r^{\prime}+T_{0}[\rho]+E_{x c}[\rho]
$$

Na equação 2.24 o primeiro e o segundo termos representam a interação de Coulomb, sendo que o primeiro fornece a interação dos elétrons com um potencial externo e o segundo a interação elétron-elétron clássica. Os termos seguintes da equação são a energia cinética de um sistema de elétrons não interagente e o último termo inclui a energia de troca e correlação eletrônica. A forma da correlação eletrônica é desconhecida mas surge de modo natural porque usamos, por exemplo, a energia cinética de um sistema não interagente. O termo de troca surge na DFT como a maneira de incluir o princípio da exclusão.

O teorema variacional aplicado na equação 2.24, com a condição $\int \rho(r) d V=N$ e utilizando $T_{0}=-\frac{1}{2} \sum_{i} \int \chi_{i}^{*} \nabla^{2} \chi_{i} d V$ resulta na equação 2.25 que é similar a equação de 


\subsection{Métodos de Química Quântica e Teoria do Funcional da Densidade 26}

Schrödinger monoeletrônica. Apesar das funções $\chi_{a}(1)$, ocuparem a posição da função de onda eletrônica elas não o são, de fato o conjunto $\chi$ é usado apenas para escrever a densidade de carga auxiliar: $\rho(r)=\sum_{i=1}^{N} \chi_{i}(r)^{*} \chi_{i}(r)$. Embora $\chi_{a}$ não tenha o significado físico de função de onda, eles são utilizados no estudo das propriedades eletrônicas, dado a similaridade de suas formas com as funções de onda do método de HF. A resolução do conjunto de equações 2.25 é feita de forma autoconsistente que é alcançada quando o $\rho(r)$ que gera o potencial de Kohn-Sham $\nu[\rho]$ (eq. 2.26) é o mesmo obtido com as funções $\chi_{a}(1)[60]$.

$$
\begin{gathered}
\left(-\frac{1}{2} \nabla^{2}+\nu^{K S}[\rho]\right) \chi_{a}(1)=\epsilon_{a} \chi_{a}(1) \\
\nu^{K S}[\rho]=\nu(r)+\int \frac{\rho\left(r^{\prime}\right)}{\left|r-r^{\prime}\right|} d^{3} r^{\prime}+\nu_{x c}(\rho)
\end{gathered}
$$

Existem diversas propostas para a forma de um funcional da DFT, a primeira a ser desenvolvida é a LSDA (Local Spin Density aproximation), obtida para um sistema com densidade eletrônica uniforme. A limitação mais aparente da LSDA é a não dependência de $\nabla \rho$ em seus termos. Os funcionais, tais como o B3LYP e o PBE[61], inserem a seu modo a dependência de $\nabla \rho$ nos termos de correlação e troca. Assim uma condição fundamental dos funcionais é que seus termos devem recair na LSDA quando a densidade eletrônica varia pouco. Utilizamos apenas dois funcionais: B3LYP e PBE . O primeiro é um funcional denominado de híbrido, pois contém parte do exchange de HF. O funcional B3LYP é implementado no programa Gaussian 03 [52] com a seguinte forma:

$$
E_{X C}=a_{0} E_{X}^{L S D A}+\left(1-a_{0}\right) E_{X}^{\text {exato }}+a_{X} \Delta E_{X}^{B 88}+a_{c} E_{c}^{L Y P}+\left(1-a_{c}\right) E_{c}^{L S D A}
$$

Os termos da equação 2.27 representam: $E_{X, C}^{L S D A}$, são as energias de troca e correlação obtidos com o gás de elétrons homogêneo, $E_{X}^{e x a t o}$ é a energia de troca exata, do mesmo modo como obtida via equação de Hartree-Fock e o termo $\Delta E_{X}^{B 88}$ [62] é uma correção de gradiente feita para o exchange, do gás de elétrons homogêneo. O termo $E_{c}^{L Y P}$ é o termo de correlação com correção de gradiente de Lee et al [63]. Mais detalhes sobre os funcionais PBE e B3LYP são discutidos no apêndice A. 
Resevamos este parágrafo para discutir algumas diferenças entre HF e DFT, que vão além da principal, relacionada com o uso de função de onda no primeiro e densidade eletrônica no segundo. Estas diferenças são: (1) O HF descreve o termo de troca de forma exata mas não possui correlação eletrônica, enquanto que o DFT descreve ambos, podendo, com isso, ser exato. (2) Em metodologias que utilizam função de onda, tal qual o HF faz parte, os aperfeiçoamentos são sistemáticos, enquanto que no DFT não existe um modo de aperfeiçoar a descrição, exceto pela inclusão da dependência de $\nabla \rho$ no funcional. (3) Ambas as metodologias, HF e DFT apresentam erros na descrição da energia cinética. (4) Os resultados da DFT são no pior dos casos similares ao de HF e apresentam resultados que são comparáveis com metodologias que incluem correlação, por um custo muito mais baixo. (5) Os autovalores na equação de HF possuem significado físico, enquanto que no DFT apenas o último autovalor ocupado possui, que é igual ao potencial de ionização exato[60, 64].

\subsection{Método de Renormalização}

Sistemas moleculares formados por átomos de carbono que possuam ligações, majoritariamente, com hibridização do tipo $s p^{2}$, geralmente apresentam uma estrutura geométrica plana. Na hibridização $s p^{2}$ os átomos de carbono apresentam três ligações $\sigma$ e uma $\pi$, a primeira é um tipo de ligação direcional, formada pela mistura de um orbital $s$ e um $p$ a segunda é formada por um orbital $p$ puro, que se projeta de forma perpendicular ao plano formado pelas ligações $\sigma$, por isso a estrutura eletrônica $\pi$ em alguns sistemas moleculares apresenta interação quase nula com a parte $\sigma$. A fraca interação $\sigma-\pi$ permite separar o hamiltoniano eletrônico nestas duas simetrias eletrônicas. A contribuição $\pi$ é mais importante na descrição das propriedades eletrônicas que a $\sigma$, uma vez que os orbitais $\pi$ possuem maior energia, fazendo com que os últimos níveis ocupados e os primeiros virtuais possuam esta simetria. Podemos utilizar apenas o hamiltoniano $\pi$ para obter a transmitância e comparar com nossos cálculos ab initio. Utilizando a aproximação tight-binding de primeiros vizinhos, que despreza a interação entre átomos mais afasta- 


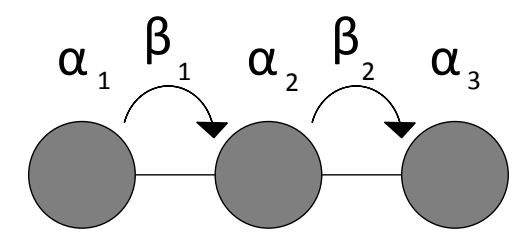

Figura 2.2: Esquema de um sistema linear formado por 3 átomos.

dos, podemos escrever um hamiltoniano $\pi$ bastante simples, para o sistema da figura 2.2 temos:

$$
H=\left(\begin{array}{ccc}
\alpha_{1} & \beta_{1} & 0 \\
\beta_{1} & \alpha_{2} & \beta_{2} \\
0 & \beta_{2} & \alpha_{3}
\end{array}\right)
$$

No hamiltoniano 2.28 os termos $\alpha$ e $\beta$ representam a interação do elétron no poço de potêncial sobre um sítio e no sítio vizinho respectivemente.

O método de Renormalização é muito útil para estudar analiticamente sistemas orgânicos cujas características podem ser satisfatoriamente descritas pelos orbitais $\pi$ e escritos na aproximação tight-bind de primeiros vizinhos. De modo geral, este procedimento reduz o hamiltoniano $\pi$ de um sistema, por exemplo de um anel ou um fio com $N$ átomos, em um sistema com dois átomos [65], como mostrado na figura 2.3.

A renormalização dos sistemas é feita utilizando a função de Green. Escrita numa base atômica, os elementos da função de Green e do hamiltoniano relacionam-se através da equação:

$$
(E-H) G=\mathbb{1}
$$

que quando escrita numa base atômica fornece:

$$
E G_{i j}-\sum_{k} H_{i k} G_{k j}=\delta_{i, j}
$$




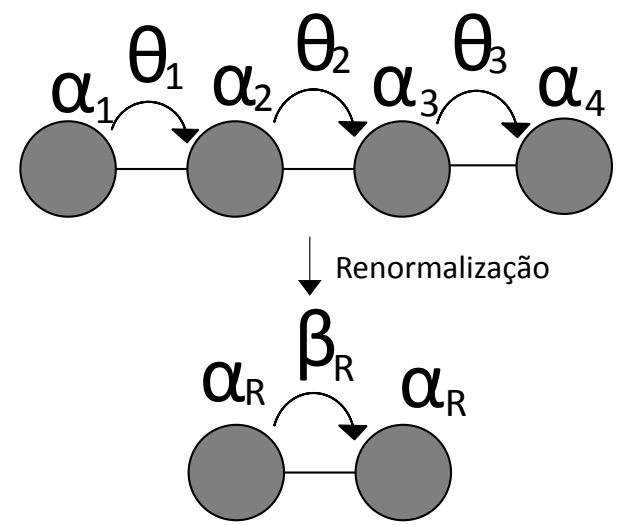

Figura 2.3: Esquema de um sistema linear formado por 4 átomos, que após renormalização dá origem a um sistema formado por apenas dois átomos.

Para explicar o método de renormalização, obteremos para o esquema mostrado na figura 2.3 os parâmetros $\alpha_{R}$ e $\beta_{R}$. O hamiltoniano do fio com 4 átomos possui a forma:

$$
H=\left(\begin{array}{cccc}
\alpha_{1} & \theta_{1} & 0 & 0 \\
\theta_{1} & \alpha_{2} & \theta_{2} & 0 \\
0 & \theta_{2} & \alpha_{3} & \theta_{3} \\
0 & 0 & \theta_{3} & \alpha_{4}
\end{array}\right)
$$

A função de Green se relaciona com este hamiltoniano através do conjunto de equações a seguir:

$$
\begin{aligned}
\left(E-\alpha_{1}\right) G_{11}+\theta_{1} G_{21} & =1 \\
\theta_{1} G_{11}+ & \left(E-\alpha_{2}\right) G_{21}+\theta_{2} G_{31}=0 \\
\theta_{2} G_{21}+ & \left(E-\alpha_{3}\right) G_{31}+\theta_{3} G_{41}=0 \\
\theta_{3} G_{31}+\left(E-\alpha_{4}\right) G_{41} & =0
\end{aligned}
$$

Queremos obter a seguinte relação: 


$$
\left(E-\alpha_{R}\right) G_{11}+\beta_{R} G_{41}=1
$$

Na equação 2.32 devemos eliminar o elemento $G_{21}$, e chegar na forma da equação 2.37. Para isso utilizamos as equações 2.33 e 2.34 para eliminar $G_{31}$ :

$$
G_{21}=\frac{\theta_{2} \theta_{3} G_{41}}{\left(E-\alpha_{2}\right)\left(E-\alpha_{3}\right)-\theta_{2}^{2}}-\frac{\theta_{1}\left(E-\alpha_{3}\right) G_{11}}{\left(E-\alpha_{2}\right)\left(E-\alpha_{3}\right)-\theta_{2}^{2}}
$$

substituindo 2.38 em 2.32 obtemos:

$$
G_{11}\left(E-\alpha_{1}-\frac{\theta_{1}^{2}\left(E-\alpha_{3}\right)}{\left(E-\alpha_{2}\right)\left(E-\alpha_{3}\right)-\theta_{2}^{2}}\right)+\frac{\theta_{1} \theta_{2} \theta_{3}}{\left(E-\alpha_{2}\right)\left(E-\alpha_{3}\right)-\theta_{2}^{2}} G_{41}=1
$$

Através das equações 2.37 e 2.39, podemos identificar $\alpha_{R}(E)$ e $\beta_{R}(E)$ como sendo:

$$
\begin{array}{r}
\alpha_{R}(E)=\alpha_{1}+\frac{\theta_{1}^{2}\left(E-\alpha_{3}\right)}{\left(E-\alpha_{2}\right)\left(E-\alpha_{3}\right)-\theta_{2}^{2}} \\
\beta_{R}(E)=\frac{\theta_{1} \theta_{2} \theta_{3}}{\left(E-\alpha_{2}\right)\left(E-\alpha_{3}\right)-\theta_{2}^{2}}
\end{array}
$$

Podemos realizar o mesmo procedimento para fios com qualquer número de átomos, embora as expressões possam ficar muito complicadas. A grande vantagem que se obtém com a renormalização reside no fato de que podemos utilizar uma expressão simples da transmitância para dois átomos e obter um resultado analítico para sistemas mais complexos.

\subsection{Funções de Base}

As funções de base permitem-nos escrever um hamiltoniano na forma matricial, com o qual resolvemos a equação de autovalores para encontrar as propriedades físicas de um sistema. Dada a importância desta ferramenta matemática no tratamento dos sistemas quânticos, nesta seção discutiremos como estas funções são contruídas e algumas propriedades obtidas diretamente das mesmas.

Seja um hamiltoniano qualquer $H$, cuja equação de autovalores é escrita a seguir: 


$$
H|\chi\rangle=\epsilon|\chi\rangle
$$

Utilizando como solução a expressão $|\chi\rangle=\sum_{i=1}^{N} c_{i}\left|\phi_{i}\right\rangle$, onde $\left|\phi_{i}\right\rangle$ e $c_{i}$ são, respectivamente as funções de base e os coeficientes da expansão, podemos obter o hamiltoniano numa forma matricial. Para isto basta multiplicar a expressão 2.42, à esquerda, por $\left\langle\phi_{j}\right|$, assim:

$$
\sum_{i} c_{i}\left\langle\phi_{j}|H| \phi_{i}\right\rangle=\epsilon \sum_{i}\left\langle\phi_{j} \mid \phi_{i}\right\rangle c_{i}
$$

O termo $\left\langle\phi_{j}|H| \phi_{i}\right\rangle$ é o elemento de hamiltoniano e $\left\langle\phi_{j} \mid \phi_{i}\right\rangle$ o elemento da matriz de sobreposição $S$, que pode ser igual a identidade para uma base ortogonal. Entretanto, de modo mais geral a matriz $S$ possui os elementos da diagonal principal iguais a um e os elementos fora da diagonal, não nulos, mas próximos de zero.

Quando o hamiltoniano depende dos coeficientes $c_{i}$, estes são obtidos de modo autoconsistente. As funções de base $\left|\phi_{i}\right\rangle$, entretanto, são construídas e destacaremos na proxima seção alguns detalhes.

\subsubsection{6-31G*}

Para entendimento da evolução das funções de base, enumeramos, em ordem de complexidade, algumas que foram e são amplamente utilizadas. Nossa sequência de bases atômicas que vai até às split valence, a qual a 6-31G* pertence, é a seguinte: $\mathrm{STO}$ (Slater Type Orbitals), STO-NG e N-XYG. As duas primeiras são ditas bases mínimas, pois descrevem com apenas um único termo cada um dos orbitais. A diferença entre STO e STO-NG reside no fato que a primeira é composta por exponenciais, e a segunda por uma soma de $\mathrm{N}$ gaussianas primitivas (indicadas pelo índice $\mathrm{G}$ ) cujo resultado ajusta-se, com certo desvio, a uma função exponencial de Slater. As STO fornecem uma descrição mais precisa dos orbitais, porém tem um custo computacional mais elevado que as STO-NG. Nas duas bases mínimas o átomo de carbono é descrito com os orbitais 1s 2 s e 2p, sendo que na STO cada termo é descrito por exponenciais multiplicadas por um polinômio, cujo grau depende do 
número quântico do momento angular, e na STO-NG ocorre a mesma descrição que na STO, com a diferença que no lugar das exponenciais utiliza-se a soma de $\mathrm{N}$ gaussianas. Finalmente, as N-XYG surgem como um modo de melhorar a descrição dos orbitais de valência, utilizando dois termos em sua composição. Novamente, é utilizado um ajuste gaussiano para descrever um comportamento próximo de uma exponencial(Orbitais de Slater). O número de gaussianas no ajuste é dado pelos termos $\mathrm{N}, \mathrm{X}$ e $\mathrm{Y}$, sendo que $\mathrm{N}$ refere-se aos orbitais de caroço e X e Y aos de valência. Os orbitais utilizados na descrição do átomo de carbono com a base 6-31G são 1s 2s 2p 3s 3p. O conjunto 6-31G* é uma função do tipo N-XYG, o símbolo '*' indica o uso adicional de funções de polarização nos orbitais de valência. No átomo de carbono, por exemplo, com a função de polarização a configuração dos orbitais fica $1 \mathrm{~s} 2 \mathrm{~s} 2 \mathrm{p}$ 3s $3 \mathrm{p} 4 \mathrm{~d}$. Uma discussão mais completa sobre funções de base atômica pode ser encontradas na referência [57].

\subsubsection{Método do Pseudopotencial}

Este método substitui a base atômica que descreve todos os elétrons por uma em que apenas os mais externos são considerados. Os elétrons mais internos de um átomo são substituidos por um potencial efetivo. O uso de pseudopotenciais traz vantagens que vão desde computacionais, dada a redução do tamanho da base que descreve o átomo, até a inclusão de correções relativísticas nos elétrons mais internos. Em alguns sistemas, onde o núcleo e os elétrons mais internos são quimicamente inativos, este método fornece um bom resultado na descrição das propriedades eletrônicas.

A obtenção de um pseudopotencial pode ser descrita em 3 passos: (1) Um cálculo quântico é realizado para um átomo isolado usando todos os elétrons; (2) De posse dos autovalores e das autofunções, uma pseudofunção de onda é criada, esta é obtida de modo a apresentar o mesmo comportamento da função de onda original a partir de um dado raio de corte. Dentro do raio de corte, estão os elétrons de caroço, e acima estão os elétrons de valência; (3)A equação de Schrödinger ou de Dirac é invertida usando a pseudofunção de onda e o autovalor, com isso é possível obter o pseudopotencial [60]. O pseudopotencial 
utilizado para os átomos de ouro LANL2DZ [54] apresenta correções relativísticas.

\subsubsection{INP}

O inverso do número de participação(INP) é um número que fornece de modo quantitativo o grau de deslocalização de um orbital. Ele é definido como [66]:

$$
I N P=\sum_{i}\left|C_{i}\right|^{4}
$$

Este número pode ser entendido ao avaliarmos seus dois casos extremos:(1) Quando um coeficiente do orbital apresenta o valor 1 e todos os outros são iguais a zero o INP é igual a 1, seu valor máximo possível. Este é o caso de função de onda mais localizado. (2) Quando os coeficientes são todos iguais entre si, seus valores são todos iguais a $N^{-1 / 2}$, sendo $N$ o tamanho do conjunto de base utilizado, neste caso o INP vale $N^{-3}$. Os exemplos acima mostram que o INP é maior quanto mais localizado é o orbital atômico.

Utilizamos funções de base que não são ortogonais que levam a seguinte condição de normalização:

$$
\langle\chi \mid \chi\rangle=C^{T} S C=I
$$

Na equação matricial 2.45 cada elemento da diagonal principal da matriz identidade está associado a um autovalor. Dada a condição de normalização depender da matriz overlap (S), devemos incluí-la no cálculo do INP através dos coeficientes da função de onda $C^{\prime}=S^{1 / 2} C$.

\subsubsection{Densidade de Estados Projetada(PDOS)}

Neste trabalho utilizamos a densidade de estados (DOS) dos sistemas moleculares para estudar as propriedades eletrônicas dos sistemas orgânicos. Para obter a DOS fazemos uma convolução gaussiana do histograma de autovalores, através da expressão: 


$$
D(E)=\sum_{i} e^{-\left(\frac{E-\lambda_{i}}{\alpha}\right)^{2}}
$$

onde $\lambda$ são os autovalores e $\alpha$ a largura da gaussiana utilizada na convolução.

Para calcular a densidade de estados projetadas incluímos um peso $P$ para cada autovalor na somatória:

$$
D(E)=\sum_{i} P(i) e^{-\left(\frac{E-\lambda_{i}}{\alpha}\right)^{2}}
$$

Os pesos são calculados utilizando a soma do quadrado dos coeficientes de função de onda $C^{\prime}$ associados com a região molecular, ou base que queremos projetar a densidade de estados.

No capítulo a seguir discutiremos os resultados, obtidos com a DFT, dos sistemas moleculares e dos eletrodos. Utilizaremos comparações da estrutura geométrica e eletrônica experimentais com o resultado fornecido com diferentes funcionais da DFT. 


\section{Capítulo 3}

\section{Análise dos oligômeros de Anilina e}

\section{Tiofeno}

Neste capítulo discutiremos características estruturais e eletrônicas dos sistemas orgânicos de oligoanilinas e oligotiofenos e aglomerados de ouro em suas formas isoladas. Escolhemos o método DFT para obter as formas do estado fundamental por apresentar uma boa relação entre o custo computacional e a qualidade dos resultados. Além de uma análise geral dos aspectos estruturais e eletrônicos de nossas cadeias, faremos uma comparação com resultados teóricos com metodologias mais sofisticadas bem como com medidas experimentais.

\section{$3.1 \quad$ Oligoanilinas}

Polianilinas são uma classe de polímeros que podem se apresentar em diversos estados de oxidação, dentre os quais citamos a Pernigranilina (PE), a Esmeraldina (EM) e a Leucoesmeraldina (LE), cujas estruturas estão esquematizadas na figura 3.1. Na forma totalmente reduzida (LE), onde todos os anéis são aromáticos, o gap ótico medido é de 3,6 
eV. Para a forma EM há a proporção de um anel quinóide para cada 3 aromáticos e seu gap ótico medido é de 2,0 eV. Na forma PE os anéis alternam-se entre aromáticos e quinóides e o gap ótico é de 2,3 eV [67]. Otimizamos oligômeros de anilinas desde o dímero até o octâmero, com o método DFT utilizando o funcional B3LYP e conjunto de base 6-31G*. Os oligômeros calculados possuem anéis de fenil nas suas extremidades, assim o tetrâmero (Fig. 3.2) apresenta 5 anéis sendo o número de átomos de nitrôgenio igual ao número de unidades monoméricas. Na figura 3.3, podemos verificar a diminuição da diferença entre o mais alto orbital de Kohn-Sham ocupado (HOMO-Highest Occupied Molecular Orbital) e o mais baixo orbital de Kohn-Sham virtual (LUMO-Lowest Unoccupied Molecular Orbital) conforme aumento da cadeia, calculados com os métodos B3LYP e PBE. A diferença de energia entre o orbital HOMO e LUMO, denominada de gap HOMO-LUMO, torna-se similar ao do polímero para os oligômeros maiores. Através da figura 3.3, nota-se que o gap HOMO-LUMO calculado com o funcional B3LYP apresenta um valor próximo ao experimental do polímero conforme o tamanho do oligômero aumenta, diferentemente do que ocorre com o PBE que fornece valores muito pequenos para todos os oligômeros.

Os anéis de 6 carbonos da LE apresentam um comprimento de ligação $\mathrm{C}-\mathrm{C}$ entre 1,39 e 1,40 A, que indica o seu caráter aromático. As ligações $\mathrm{N}-\mathrm{C}$ possuem tamanho entre 1,40 e 1,39 A. O ângulo de torção formado entre o anel central do tetrâmero e o anel vizinho é de $31^{\circ}$ (calculado com os átomos 17, 15, 14 e 11 na figura 3.2(a)). A forma esmeraldina apresenta os anéis quinóides bem distinguíveis com as ligações curtas de 1,35 $\AA$ e as longas de 1,46 A. As ligações dos anéis aromáticos apresentam diferenças sutis no comprimento, entre 1,41 e 1,38 Å. O ângulo de torção do anel quinóide com o anel aromático vizinho possui um valor de $10^{\circ}$ (calculado com os átomos $9,8,7$ e 4 na figura3.2(b)). A geometria calculada obtida para a forma pernigranilina apresenta alternância entre os anéis quinóides e aromáticos. Nos anéis quinóides as ligações curtas e longas apresentam os valores de $1,35 \AA$ e $1,46 \AA$ respectivamente, enquanto que os

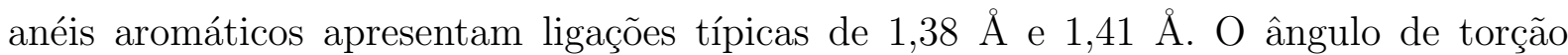
entre anéis adjacentes é de $44^{\circ}$ (calculado do mesmo modo que nas outras cadeias). Nas tabelas 3.1 e 3.2 observamos uma boa concordância dos diversos métodos de cálculo (HF, 


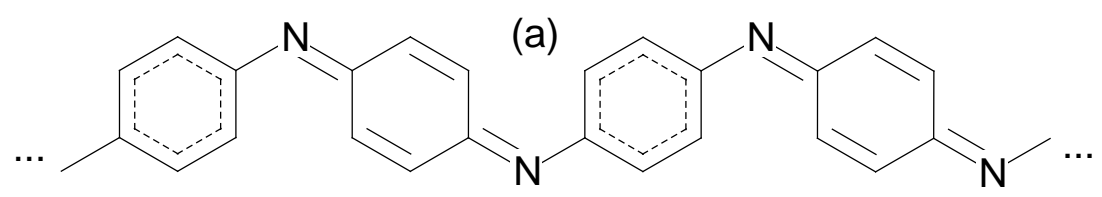<smiles>CCN=C1C=CC(=Nc2ccc(Nc3ccc(Nc4ccc(CC)cc4)cc3)cc2)C=C1</smiles><smiles>CNc1ccc(Nc2ccc(Nc3ccc(Nc4ccc(C)cc4)cc3)cc2)cc1</smiles>

Figura 3.1: Polianilinas nos estados de oxidação (a) Pernigranilina (PE), (b) Esmeraldina (EM) e (c) Leucoesmeraldina (LE).

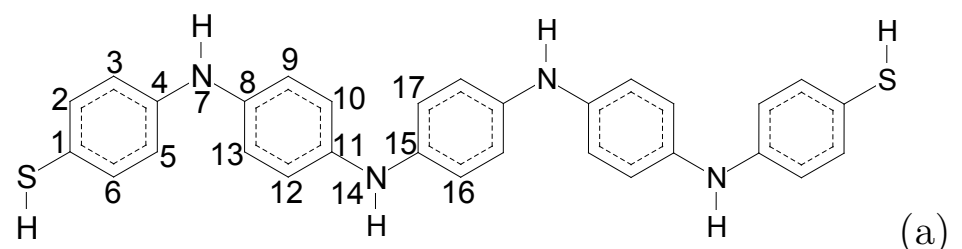<smiles>Sc1ccc(Nc2ccc(N=C3C=CC(=Nc4ccc(Nc5ccc(S)cc5)cc4)C=C3)cc2)cc1</smiles><smiles>Sc1ccc(N=C2C=CC(=Nc3ccc(N=C4C=CC(=Nc5ccc(S)cc5)C=C4)cc3)C=C2)cc1</smiles>

Figura 3.2: Tetrâmero de Leucoesmeraldina (a), Esmeraldina (b) e Pernigranilina (c) com grupos SH ligados nas extremidades. 


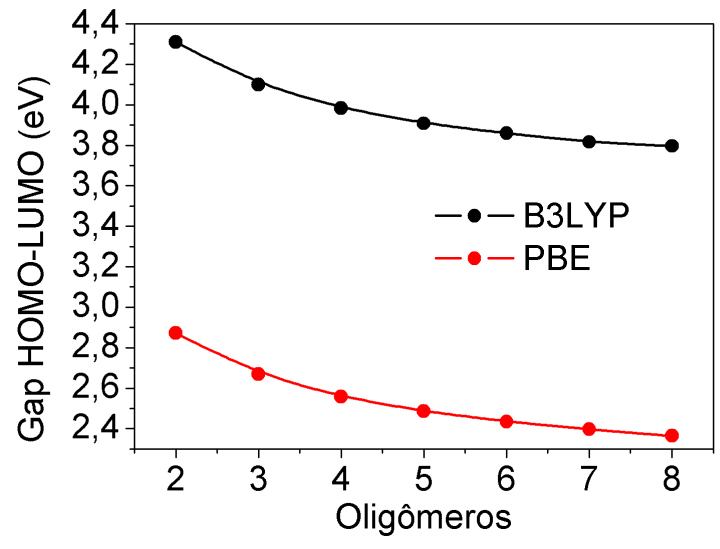

(a)

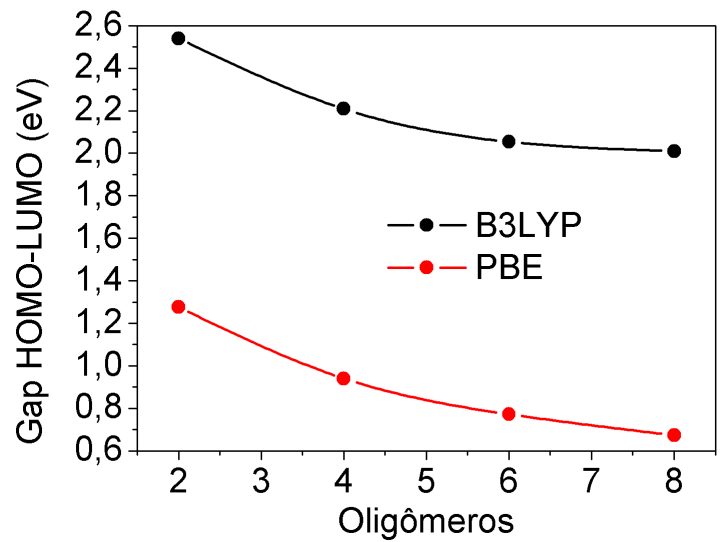

(b)

Figura 3.3: Evolução do gap HOMO-LUMO dos oligômeros de LE (a) e PE (b). Dada a proporção de 3 anéis aromáticos e um quinóide na forma EM, calculamos apenas dois pontos: tetrâmero e octâmero, cujos gaps HOMO-LUMO calculados são de 2,25 eV e 2,01 $\mathrm{eV}$, respectivamente, obtidos com B3LYP/6-31G*. 


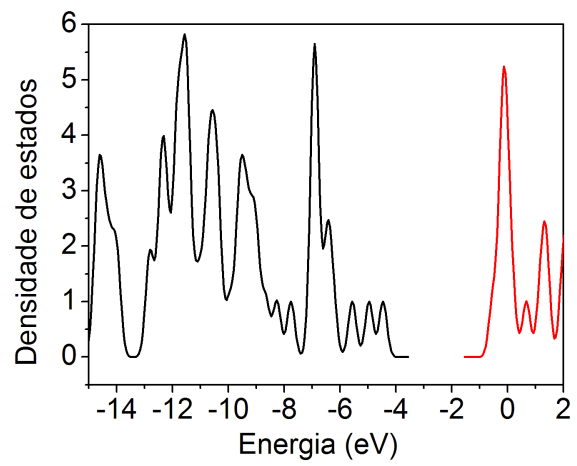

(a)

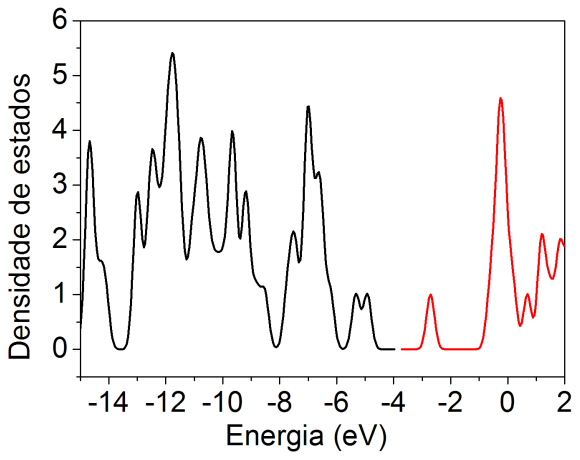

(b)

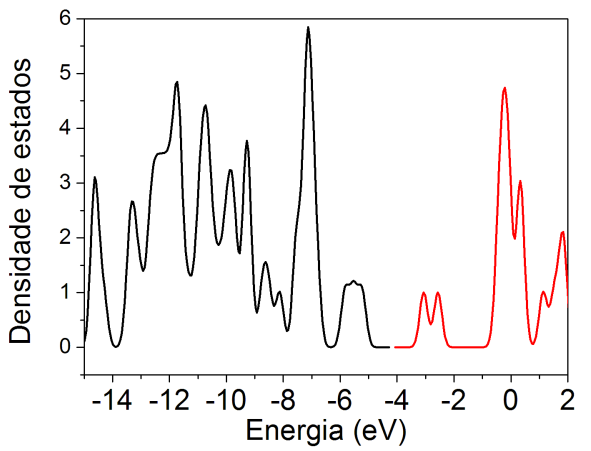

(c)

Figura 3.4: Densidade de estados dos tetrâmeros de (a) leucoesmeraldina, (b)esmeraldina e (c) pernigranilina com o grupo SH nas extremidades. As curvas em preto e vermelho representam respectivamente os estados ocupados e os virtuais.

B3LYP e PBE), com relação ao resultado experimental, na descrição dos comprimentos de ligação das cadeias. Nas tabelas 3.1 e 3.2 são mostradas estruturas geométricas das LE e EM, as PE podem ser avaliadas através dos valores estruturais da EM uma vez que ambas possuem anéis aromáticos e quinóides. As diferenças entre os métodos é maior na descrição do anél quinóide da forma esmeraldina, onde o método B3LYP é o que apresenta a distorção quinóide mais próxima do valor experimental.

As mudanças estruturais entre as diferentes formas de oxidação das oligoanilinas são acompanhadas de mudanças eletrônicas, como a redução do gap. Utilizamos as densidades de estados molecular, obtidas através de uma convolução gaussiana do histograma de autovalores dos oligômeros, para estudar as propriedades eletrônicas. Na figura 3.4, as densidades de estados dos diferentes estados de oxidação do tetrâmero de LE, EM e PE 
Tabela 3.1: Comparações estruturais entre os diveros métodos teóricos e experimentais da LE. Os valores experimentais foram obtidos com os sais de $\mathrm{ClO}_{4}^{-}$e $\mathrm{BF}_{4}^{-}$(com comprimentos de ligação entre parênteses na tabela) de LE. Os índices dos átomos estão indicados na figura 3.2. Os comprimentos de ligação são dados em $\operatorname{angstroms}(\AA)$.

\begin{tabular}{|c|c|c|c|c|}
\hline Ligação LE & RHF $/ 6-31 \mathrm{G}[68]$ & $\mathrm{B} 3 \mathrm{LYP} / 6-31 \mathrm{G}^{*}$ & $\mathrm{PBE} / 6-31 \mathrm{G}^{*}$ & Expt. $[69]$ \\
\hline$C_{1}-C_{2}$ & 1,397 & 1,401 & 1,408 & $1,360(1,360)$ \\
\hline$C_{2}-C_{3}$ & 1,384 & 1,389 & 1,395 & $1,400(1,397)$ \\
\hline$C_{3}-C_{4}$ & 1,391 & 1,409 & 1,417 & $1,378(1,386)$ \\
\hline$C_{4}-C_{5}$ & 1,391 & 1,408 & 1,415 & $1,389(1,383)$ \\
\hline$C_{5}-C_{6}$ & 1,384 & 1,392 & 1,398 & $1,380(1,386)$ \\
\hline$C_{6}-C_{1}$ & 1,397 & 1,399 & 1,407 & $1,360(1,392)$ \\
\hline$C_{4}-N_{7}$ & 1,421 & 1,390 & 1,392 & $1,401(1,403)$ \\
\hline$N_{7}-C_{8}$ & 1,399 & 1,409 & 1,407 & $1,335(1,373)$ \\
\hline$C_{8}-C_{9}$ & 1,393 & 1,402 & 1,410 & $1,415(1,407)$ \\
\hline$C_{9}-C_{10}$ & 1,385 & 1,392 & 1,396 & $1,338(1,358)$ \\
\hline$C_{10}-C_{11}$ & 1,393 & 1,405 & 1,413 & $1,423(1,426)$ \\
\hline$C_{11}-C_{12}$ & 1,393 & 1,406 & 1,414 & $1,406(1,407)$ \\
\hline$C_{12}-C_{13}$ & 1,385 & 1,390 & 1,395 & $1,359(1,374)$ \\
\hline$C_{13}-C_{8}$ & 1,393 & 1,404 & 1,412 & $1,419(1,415)$ \\
\hline$C_{11}-N_{14}$ & 1,399 & 1,398 & 1,399 & $1,371(1,378)$ \\
\hline$N_{14}-C_{15}$ & 1,421 & 1,402 & 1,402 & $1,357(1,359)$ \\
\hline$C_{15}-C_{16}$ & 1,391 & 1,404 & 1,412 & $1,417(1,414)$ \\
\hline$C_{15}-C_{17}$ & 1,391 & 1,405 & 1,413 & $1,400(1,424)$ \\
\hline \hline
\end{tabular}


Tabela 3.2: Comparações estruturais entre os diveros métodos teóricos e experimentais da EM. Os índices dos átomos estão indicados na figura 3.2. Os comprimentos de ligação são dados em angstroms $(\AA)$.

\begin{tabular}{|c|c|c|c|c|}
\hline Ligação EM & $\mathrm{RHF} / 6-31 \mathrm{G}[68]$ & $\mathrm{B} 3 \mathrm{LYP} / 6-31 \mathrm{G}^{*}$ & $\mathrm{PBE} / 6-31 \mathrm{G}^{*}$ & Expt. $[69]$ \\
\hline$C_{1}-C_{2}$ & 1,397 & 1,407 & 1,417 & 1,37 \\
\hline$C_{2}-C_{3}$ & 1,384 & 1,388 & 1,391 & 1,38 \\
\hline$C_{3}-C_{4}$ & 1,391 & 1,413 & 1,425 & 1,37 \\
\hline$C_{4}-C_{5}$ & 1,391 & 1,411 & 1,422 & 1,37 \\
\hline$C_{5}-C_{6}$ & 1,384 & 1,387 & 1,390 & 1,39 \\
\hline$C_{6}-C_{1}$ & 1,397 & 1,408 & 1,417 & 1,37 \\
\hline$C_{4}-N_{7}$ & 1,421 & 1,389 & 1,381 & 1,42 \\
\hline$N_{7}-C_{8}$ & 1,399 & 1,306 & 1,323 & 1,32 \\
\hline$C_{8}-C_{9}$ & 1,393 & 1,462 & 1,457 & 1,46 \\
\hline$C_{9}-C_{10}$ & 1,385 & 1,353 & 1,367 & 1,33 \\
\hline \hline
\end{tabular}


HOMO

LUMO
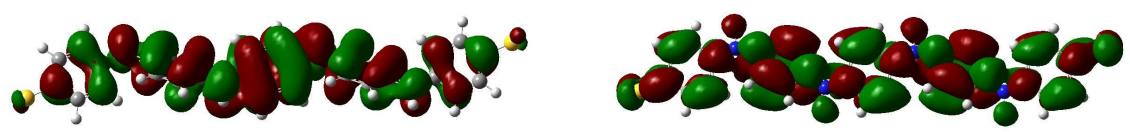

(a)

HOMO

LUMO
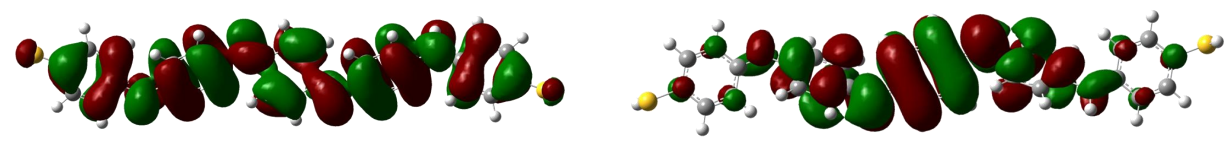

(b)

HOMO

LUMO
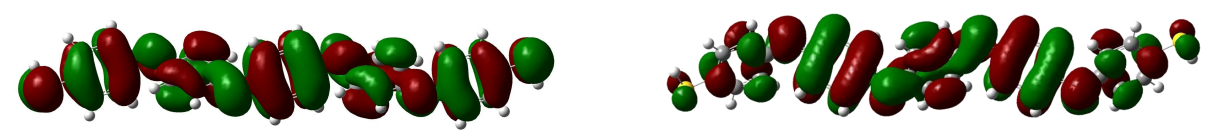

(c)

Figura 3.5: Orbitais de fronteira HOMO e LUMO dos tetrâmeros de (a) LE, (b) EM e (c) PE. Os orbitais LUMO apresentam-se localizados principalmente sobre os anés quinóides nas estruturas oxidadas.

apresentam, de modo geral, o mesmo aspecto, com a diferença mais notável no valor do gap. A leucoesmeraldina apresenta o maior gap, em torno de 3,98 eV(tetrâmero). As formas EM e PE possuem níveis de energia na região central do gap equivalente ao da forma LE. Cada novo nível formado nestas duas formas está associado com os anéis quinóides (Fig. 3.5), uma vez que a oxidação se dá nos elétrons $\pi$ destes anéis.

As propriedades estruturais e eletrônicas obtidas para as oligoanilinas, nos diversos estados de oxidação, com o método B3LYP/6-31G* são compatíveis com o experimento. Estes resultados fornecem o indicativo que este método de cálculo é adequado para esta classe de oligômeros. A seguir, faremos a mesma análise estrutural e geométrica para os oligotiofenos. 


\subsection{Oligotiofenos}

A estrutura geométrica do tiofeno pode ser descrita como um anel de pentágono formado por átomos de carbono com exceção de um heteroátomo de enxofre. Os oligômeros com duas e quatro unidades monoméricas estão representados na figura 3.6.

As otimizações de geometria indicam que na conformação mais estável os anéis estão fora de um plano comum e os átomos de enxofre apresentam-se em oposição um ao outro. Para o bitiofeno encontramos um valor de $157^{\circ}$ do ângulo diedral entre os dois anéis, resultado comparável $\left(141^{\circ}\right)$ ao obtido com o método MP2[60] (M $\phi$ ller Plesset-que utiliza a teoria de perturbação para inserir a correlação eletrônica) com a base $6-31 \mathrm{G}^{*}[70]$. No tetrâmero, o valor das ligações duplas encontra-se entre 1,38 e 1,37 $\AA$, as ligações simples intra-anel 1,41 $\AA$, as inter-anéis 1,44 $\AA$ e as ligações S-C dos anéis apresentam comprimentos em torno de 1,75 A. Estes resultados estão detalhados na tabela 3.3 e mostram que, de modo geral, há uma concordância entre os métodos teóricos e os resultados experimentais. Entretanto, nas propriedades eletrônicas o método B3LYP/6-31G* apresenta o melhor resultado, evidenciado pala evolução do gap em função do tamanho dos oligômeros, mostrado na figura 3.7 e que foram calculados com os métodos B3LYP e PBE. Experimentalmente, o gap do trímero e do tetrâmero são reportados em 3,0 e 4,0 eV [48], enquanto que o polímero apresenta um valor um pouco maior que 2,5 eV[71], que está em excelente concordância com o valor obtido com o octâmero calculado com a metodologia B3LYP/6-31G*.

O funcional B3LYP com a função de base 6-31G* reproduz de modo eficaz as características eletrônicas e estruturais dos oligotiofenos, sendo comparável com métodos mais custosos, tais como o MP2.

\subsection{Eletrodos}

Os modelos de eletrodos são utilizados para fazer a conexão entre as cadeias orgânicas e o reservatório de elétrons (Fig. 3.8) formado pela forma cristalina do ouro. O arranjo 

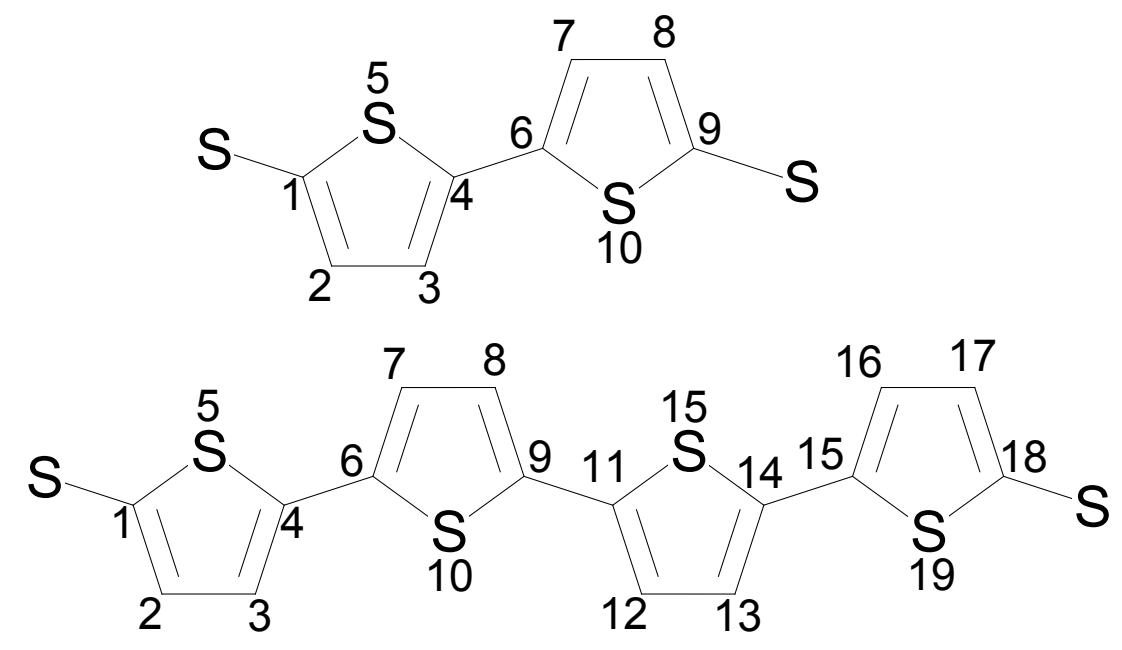

Figura 3.6: Estrutura esquemática do bitiofeno (superior) e quatertiofeno (inferior).

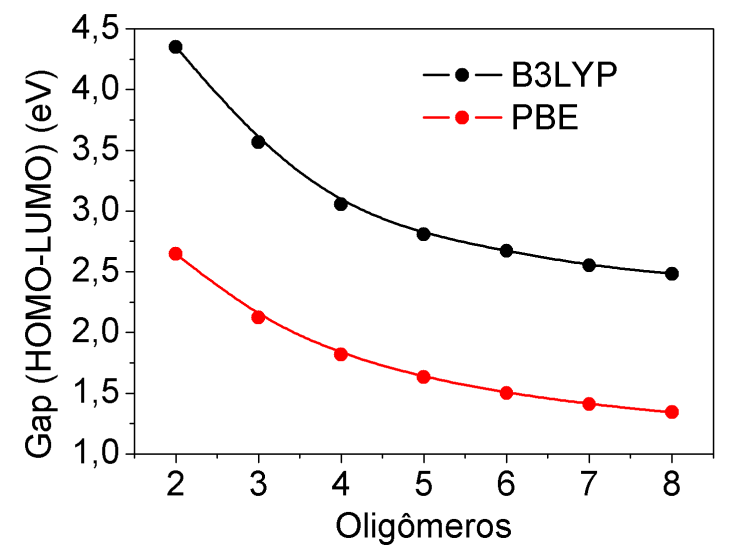

Figura 3.7: Evolução do gap HOMO-LUMO dos oligômeros de tiofeno. 
Tabela 3.3: Parâmetros estruturais calculados e experimentais do dímero (2T) e tetrâmero (4T) de tiofeno. Os comprimentos de ligação são dados em angstroms $(\AA)$.

\begin{tabular}{|c|c|c|c|c|c|}
\hline Ligação $2 \mathrm{~T}$ & B3LYP/6-31G* & $\mathrm{PBE} / 6-31 \mathrm{G}^{*}$ & $\mathrm{HF} / 6-31 \mathrm{G}^{*}[72]$ & Exp. [72] & Exp. [73] \\
\hline$C_{1}-C_{2}$ & 1,373 & 1,385 & 1,344 & 1,363 & \\
\hline$C_{2}-C_{3}$ & 1,420 & 1,419 & 1,433 & 1,452 & 1,433 \\
\hline$C_{3}-C_{4}$ & 1,380 & 1,391 & 1,351 & 1,370 & 1,357 \\
\hline$C_{4}-S_{5}$ & 1,754 & 1,757 & 1,739 & 1,733 & \\
\hline$S_{5}-C_{1}$ & 1,752 & 1,755 & 1,725 & 1,719 & \\
\hline$C_{4}-C_{6}$ & 1,450 & 1,447 & 1,464 & 1,456 & 1,480 \\
\hline Ligação 4T & B3LYP/6-31G* & $\mathrm{PBE} / 6-31 \mathrm{G}^{*}$ & $\mathrm{HF} / 3-21 \mathrm{G}^{*}[74]$ & \multicolumn{2}{|c|}{$\mathrm{MP} 2 / 6-31 \mathrm{G}^{*}[75]$} \\
\hline$C_{1}-C_{2}$ & 1,373 & 1,385 & 1,350 & \multicolumn{2}{|c|}{1,377} \\
\hline$C_{2}-C_{3}$ & 1,419 & 1,418 & 1,430 & \multicolumn{2}{|c|}{1,414} \\
\hline$C_{3}-C_{4}$ & 1,381 & 1,393 & 1,350 & \multicolumn{2}{|c|}{1,388} \\
\hline$C_{4}-S_{5}$ & 1,755 & 1,759 & & & \\
\hline$S_{5}-C_{1}$ & 1,753 & 1,756 & 1,720 & & \\
\hline$C_{4}-C_{6}$ & 1,446 & 1,443 & 1,460 & \multicolumn{2}{|c|}{1,445} \\
\hline$C_{6}-C_{7}$ & 1,380 & 1,393 & 1,350 & \multicolumn{2}{|c|}{1,389} \\
\hline$C_{7}-C_{8}$ & 1,415 & 1,413 & 1,430 & \multicolumn{2}{|c|}{1,406} \\
\hline$C_{8}-C_{9}$ & 1,381 & 1,394 & 1,350 & \multicolumn{2}{|c|}{1,390} \\
\hline$C_{9}-S_{1} 0$ & 1,757 & 1,760 & 1,730 & \multicolumn{2}{|c|}{1,739} \\
\hline$S_{10}-C_{6}$ & 1,756 & 1,760 & & \multicolumn{2}{|c|}{1,738} \\
\hline
\end{tabular}


eletrodo-molécula-eletrodo é similar aos experimentos que medem a condutância em uma única cadeia orgânica, onde um lado do eletrodo equivale a ponta de STM e o outro ao substrato metálico. Uma vez que os contatos são estruturas com poucos átomos, utilizamos suas formas mais estáveis, reportadas na referência [76]. Esquematicamente, os eletrodos são mostrados na figura 3.9. Escolhemos estruturas planas e um modelo tridimensional de eletrodo e variamos o modo de conexão com a cadeia orgânica nas formas bridge e atop. Na primeira dois átomos de ouro ligam-se simultâneamente ao átomo de enxofre na extremidade da cadeia, enquanto que na segunda apenas um.

Para escolher o melhor método de cálculo dos eletrodos, utilizamos alguns aspectos eletrônicos e estruturais (tabela 3.4) reportados experimentalmente. Um aglomerado com 2 átomos de ouro é utilizado como sistema de comparação, e indica que a melhor descrição de suas propriedades eletrônicas e estruturais é obtida com o método PW91/LANL2DZ (troca e correlação). Uma boa descrição do aglomerado também é obtida com o método B3LYP/LANL2DZ. Como o método PW91 fornece a melhor descrição do metal e o B3LYP da molécula orgânica, comparamos os resultados entre estes dois funcionais, no cálculo de um sistema de 14 átomos de ouro(Fig. 3.9), para demonstrar que é justificável o uso do funcional B3LYP no sistema eletrodo-cadeia-eletrodo. Na tabela 3.5 os parâmetros estruturais indicam que os métodos fornecem resultados muito similares entre si. Avaliamos também, alguns aspectos eletrônicos, tais como gap HOMO-LUMO e a posição energética destes. Os valores dos gaps obtidos com os métodos B3LYP, PBE e PW91 são, respectivamente 2,498 eV, 1,621 eV e 1,620 eV, dado que o método B3LYP têm mostrado melhor resultado na descrição do gap que o método PBE que o subestima, estes resultados são bastante similares. O valor do HOMO e LUMO, que possuem boa concordância entre os métodos, são respectivamente -6,251 eV (-5,811 eV) e -3,752 eV (-4,190 eV) calculados com o método B3LYP(PBE).

Expomos argumentos ao longo deste capítulo que deixam claro que na descrição de sistemas orgânicos o método B3LYP é muito mais adequado que o método PBE e que em metais essa situação é um tanto invertida. Entretanto, alguns aspectos sobre o desempenho destes dois métodos devem ser lembrados: (1) As diferenças nos resultados(estruturais 
Tabela 3.4: Comparações estruturais entre os diversos métodos teóricos para um eletrodo de dois átomos de ouro.

\begin{tabular}{|c|c|c|c|c|}
\hline Método & conjunto de base & $R_{L} \AA$ & Energia de ligação $(\mathrm{eV})$ & Eletroafinidade(eV) \\
\hline PW91 & LANL2DZ & 2,531 & 2,196 & 2,018 \\
\hline B3LYP & LANL2DZ & 2,574 & 1,973 & 2,107 \\
\hline Exp. $[76,77]$ & & 2,47 & 2,30 & 1,94 \\
\hline
\end{tabular}

e eletrônicos) obtidos em aglomerados de ouro são bastante pequenas e (2) O erro do método PBE, em fornecer gaps subestimados, não é tão relevante em cálculos de sistemas metálicos, uma vez que possuem um gap pequeno ou nulo no caso do bulk, mas é extremamente importante descrevermos corretamente a estrutura eletrônica das cadeias orgânicas. O método ideal para os cálculos deve ser aquele que forneça resultados estruturais e eletrônicos comparáveis com as medidas experimentais tanto dos compostos orgânicos quanto das estruturas metálicas. Entretanto, para tratar os sistemas que estamos interessados, métodos mais precisos como os pós Hartree-Fock (como o MP2), são muito custosos. Com isso utilizamos a DFT, por apresentar bons resultados e um baixo custo computacional. Estudamos dois funcionais, cuja diferença fundamental está no fato do B3LYP ser híbrido, ou seja, contém em sua construção termos obtidos nos moldes da DFT (obtidos com base na densidade eletrônica) e no método de Hartree-Fock (obtido através do conceito de função de onda). A comparação entre os funcionais, mostrada ao longo deste capítulo, indica que o B3LYP é o mais adequado que o PBE, dada sua boa comparação com os resultados experimentais e métodos mais acurados, tanto das cadeias orgânicas quanto das metálicas. 
Tabela 3.5: Comparações estruturais e eletrônicas entre os métodos DFT para o eletrodo 7 com 14 átomos de ouro. Os átomos estão indicados na figura 3.9. Os comprimentos de ligação são dados em angstrons $(\AA)$.

\begin{tabular}{|c|c|c|c|}
\hline Ligação & B3LYP/LANL2DZ & PBE/LANL2DZ & PW91/LANL2DZ \\
\hline$A u_{1}-A u_{2}$ & 2,878 & 2,872 & 2,861 \\
\hline$A u_{2}-A u_{3}$ & 2,742 & 2,718 & 2,718 \\
\hline$A u_{3}-A u_{4}$ & 2,909 & 2,844 & 2,845 \\
\hline$A u_{1}-A u_{5}$ & 2,870 & 2,809 & 2,814 \\
\hline$A u_{2}-A u_{5}$ & 2,890 & 2,819 & 2,821 \\
\hline$A u_{3}-A u_{6}$ & 2,886 & 2,839 & 2,838 \\
\hline$A u_{4}-A u_{7}$ & 2,785 & 2,748 & 2,747 \\
\hline$A u_{5}-A u_{6}$ & 2,745 & 2,724 & 2,721 \\
\hline$A u_{6}-A u_{8}$ & 2,794 & 2,782 & 2,781 \\
\hline$A u_{6}-A u_{7}$ & 3,014 & 2,936 & 2,941 \\
\hline \hline
\end{tabular}

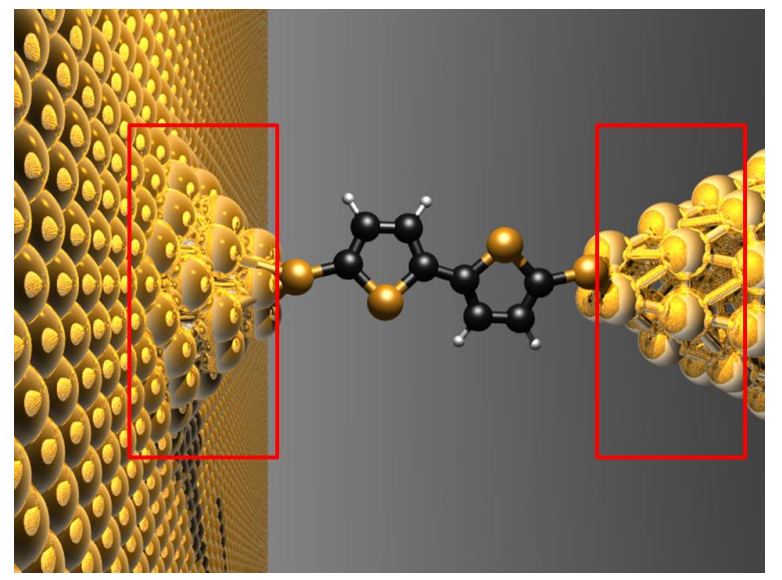

Figura 3.8: Esquema do arranjo entre os eletrodos e a cadeia orgânica (dímero de tiofeno). Os retângulos vermelhos indicam a região dos modelos de eletrodos utilizados. 

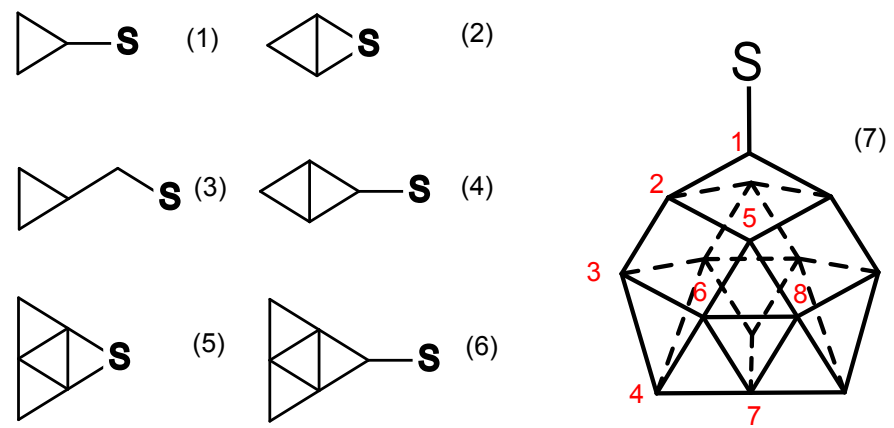

Figura 3.9: Eletrodos utilizados neste trabalho e suas diferentes formas de conexão com o átomo de enxofre das cadeias orgânicas. 


\section{Capítulo 4}

\section{Resultados I: Análise estrutural e}

\section{eletrônica das cadeias orgânicas}

\section{conectadas aos eletrodos metálicos.}

Realizamos cálculos de otimização de geometria de oligoanilinas conectadas aos eletrodos mostrados na figura 3.9. Nos sistemas eletrodo-molécula-eletrodo variamos o tamanho da cadeia central e seu estado de oxidação (leucoesmeraldina, esmeraldina e pernigranilina), bem como o tamanho dos eletrodos e a forma de conexão. De acordo com o tipo de conexão da cadeia com o eletrodo observamos mudanças em sua geometria e estrutura eletrônica. Estes aspectos serão cuidadosamente mostrados neste capítulo e nos seguintes. Discutiremos os resultados apenas para a forma leucoesmeraldina, dada a similaridade dos resultados obtidos com as formas esmeraldina e pernigranilina e dos oligotiofenos. Ao final deste capítulo faremos uma breve menção sobre os aspectos eletrônicos e estruturais das pernigranilinas e oligotiofenos conectados aos eletrodos de ouro. 


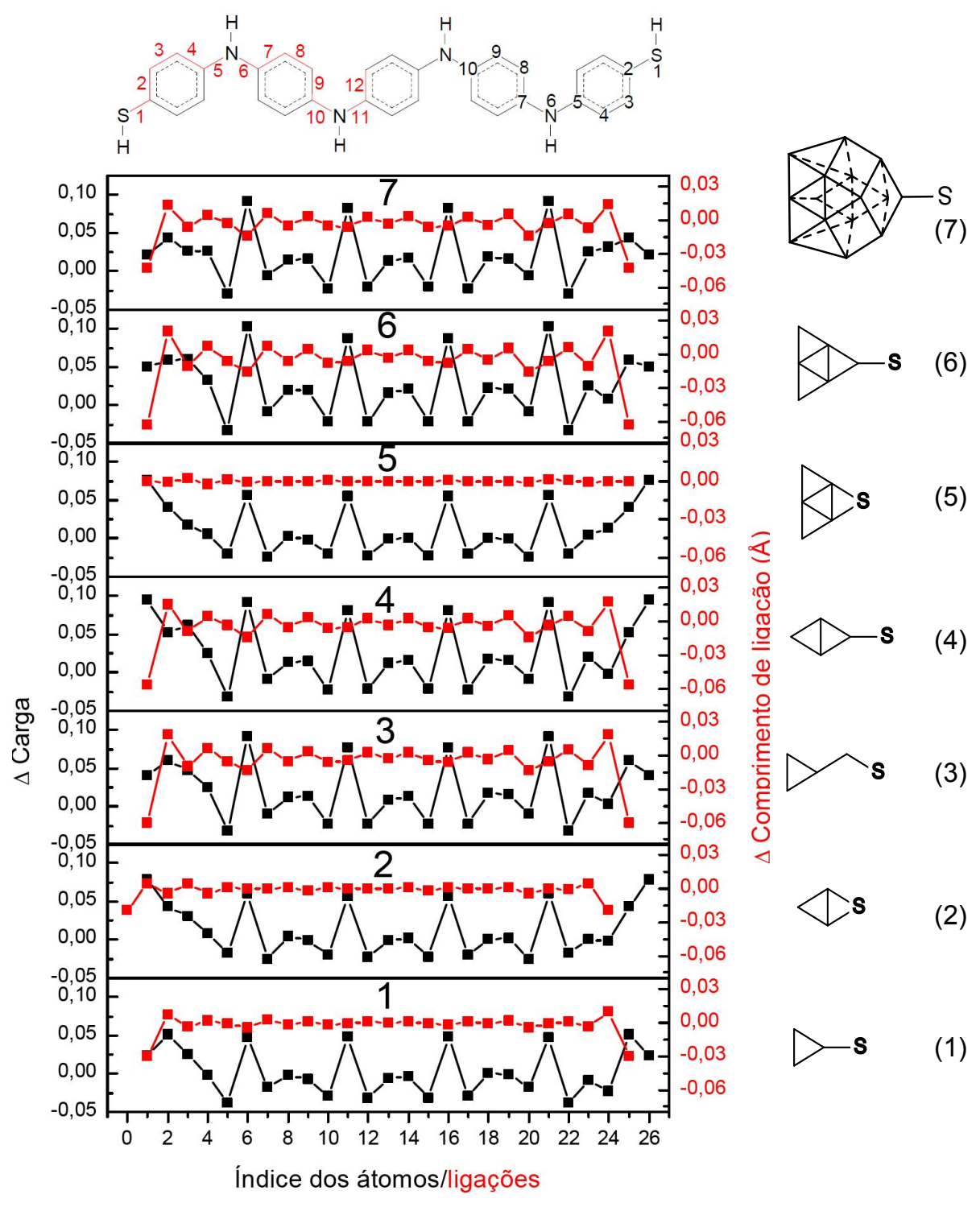

Figura 4.1: Variação da carga e comprimento de ligação do tetrâmero de leucoesmeraldina após conexão com eletrodos de ouro. O tipo de conexão com o eletrodo é indicada pelos números $1,2, .$. e 7 na parte superior de cada gráfico. As geometrias dos contatos são mostradas à direita. Os índices dos átomos e das ligações no oligômero estão indicados na cadeia do topo da figura. 


\subsection{Leucoesmeraldina}

Utilizamos nestes cálculos um número finito de átomos de ouro, estes aglomerados representam a vizinhança imediata da cadeia no bulk. É demonstrado que o uso de aglomerados metálicos é um bom modelo para o estudo da interação metal-orgânico, como é mostrado na referência [78] no estudo da adsorção da molécula de $\mathrm{CO}$ em superfícies de cobre e prata. A energia de adsorção da molécula de CO nestas superfícies converge para 10 átomos no aglomerado. Adicionamente é reportado que o método B3LYP fornece corretamente a absorção da cadeia de CO no sítio atop, diferentemente do que é obtido com o método PBE.

Um aspecto importante dos sistemas que possuem interface metal/orgânico é relativo à troca de carga entre estas partes. O deslocamento de carga não pode ser entendido apenas pela análise da posição dos níveis de cada parte isoladamente, uma vez que os detalhes da interface desempenham um papel crucial na barreira de injeção de carga[79, 80]. O processo de transferência de carga é referido como "dopagem por transferência de carga" [81] e pode induzir mudanças estruturais na cadeia, como num processo usual de dopagem.

Após a conexão com os eletrodos, ocorrem mudanças na geometria dos oligômeros de Leucoesmeraldina. A figura 4.1 foi obtida com a diferença da carga em cada átomo e comprimento de ligação entre pares de átomos entre as cadeias isoladas de tetrâmero e os sistemas estendidos (estrutura composta pela cadeia orgânica e parte dos eletrodos). A análise da carga e do comprimento de ligação indica a existência de dois padrões eletrônicos e estruturais: (I) Quando a cadeia conecta-se aos eletrodos 1, 2 e 5 ocorre pouca troca de carga entre cadeia e eletrodo, que consequentemente leva a pouca mudança nos comprimentos de ligação. (II) Quando a cadeia é conectada aos eletrodos 3, 4, 6 e 7 as mudanças na carga e no comprimento de ligação ao longo da cadeia são apreciáveis. De modo geral, em todas as conexões com os eletrodos, a carga sobre a cadeia é positiva. A maior mudança de carga é usualmente reportada na interface orgânico-metal, como descrito na literatura [81, 82]. Entretanto, nos sistemas de oligoanilinas que calculamos, 
os átomos de nitrogênio, que estão presentes em toda a extensão das cadeias, apresentam forte perda de carga negativa, portanto indicam que o rearranjo de carga é intenso em toda a estrutura molecular. Por outro lado, as variações nos comprimentos de ligação dos oligômeros são maiores nas extremidades, comportamento que indica que a grande diferença de carga sobre os átomos de nitrôgenio é bastante localizada e não induz fortes alterações nos comprimentos de ligação. Assim, de modo análogo aos resultados reportados na literatura, a maior mudança conjunta carga/geometria ocorre nas extremidades das cadeias orgânicas.

Informações relevantes sobre a estrutura eletrônica são obtidas com a análise dos orbitais de Kohn-Sham. Na figura 4.2 estão desenhados os orbitais de fronteira mais estendidos dos sistemas eletrodo-molécula-eletrodo, bem como estão presentes o INP e a porcentagem de participação dos átomos da cadeia. Os orbitais HOMO e LUMO da cadeia isolada estão também indicados, e fornecem um valor de base para o INP de um estado estendido. O INP é um número que indica o grau de localização e/ou deslocalização: quanto menor seu valor mais estendido será o orbital associado. O INP deve ser utilizado para sistemas cujo número de orbitais atômicos (funções de Kohn-Sham auxiliares) sejam próximos ou de preferência iguais entre si, uma vez que torna-se menor quanto maior é o conjunto de funções de base. Nossos sistemas apresentam tamanho de eletrodos diferentes (diferentes tamanhos da base atômica), com isso torna-se necessário, para análise completa dos estados de fronteira, o uso da imagem dos mesmos e da porcentagem de contribuição dos estados da cadeia em cada nível. Tipicamente, verificamos estados estendidos, com INP comparável ao da cadeia isolada, para os orbitais $\mathrm{HOMO}$ e $\mathrm{LUMO}+\mathrm{N}$, com $\mathrm{N}$ igual a 6 e 8 para conexão com os eletrodos 2 e 5, respectivamente. Os INPs dos orbitais $\mathrm{HOMO}$ e LUMO+N são similares com os seus correspondentes na cadeia isolada, e a contribuição dos coeficientes da cadeia orgânica é maior que 80 \%. A forma dos orbitais indica que os sistemas 2 e 5 são mais similares à cadeia isolada que os demais sistemas estendidos. De modo geral, a conexão com os eletrodos de ouro sempre leva a redução do gap HOMO-LUMO, não importando o modo de conexão ou a quantidade de átomos de ouro. 
Os sistemas estendidos metal-molécula diferem entre si quanto à localização ou deslocalização dos orbitais de fronteira (HOMO e LUMO) e dos estados que se encontram entre o HOMO e LUMO da cadeia isolada. A redução do gap, com relação à cadeia isolada, nos sistemas estendidos formados com os eletrodos 2 e 5 , não indica que isto beneficiará o transporte eletrônico. A razão é porque os estados intra-gap são localizados nas extremidades e sobre os átomos de ouro. As cadeias conectadas aos eletrodos chamados de atop, ou sistemas 1, 3, 4, 6 e 7, apresentam os estados LUMO bastante deslocalizados, com exceção do sistema 1, indicando que tais conexões (atop) induzem mudanças nas cadeias orgânicas que favorecem a condução eletrônica.

As densidades de estados projetadas mostradas na figura 4.3 foram obtidas para o tetrâmero de leucoesmeraldina conectado aos eletrodos $1,2,3,4,5$ e 6 . A estrutura eletrônica dos sistemas estendidos pode ser enquadrada em dois padrões, cada um associado ao tipo de ligação dos sistemas (bridge ou atop): Nos sistemas atop ocorre um deslocamento para menores energias de todo o espectro de autovalores, bem como a formação de estados com considerável participação das cadeias orgânicas. Os sistemas bridge apresentam, na contribuição da cadeia orgânica, grande semelhança com a densidade de estados da cadeia isolada. Ocorre, nos dois casos, a formação de muitos estados associados com os eletrodos. Para que as mudanças eletrônicas, induzidas pelas conexões com os eletrodos, levem à melhoria do transporte eletrônico, os estados do eletrodo devem apresentar uma forte mistura com os estados da cadeia. A PDOS do sistema de conexão 1 difere, aparentemente, do comportamento dos demais sistemas atop. Discutiremos com mais detalhes o caso desta conexão em uma seção mais adiante.

O modo como a carga acumula-se nos eletrodos em função do comprimento da cadeia é bastante distinto entre os sistemas bridge e atop (Fig. 4.4). No primeiro ocorre uma rápida saturação desta em função do tamanho dos oligômeros, diferentemente, no segundo caso o valor da carga total se assemelha a um simples decaimento linear em função do tamanho da cadeia. Um comportamento curioso é o fato de que nos sistemas bridge a carga acumulada é maior quanto menor é o eletrodo, comportamento inverso ao obtido com os sistemas atop. Quando calculamos a carga média nos átomos de ouro, encontramos resultados 


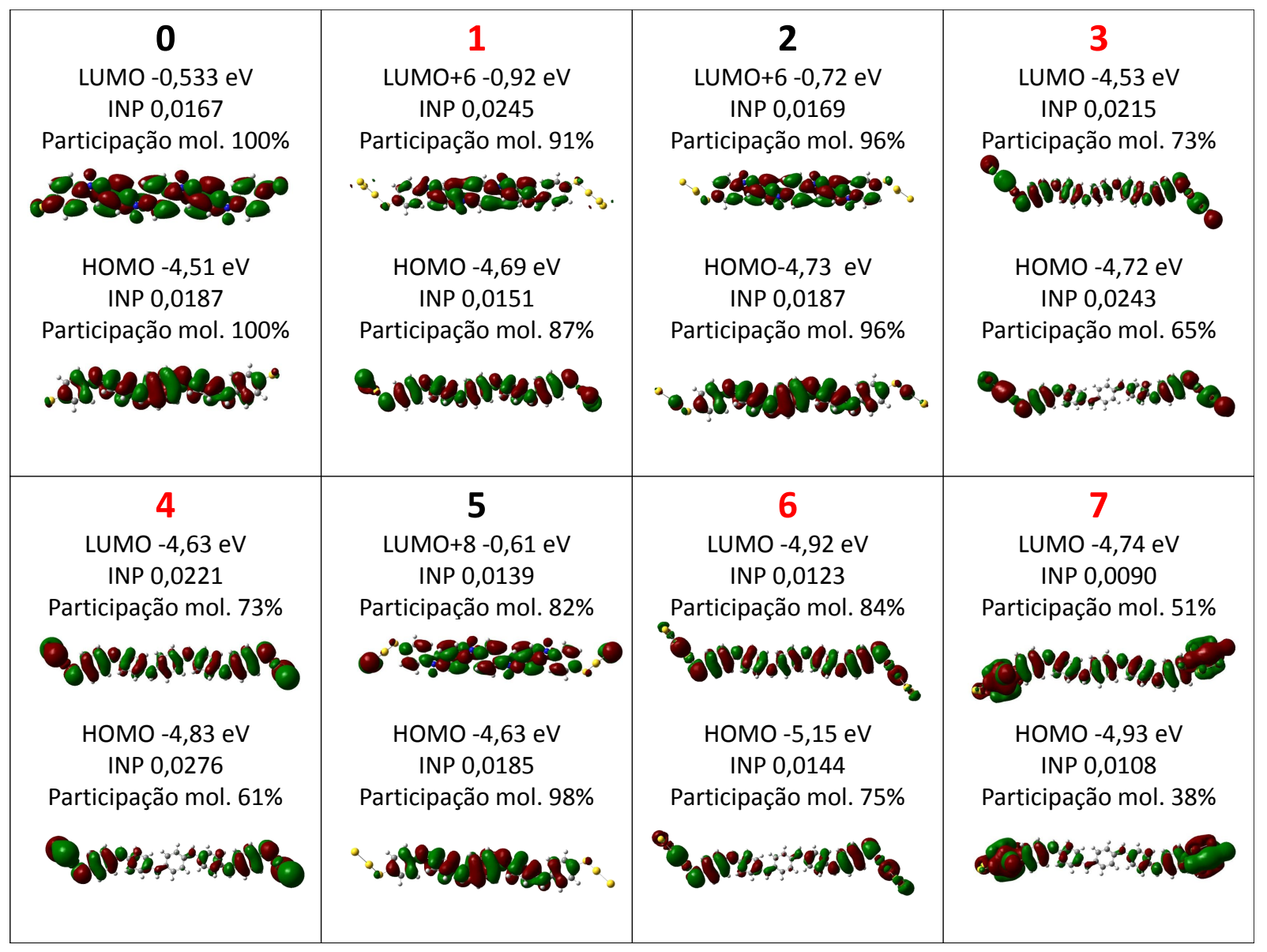

Figura 4.2: Orbitais de Kohn-Sham do tetrâmero de Leucoesmeraldina. Estão indicados o número de participação (INP) e a contribuição dos orbitais dos átomos da cadeia. Os índices $1,2 .$. e 7 indicam o eletrodo, cujas formas de conexão bridge e atop são indicadas respectivamente pelas cores preta e vermelha. 
similares entre os sistemas bridge e atop, nos quais, nos maiores eletrodos um átomo de ouro acumula em média menos carga que nos menores eletrodos. Tal comportamento é explicado pelo fato de que quanto maior o eletrodo mais átomos de ouro não irão interagir com a cadeia. Ou seja, para um eletrodo suficientemente grande, um outro eletrodo similar, mas com alguns átomos adicionais não acumulará mais carga que o primeiro, pois estes novos átomos estarão distantes da cadeia e não devem ser percebidos pela mesma. A carga média por átomo nos eletrodos pode ser utilizada, portanto, como um índicador de convergência do número de átomos do eletrodo.

\subsubsection{Análise dos níveis}

Nesta subseção analisamos as mudanças dos estados das cadeias e dos eletrodos após a conexão entre os mesmos. Para comparar as diferenças que ocorrem entre os sistemas bridge e atop, estudamos em detalhes o tetrâmero de LE conectado ao eletrodo 5 e 7 , como indicado na figura 4.5.

A conexão com o eletrodo 7 (atop) induz no sistema um forte deslocamento dos níveis de energia do eletrodo para maiores energias, enquanto que os estados da cadeia sofrem uma mudança para energias mais negativas. Esta mudança é explicada pela posição do HOMO e LUMO da cadeia e do aglomerado de ouro. O nível HOMO do eletrodo isolado está posicionado abaixo do HOMO da cadeia isolada. Com a conexão entre estes, ocorre um deslocamento de elétrons da cadeia para o eletrodo. Isto leva a uma diminuição do número de elétrons da cadeia que acarreta a desocupação do nível HOMO, fazendo-o assumir a posição de LUMO no sistema molécula-eletrodo. A posição do HOMO, próxima da energia de Fermi do ouro bulk $\left(\mathrm{E}_{f}=-4,48 \mathrm{eV}\right.$, calculado com o programa crystal 03 [83] com o método B3LYP/LANL2DZ) e do ponto $(\mathrm{HOMO}+\mathrm{LUMO}) / 2($ Energia de Fermi do aglomerado) do eletrodo é comumente encontrada em sistemas orgânicos conectados a eletrodos metálicos $[47,81,84,85,14]$. Em ambos tipos de conexão (bridge ou atop), os elétrons deslocam-se da cadeia para os eletrodos dado o posicionamento do HOMO da cadeia e dos aglomerados. Analisamos a contribuição dos orbitais de ouro na composição 

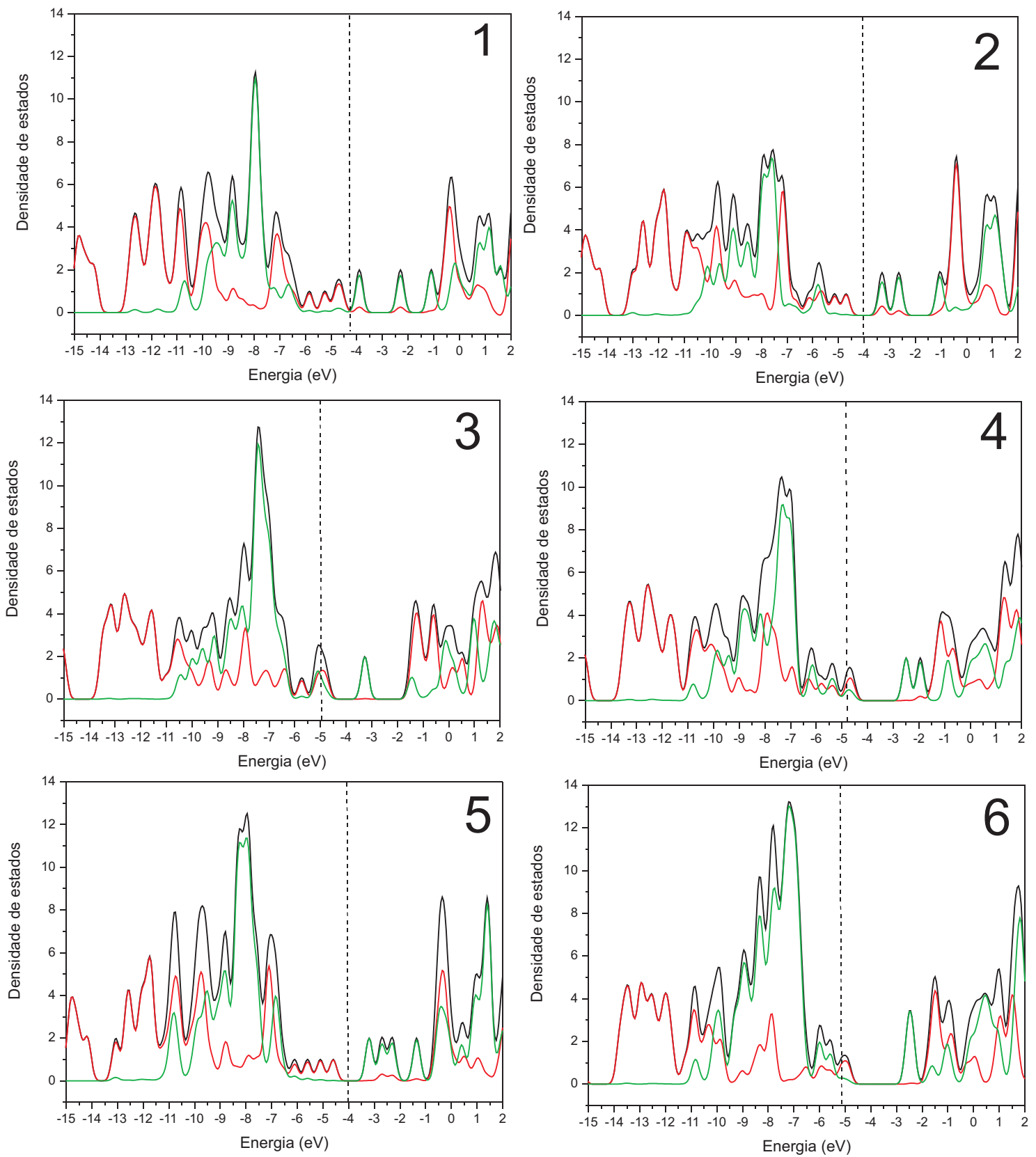

Figura 4.3: Densidade de estados projetada calculadas com o tetrâmero de LE. As curvas em preto, vermelho e verde indicam, respectivamente, a densidade de estados total, a densidade projetada na base atômica da cadeia orgânica e a densidade projetada na base atômica do ouro. Os eletrodos estão indicados pelos números 1, 2, .. e 6 . 

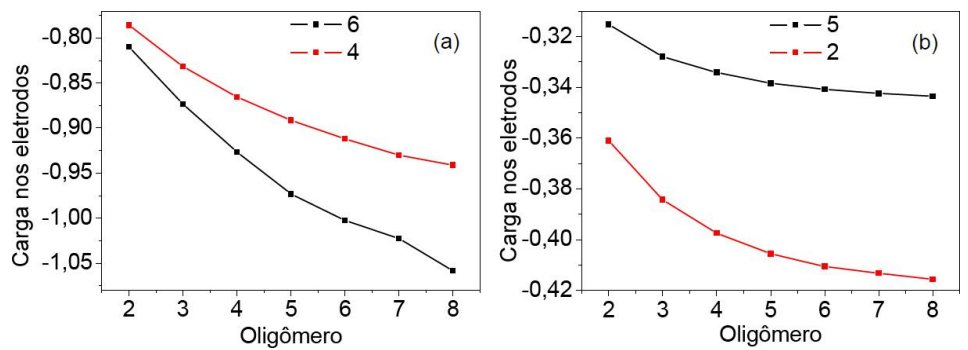

Figura 4.4: Carga acumulada nos eletrodos de ouro conectados de forma (a) atop e (b) bridge aos oligômeros.

dos níveis de energia da cadeia estendida. Na figura 4.6 são mostrados a participação $s$, $p$ e $d$ dos eletrodos de ouro nas conexões 2, 5, 4 e 6. Nos sistemas com conexão bridge notamos que os orbitais $p$ contribuem majoritariamente nos níveis HOMO e LUMO, e HOMO-N próximos do gap. Enquanto que nas cadeias conectados na forma atop há uma participação igualmente distribuída entre os orbitais $s, p$ e $d$ sendo que a participação $s$ aumenta com o número de átomos do contato. Com isto, podemos estabelecer que a forma da ligação atop apresenta uma maior interação da cadeia orgânica com os orbitais $s$, comportamento que pode ser explicado pela sua geometria em forma de ponta.

\subsection{Cadeias sob ação de um campo elétrico externo}

Os sistemas eletrodo-molécula-eletrodo foram submetidos a um campo elétrico externo direcionado de modo paralelo ao eixo longo da cadeia. Nestes cálculos utilizamos a geometria fixa do estado fundamental. Mostraremos os resultados obtidos para o tetrâmero conectado aos eletrodos 2 e 4, uma vez que os resultados dos sistemas bridge são similares entre si, bem como os dos sistemas atop. Assim, os sistemas formados pelos eletrodos $2 \mathrm{e}$ 4 são representativos de todas as configurações.

A figura 4.7 mostra a evolução dos níveis HOMO, LUMO e LUMO+5, 6 em função do campo elétrico aplicado no arranjo eletrodo-molécula-eletrodo 2, onde cada ponto apresenta o tamanho proporcional ao INP. O efeito nos níveis de energia é, principalmente, o de deslocamento destes para menores energias e a mudança no grau de localização. De 

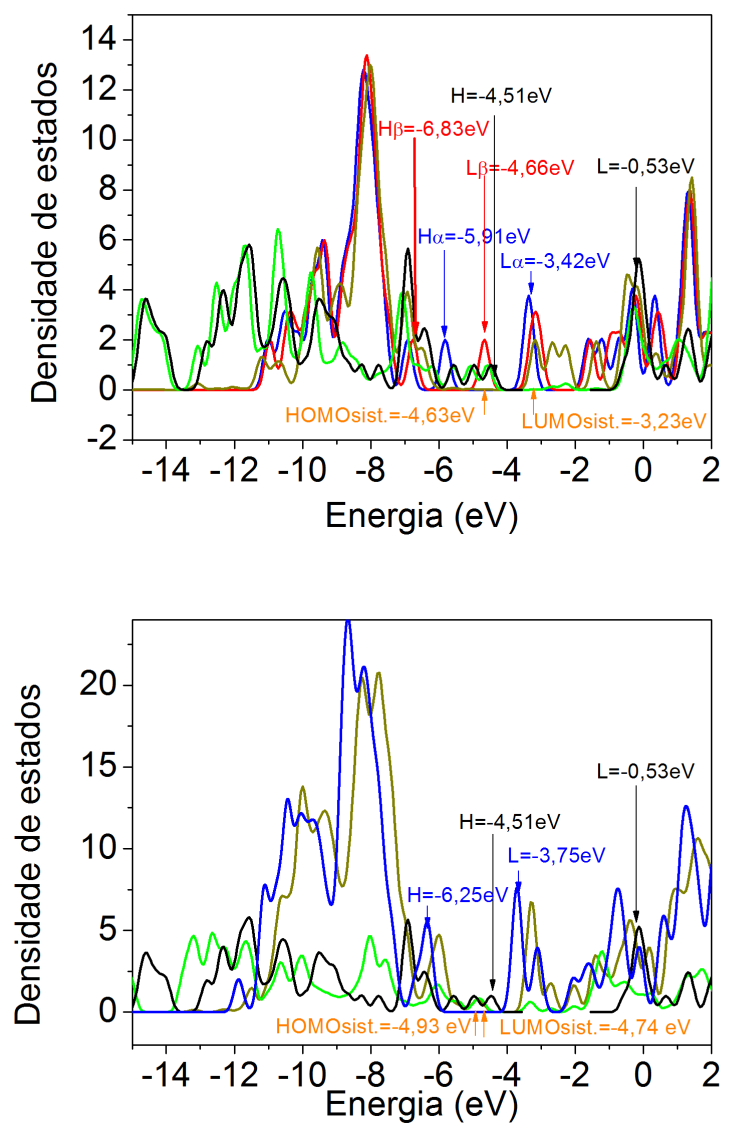

Figura 4.5: Densidade de estados dos sistemas isolados e estendidos. No gráfico superior, a densidade de estados do eletrodo (5) é indicada em azul ( $\operatorname{spin} \alpha)$ e vermelho $(\operatorname{spin} \beta)$, a DOS do eletrodo no sistema estendido é indicado pela cor amarelo-escuro. No gráfico inferior, o sistema (7) é explorado, a DOS do eletrodo isolado é indicado em azul e no sistema estendido em amarelo. Em ambos os casos a densidade de estados da cadeia orgânica é indicada em preto quando isolada e de verde no sistema estendido. Os níveis de energia seguem o mesmo código de cores para a densidade de estados, e adicionalmente são inseridos em laranja as indicações dos níveis de fronteira do sistema estendido. 

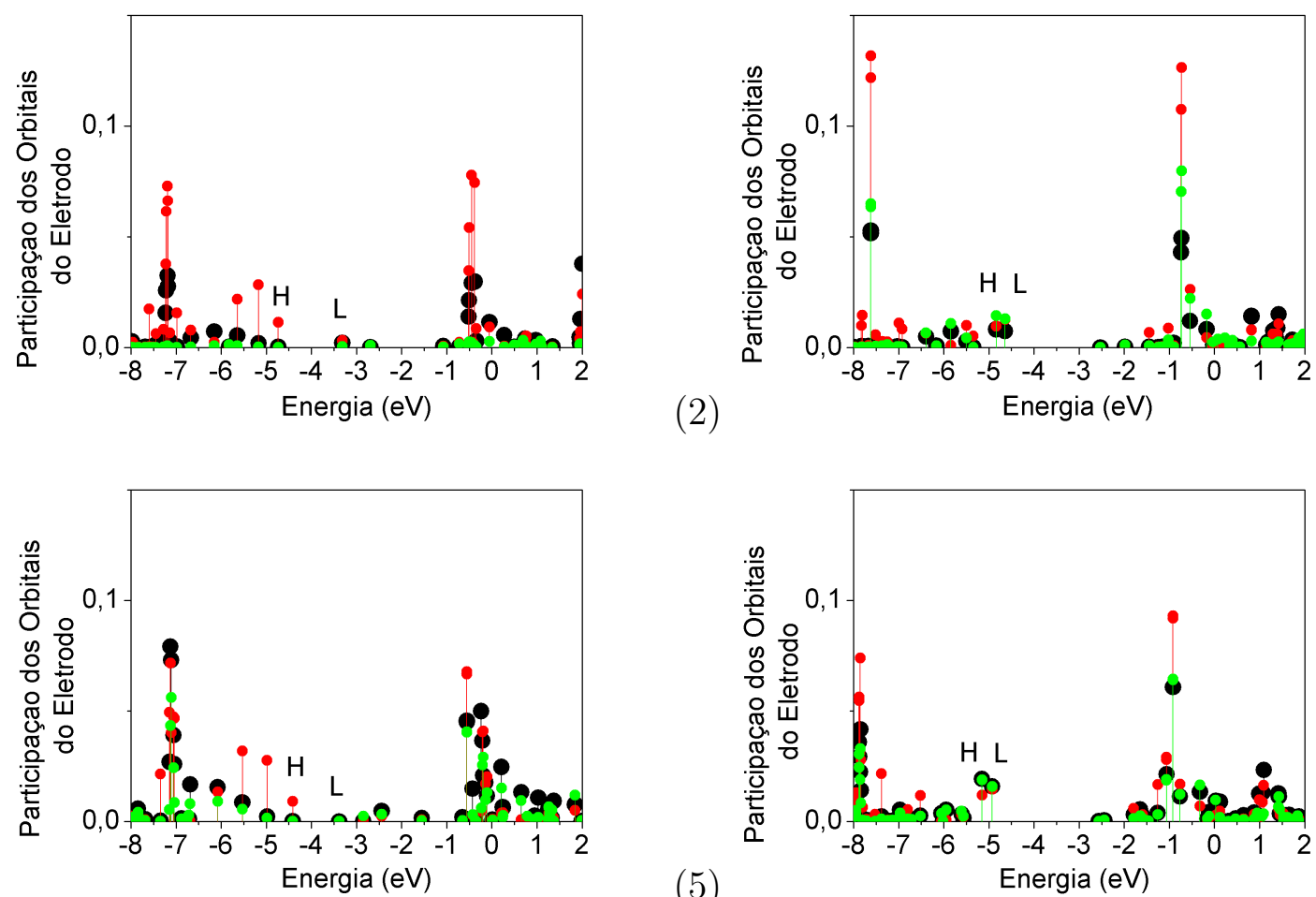

$(2)$

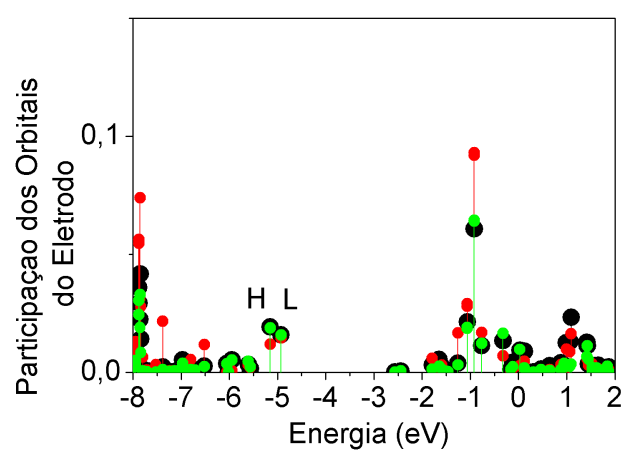

Figura 4.6: Participação dos orbitais $s, p$ e $d$ do ouro nos níveis de energia do sistema estendido. Em preto, vermelho e verde indicamos, respectivamente, os orbitais $s, p$ e $d$. O sistema estendido está indicado pelos índices (2), (4), (5) e (6). 


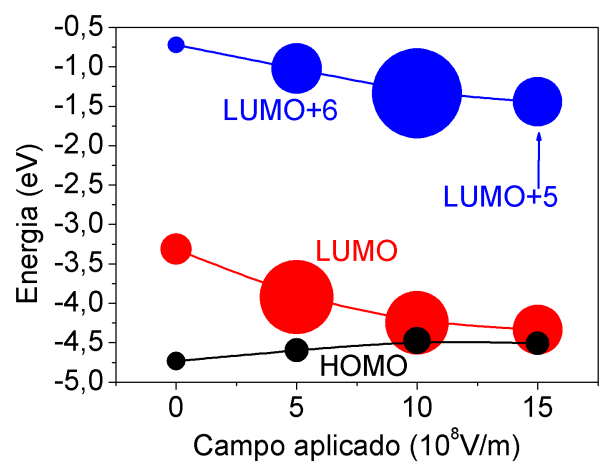

(a)

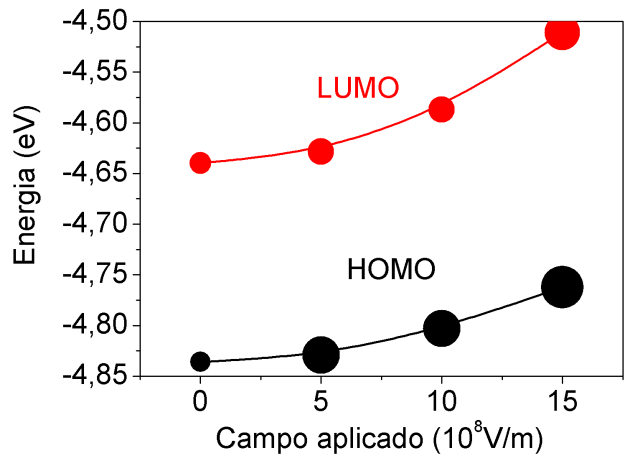

Figura 4.7: Variação dos níveis de fronteira do tetrâmero de lecoesmeraldina sob ação de campo elétrico externo. Em (a) são mostrados os níveis do sistema de conexão 2 (bridge) e em (b) do sistema 4 (atop). Cada círculo possui a área proporcional ao INP.

modo geral o gap HOMO-LUMO é reduzido, mas simultaneamente ocorre uma grande localização do LUMO, com um máximo em $5 \times 10^{8} \mathrm{~V} / \mathrm{m}$.

A mudança dos níveis HOMO e LUMO, do tetrâmero de leucoesmeraldina conectado com o eletrodo 4, não altera o gap HOMO-LUMO de modo significativo. Os níveis de fronteira HOMO e LUMO deslocam-se para maiores energias e o grau de localização aumenta nos diversos valores de campo aplicado.

\subsection{Cadeias sob estiramento}

Para obtermos uma descrição mais detalhada do experimento de quebra de junção, realizamos cálculos dos sistemas eletrodo-cadeia-eletrodo sob estiramento. Para obter estas geometrias o seguinte procedimento foi adotado: (1) As cadeias isoladas tiveram o átomo de enxofre das extremidades deslocados no sentido de aumentar o comprimento de ligação S-C. (2) A posição do átomo de enxofre é mantida fixa enquanto que o restante da geometria é otimizada. (3) Os aglomerados de ouro são anexados nas extremidades das cadeias, em seguida, juntamente com o átomo de enxofre, são mantidos fixos enquanto que os átomos da cadeia são novamente otimizados. 


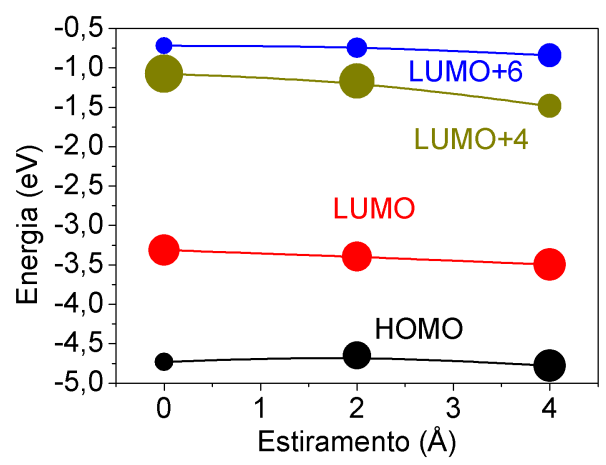

(a)

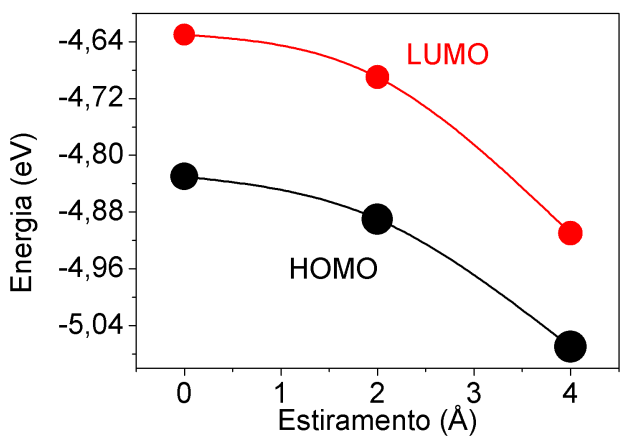

Figura 4.8: Variação dos níveis de energia, sob estiramento, do tetrâmero de leucoesmeraldina conectado com os eletrodos na forma (a)2(bridge) e (b)4(atop).

Na figura 4.8 podemos avaliar as mudanças nos níveis de energia dos sistemas eletrodomolécula-eletrodo sob estiramento. O tipo de conexão entre a cadeia orgânica e a parte metálica induz diferentes comportamentos dos níveis de energia. Os sistemas com eletrodos conectados de forma bridge apresentaram pouca alteração dos níveis com o aumento do estiramento. O orbital LUMO apresenta uma leve deslocalização para o estiramento de 2 A. A localização de alguns orbitais é esperada, uma vez que o comprimento de ligação médio entre átomos adjacentes fica maior, deixando cada átomo interagindo de maneira mais fraca com seu vizinho. A participação dos orbitais da cadeia orgânica (Pmol) quase não muda para os orbitais HOMO (Pmol de 95,9\% a 98,57 \%), LUMO (Pmol de 21,1 \% a 16,5 \%) e LUMO+6 (Pmol de 96,4 \% a 98,2 \%), entretanto os níveis LUMO+4 e LUMO+5 apresentam um aumento na participação dos estados da cadeia orgânica, que vão de $9 \%$ a 30\%. Obtivemos também um mínimo no gap HOMO-LUMO no estiramento de $2 \AA$. O valor do gap para cada estiramento vale respectivamente 1,41, 1,25 e 1,28 eV.

O sistema formado pelo tetrâmero conectado de forma atop apresenta níveis mais sensíveis ao estiramento da cadeia que os sistemas bridge, no que se refere à mudança na participação dos estados da cadeia orgânica. A Pmol diminui no orbital HOMO (LUMO), indo de $61,8 \%$ (73 \%) a 47,2 \% (62 \%). Ocorre uma pequena redução do gap e o grau de deslocalização sofre um aumento. 


\subsection{A origem das diferenças entre as conexões bridge e atop e o caso da conexão com o eletrodo 1}

Nas medidas de condutância da leucoesmeraldina são observadas respostas de alta e de baixa condutância nos experimentos feitos com o STM [46]. Partimos da possibilidade destas observações terem origem na forma como o contato entre a cadeia e o eletrodo é formado, com isso, variamos a maneira como a conexão ocorre entre bridge e atop. Os resultados indicam até este ponto que a conexão tipo atop com o eletrodo de ouro, com exceção da conexão 1, leva a cadeia a assumir características eletrônicas que melhoram seu transporte eletrônico. Nesta seção, vamos discutir em que padrão a conexão 1 melhor se encaixa, a fim de obter um modelo mais geral que relaciona a forma de conexão com as mudanças eletrônicas apresentadas pelas cadeias.

As conexões eletrodo-cadeia-eletrodo do tipo atop são aquelas em que apenas um átomo de ouro do eletrodo liga-se com a cadeia. Os sistemas formados pela cadeia orgânica e eletrodos 1, 3, 4 e 6 fornecem que o tamanho desta ligação é em torno de 2,3 e 2,4 , enquanto que as ligações com os eletrodos 2 e 5 fornecem valores de 2,4 e 2,5 A. As conexões com os eletrodos 1 e 2 fornecem a ligação mais curta (eletrodo 1) e a mais longa (eletrodo 2). Este resultado indica a forte influência do tipo de conexão cadeia-eletrodo, uma vez que os dois aglomerados apresentam o mesmo número de átomos de ouro. Apesar da configuração 1 apresentar o menor comprimento de ligação S-Au, este eletrodo altera muito menos as características eletrônicas e estruturais das cadeias orgânicas que os eletrodos 3, 4, 6 e 7. Em contrapartida, ele modifica os estados da cadeia orgânica mais que as configurações 2 e 5. Para enquadrar o eletrodo 1 com os demais com configuração atop precisamos verificar a posição dos níveis de energia e a forma dos orbitais de Kohn-Sham. O primeiro critério é mostrado na figura 4.9, e o segundo na figura 4.10. A informação mais direta obtida com a figura 4.9 é o modo como o tamanho do eletrodo influencia a posição dos níveis de energia, ao deslocá-los para menores energias conforme aumenta o número de átomos de ouro. A segunda informação é obtida pela observação da posição relativa dos níveis $\mathrm{H}(\mathrm{HOMO})$ e $\mathrm{L}(\mathrm{LUMO})$ dos sistemas: encontramos que em 3, 4 e 6 
estão mais próximos entre si, com uma diferença em torno de $0,2 \mathrm{eV}$, e os sistemas 2 e 5 com os níveis $\mathrm{H}$ e L bastante afastados. As conexões atop tipicamente favorecem a presença de mais carga negativa sobre os eletrodos, este deslocamento de carga explica a formação do nível LUMO estendido nesses sistemas. Ao compararmos os níveis de energia dos sistemas eletrodo-cadeia percebemos que os níveis HOMO-1 e HOMO sofreram um deslocamento, passando a assumir as posições HOMO e LUMO, respectivamente. Esta suposição é confirmada observando a forma dos orbitais na figura 4.10. Quando o sistema apresenta a conexão 1 a quantidade de átomos do eletrodo é pequena para diminuir a energia dos estados, e assim, diferentemente do que ocorre com as demais conexões atop o orbital LUMO não é deslocalizado. Ao compararmos a posição dos níveis de energia H-1 e $\mathrm{H}$ do sistema 1 com os níveis $\mathrm{H}$ e L dos sistemas 3, 4 e 6, verificamos o mesmo posicionamento, indicando que o pequeno tamanho do eletrodo não é suficiente para desocupar o nível HOMO. As conexões 1 e 3 são similares entre si na geometria, sendo que a última difere da primeira pela presença de um átomo de ouro a mais. Ao compararmos os níveis de energia (Fig. 4.3 e 4.9) destes dois sistemas verificamos que a suposição de que a conexão 1 se enquadra nas outras do tipo atop é verdadeira, dada a similaridade do espectro de autovalores.

\subsection{Aspectos estruturais e eletrônicos das formas oxi- dadas das oligoanilinas e dos oligotiofenos conec- tados aos eletrodos}

Apesar das semelhanças existentes nas estruturas geométricas e eletrônicas das cadeias orgânicas após a conexão com os eletrodos metálicos, nesta seção faremos menção a alguns detalhes referentes a cada grupo. Nas pernigranilinas, a geometria isolada apresenta a alternância entre anéis aromáticos e quinóides, com os anéis aromáticos nas extremidades da cadeia. A conexão com o metal, quando é do tipo atop, induz uma alteração na 
4.5 Aspectos estruturais e eletrônicos das formas oxidadas das oligoanilinas e dos oligotiofenos conectados aos eletrodos

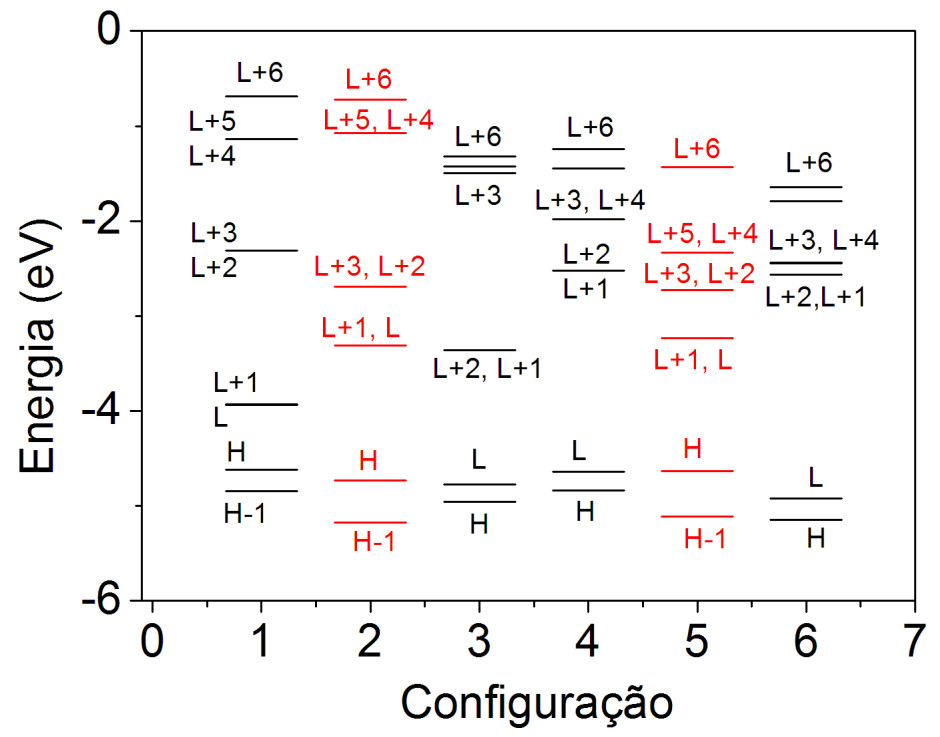

Figura 4.9: Níveis de energia das configurações eletrodo-tetrâmero-eletrodo. Os orbitais de Kohn-Sham HOMO e LUMO são representados por H e L e os eletrodos são indicados pelos números $1,2, .$. e 6 .

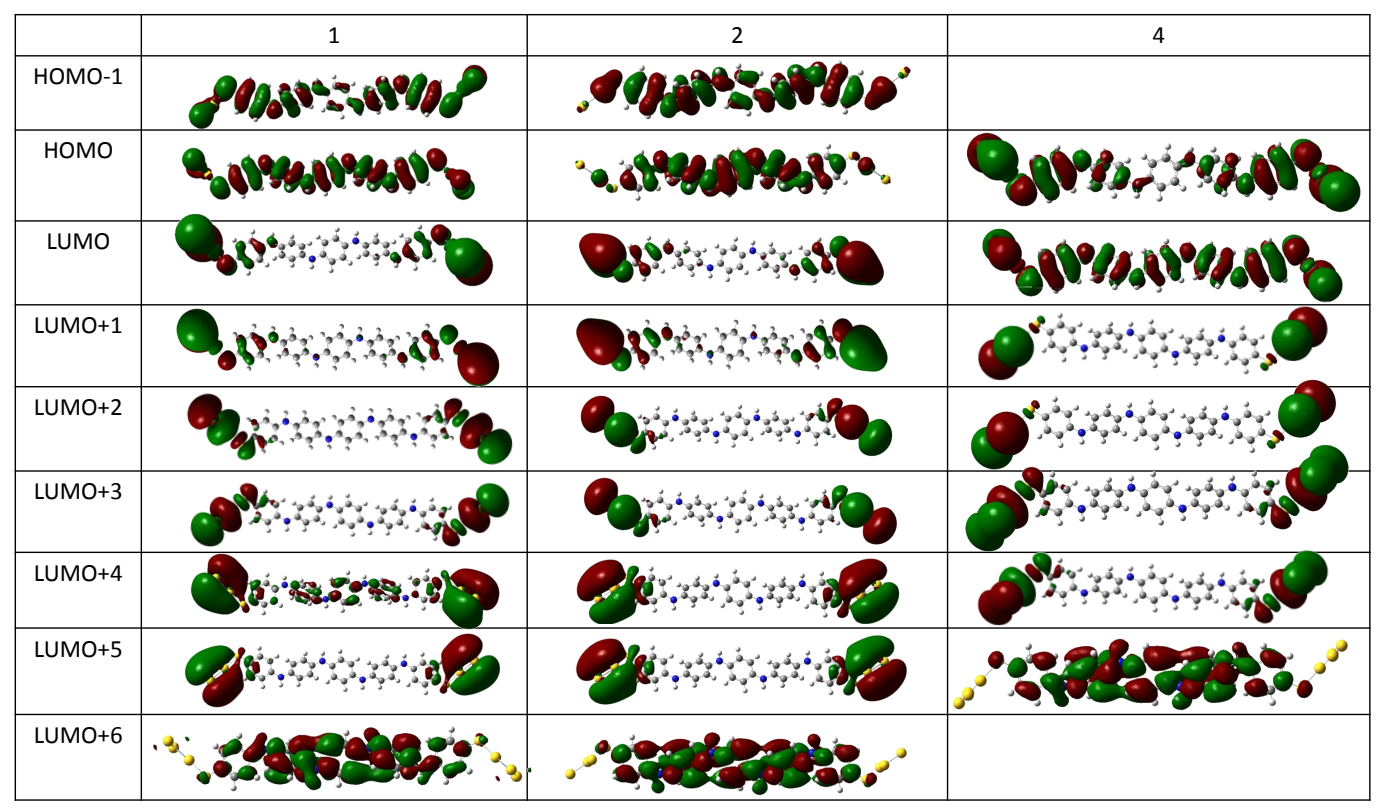

Figura 4.10: Comparação entre os orbitais dos sistemas 1, 2 e 4. 


\subsection{Aspectos estruturais e eletrônicos das formas oxidadas das}

oligoanilinas e dos oligotiofenos conectados aos eletrodos

sequência dos tipos de anéis, assim na extremidade os anéis tornam-se quinóides. Esta nova conformação é associada ao fato das extremidades serem mais afetadas com a conexão metálica. Os oligotiofenos, conectados de forma atop com o aglomerado metálico, sofrem uma forte distorção quinóide e a cadeia assume uma configuração plana. Por fim, as esmeraldinas são o grupo menos afetado geometricamente pela conexão com o metal. Nestas cadeias ocorre uma pequena mudança no comprimento de ligação dos anéis das bordas, com ligações $\mathrm{C}-\mathrm{C}$ assumindo valores entre $1,38 \AA$ e 1,41 $\AA$. A mudança da estrutura eletrônica após a conexão com o metal é similar à reportada com as leucoesmeraldinas.

Neste capítulo discutimos as mudanças estruturais e eletrônicas de cadeias de leucoesmeraldina conectadas a eletrodos metálicos. Os eletrodos foram conectados às cadeias através das formas bridge e atop, que levaram a diferentes comportamentos estruturais e eletrônicos. Quando a cadeia se conecta ao eletrodo de forma bridge, existe pouco deslocamento de carga e os comprimentos de ligação variam muito pouco. Nestes sistemas obtivemos que o espectro de autovalores das cadeias sofre pouca mudança. A densidade de estados projetada revela que ocorre quase uma superposição entre os estados da cadeia e dos eletrodos, e embora haja um gap HOMO-LUMO muito pequeno, este é majoritariamente associado com os eletrodos. Por outro lado, quando a cadeia conecta-se de forma atop com o eletrodo as mudanças eletrônicas sofridas pela molécula são muito fortes. Há uma grande transferência de carga entre a parte metálica e a orgânica. Os orbitais de Kohn-Sham de fronteira apresentam grande contribuição da cadeia orgânica. Conseguimos ainda, neste capítulo, enquadrar satisfatoriamente as mudanças induzidas pelos eletrodos nos padrões bridge e atop e explicar a origem dos estados LUMO deslocalizados nos sistemas atop. 


\section{Capítulo 5}

\section{Resultados II: Transmitância dos Oligômeros Orgânicos}

Discutimos neste capítulo os resultados da transmitância eletrônica das cadeias de oligoanilinas e dos oligotiofenos calculados com a DFT. Para análise das curvas obtidas, utilizamos o método tight-binding de primeiros vizinhos e o método de renormalização, que fornecem uma expressão analítica da transmitância dos oligômeros. Investigamos o efeito do estado de oxidação das cadeias, da forma de conexão com os eletrodos, tamanho dos oligômeros, estiramento e campo elétrico. Estes parâmetros, que estão presentes nas medidas de condutância, podem revelar a origem da condutância alta e baixa medida em oligoanilinas e o comportamento anômalo da transmitância em função do comprimento da cadeia, observado nos oligotiofenos.

\subsection{Oligoanilinas}

Nas próximas seções serão mostrados os resultados da transmitância das oligoanilinas em seus diversos estados de oxidação. As cadeias foram conectadas com os eletrodos indicados na figura 3.9, que variam entre si pelo número de átomos de ouro e a forma de ligação com a cadeia orgânica. Analisamos também o efeito do campo elétrico bem 
como o estiramento nas cadeias. Cálculos de transmitância em oligoanilinas já foram realizados[86, 47], encontramos no primeiro o estudo de diferentes conformações estáveis de dímeros de leucoesmeraldinas, que foram calculados sob ação de um campo elétrico. A estrutura eletrônica do sistema estendido foi obtido com o método DFT PW91, que é a base do método PBE, e que por conta disto estes dois funcionais apresentam resultados similares. Discutimos no capítulo 3 que o funcional PBE não fornece uma descrição muito precisa da estrutura eletrônica e geométrica das cadeias orgânicas, quando comparamos com dados esperimentais, diferentemente do que ocorre com o B3LYP. No segundo trabalho, os resultados são obtidos com um método DFT tight-binding, com um funcional GGA de troca-correlação (BLYP), encontramos uma certa similaridade com nossos resultados cujas cadeias estão conectadas na forma bridge com os eletrodos.

\subsubsection{Método tight-binding de primeiros vizinhos}

O hamiltoniano $\pi$ eletrônico do método tight-binding[60], que utilizamos para obter as expressões analíticas da transmitância, é construído através de uma parametrização, que avalia a semelhança da sua densidade de estados com a calculada com a DFT. Na figura 5.1 temos a curva da DOS projetada nos orbitais $P z$ do octâmero de LE, calculadas com a DFT, e a DOS calculada com o método tight-binding. A principal origem da diferença entre as densidades de estado obtidas via DFT e Hückel (ou tight-binding) vem do fato que a leucoesmeraldina apresenta uma torção entre os anéis de fenil, que leva a uma mistura dos orbitais de simetria $\sigma$ e $\pi$. O cálculo DFT leva em conta estes aspectos estruturais, enquanto que no método tight-binding a cadeia apresenta-se plana e, portanto, a separação entre as diferentes simetrias eletrônicas $(\sigma$ e $\pi)$ é total. Apesar de não ser possível um ajuste perfeito entre as curvas de densidade de estados dos dois métodos, podemos reproduzir o mesmo gap, a largura das bandas e as singularidades da DOS. Estas semelhanças permitem-nos seguir utilizando o método tight-binding.

Calculamos a transmitância da leucoesmeraldina, via método tight-binding, com os parâmetros indicados na figura 5.2 e obtivemos uma curva de transmitância bastante 


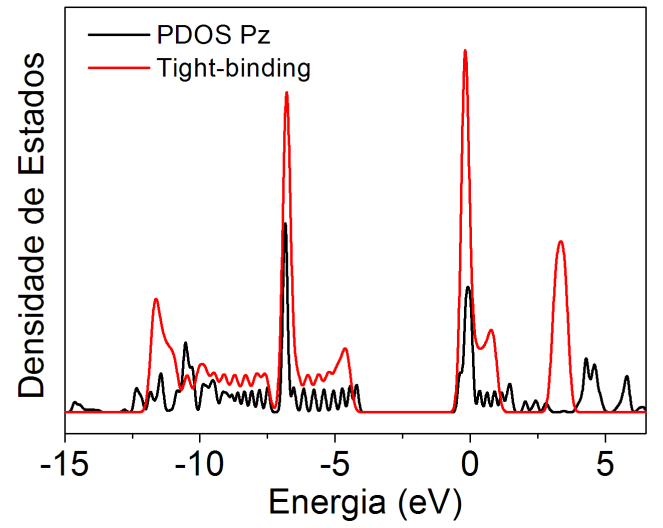

Figura 5.1: Densidade de estados obtidas com o método tight-binding e com o método DFT do octâmero de LE. No método DFT é feita uma projeção da DOS total nos orbitais $P z$.

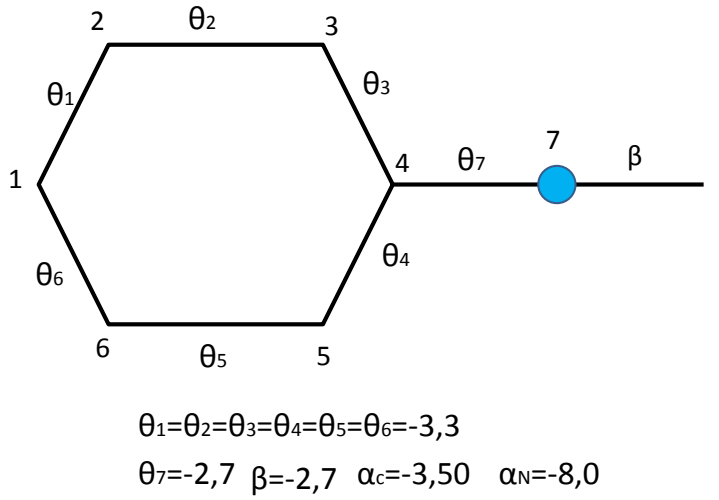

Figura 5.2: Parâmetros em eV utilizados no hamiltoniano tight-binding da leucoesmeraldina. Os átomos de carbono ocupam os vértices da figura e o átomo de nitrogênio está indicado pelo círculo azul. 


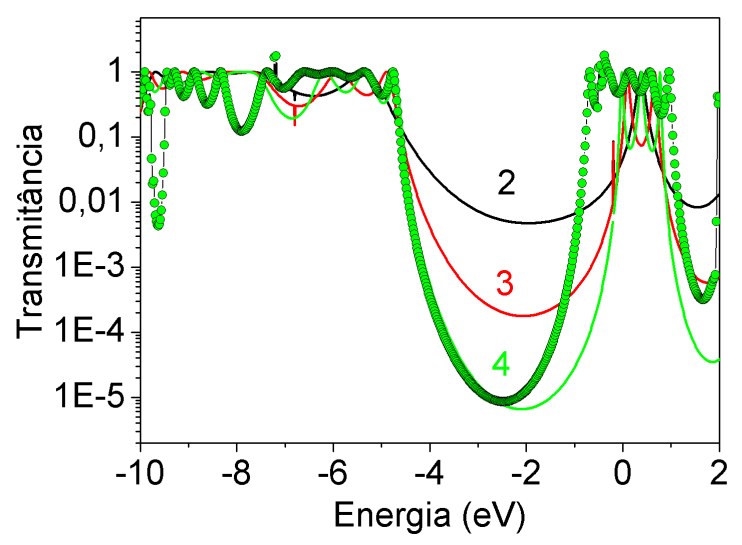

Figura 5.3: Transmitância dos oligômeros dímero (2), trímero (3) e tetrâmero (4) de LE obtido via método tight-binding e DFT (apenas o tetrâmero, mostrado na curva dos círculos verdes). No cálculo realizado com o método DFT a conexão com o eletrodo é do tipo bridge (2).

similar àquela calculada com a DFT (Fig. 5.3) do sistema de conexão 2 (Fig. 3.9). Deste resutado, podemos concluir que apesar da mistura existente entre os orbitais $\sigma$ e $\pi$ da LE há a predominância dos estados de elétrons $\pi$ nas propriedades de transporte, dada a boa correspondência entre as curvas. Resultados na literatura indicam que, de modo geral, a transmitância calculada com os métodos DFT e tight-binding é bastante similar quando há forte influência dos elétrons $\pi$ no transporte eletrônico[87]. Esta metodologia, constitui uma ferramenta muito valiosa no estudo do transporte eletrônico de sistemas moleculares, como é demonstrado na investigação da Quantum Interference (QI). A QI leva um sistema a apresentar um valor nulo da probabilidade de transmissão na energia de Fermi, e as regras que explicam sua origem são obtidas apenas utilizando os elétrons $\pi$ [88]. Discutiremos ainda neste capítulo, em outra seção, a transmitância calculada via tight-binding para as formas LE e EM.

Nesta seção estabelecemos que podemos descrever bem os aspectos da transmitância com o método tight-binding observados na conexão com o eletrodo 2, quando comparados com o resultado ab-initio. A conexão da cadeia orgânica com este eletrodo é um bom teste 
para comprovar a eficácia do método tight-binding, pois como vimos no capítulo anterior, a forma de conexão bridge não altera de modo significativo a estrutura eletrônica da cadeia com relação à sua forma isolada. Esta característica permite-nos utilizar os mesmos parâmetros obtidos com a cadeia livre para reproduzir a transmitância do sistema conectado com o aglomerado metálico na forma bridge. A seguir, exploraremos as diferenças na transmitância que surgem para a conexão com os diversos tipos de eletrodos. Alterações nos parâmetros $\theta_{i}$ e $\beta$ (indicados na figura 5.2) das cadeias isoladas deverão ser feitas para a obtenção das curvas de transmitância que sejam equivalentes às calculadas com a DFT.

\subsubsection{Transmitância calculada via DFT}

O resultado mais incomum, relativo às propriedades de transporte das oligoanilinas, é a medida de dois sinais de condutância, denominadas de alta e baixa [89, 46]. A condutância baixa decresce de intensidade de modo exponencial com o tamanho da cadeia, como é usualmente medido em sistemas com comprimentos pequenos [90, 91]. Diferentemente, a condutância alta apresenta um decaimento quase linear com o comprimento da cadeia, comportamento que é consistente apenas com cadeias com comprimentos grandes. É reportado apenas um cálculo de transporte que reproduz corretamente apenas o padrão de baixa condutância [47]. Medidas feitas com oligoanilinas na forma de filme apresentam sinais de condutância alto e baixo, sendo que estes estados são acessados via um campo elétrico externo. Os autores associam os estados de alta condutância à mudança no estado de oxidação das cadeias[92]. Esse comportamento, entretanto, é diferente do observado em medidas com apenas uma cadeia, uma vez que não há alteração do estado de oxidação das moléculas.

Para avaliar o quanto cada sistema é condutor, inspecionamos a transmitância na região de energia em torno do gap HOMO-LUMO da cadeia isolada. Temos como motivação em avaliar uma região ampla da transmitância, o fato de que buscamos generalizações desta propriedade em termos dos parâmetros estudados. Entretanto, a condutância é obtida com a transmitância apenas na energia de Fermi. Há o indicativo, 
fornecido pelo estudo do benzenoditiol, que a localização da energia de Fermi do sistema encontra-se muito próximo do HOMO da cadeia orgânica[93]. Faremos uma análise qualitativa dos resultados da transmitância, pois a teoria de Landauer fornece, em geral, valores maiores da condutância quando comparados com o experimento [7]. Esta teoria, apesar de apresentar bons resultados, é do tipo monoeletrônica e mesmo aperfeiçoamentos em sua descrição e implementação não fornecem corretamente o valor da condutância para voltagem zero, como comentado na referência [56].

Dois comportamentos distintos são obtidos na transmitância calculada para as oligoanilinas (figuras 5.4 e 5.5): (1) o sinal mais intenso nos sistemas 3, 4, 6 e 7, acompanhado de um decaimento quase linear na região do gap HOMO-LUMO e, (2) uma resposta mais convencional, que revela um decaimento exponencial em função do tamanho da cadeia dos sistemas 1, 2 e 5, bastante similar ao reportado na literatura para outras cadeias $[94,47,95]$. A diferença na transmitância entre os sistemas bridge e atop é maior para as LE e EM. Associamos estas respostas aos sinais de condutância alto e baixo reportados nestes sistemas. O sinal alto da transmitância obtido com os sistemas conectados na forma atop é associado com o orbital LUMO que se apresenta estendido e com grande participação dos estados da cadeia orgânica. Este nível está próximo do HOMO nas LE e EM, daí a forma assimétrica da transmitância na região do gap. Embora o sistema (1) apresente a forma da transmitância mais similar com os sistemas bridge, associamos isto ao fato de não ter ocorrido a desocupação total do nível HOMO, como ocorreu nos demais sistemas atop. Com isso não há um nível estendido na região do gap, que produziria um valor elevado na transmitância. Resultados na literatura dão indicativos da maior condutância em sistemas moleculares conectados na forma atop com os eletrodos metálicos[96]. Nesta referência cálculos de transporte em sistemas de benzenoditiol e fenileno-etinileno revelam que um átomo de ouro, colocado na interface metal-moléula, aumenta a participação na densidade de estados dos estados do átomo de enxofre, localizados nas extremidades da cadeia, que aumenta o valor da condutância. As curvas de transmitância das formas EM e PE, mostradas na figura 5.5 exibem níveis de energia associados com a presença dos anéis quinóides na região entre -3 e -4 eV. Nestes sistemas, 

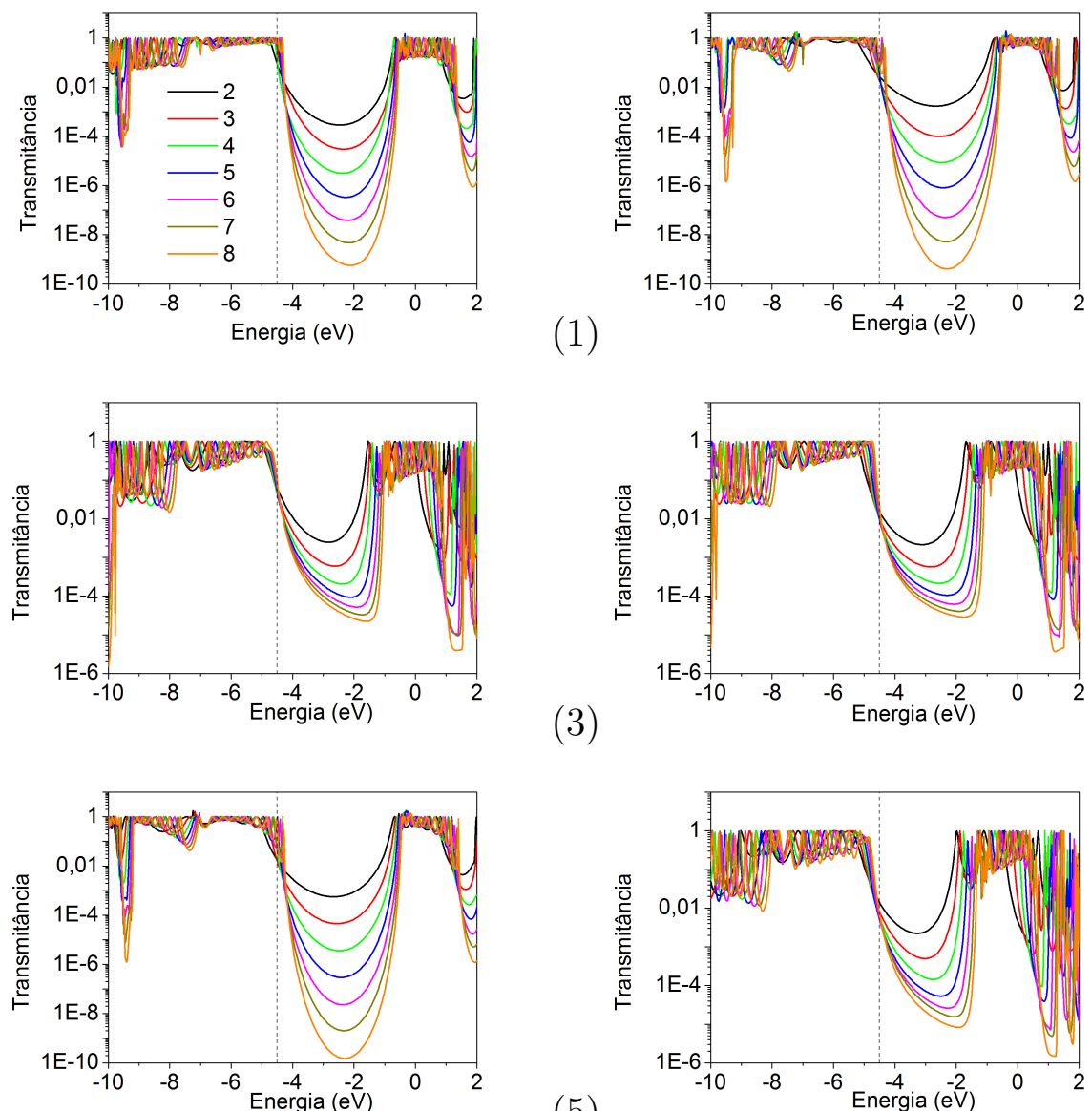

$(3)$

$(5)$

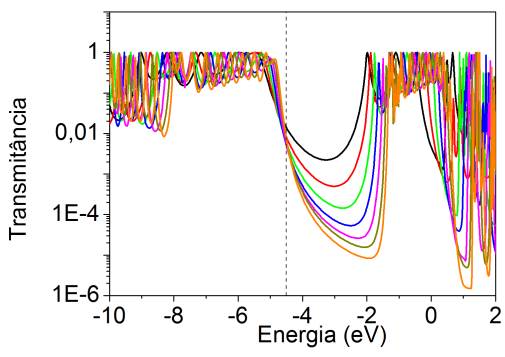

(6)
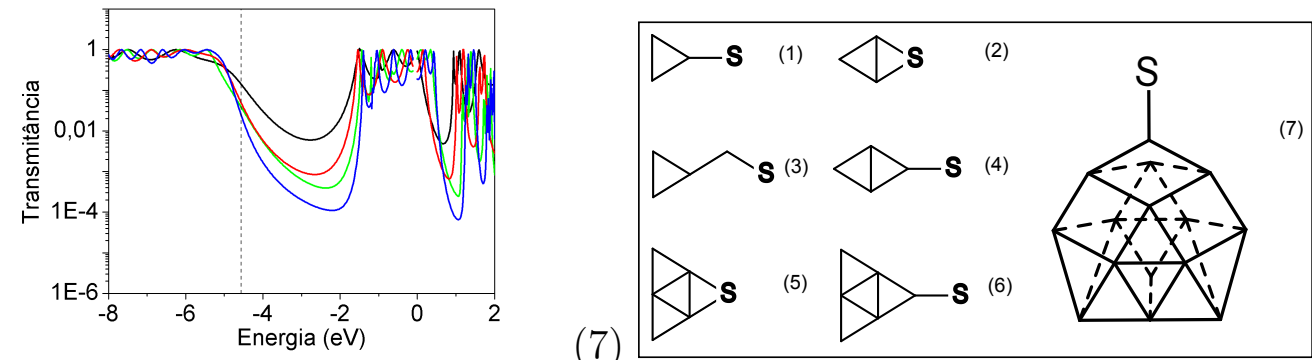

Figura 5.4: Transmitância dos oligômeros de leucoesmeraldina obtida via DFT. A forma de conexão com os eletrodos está indicada ao lado de cada gráfico, bem como a estrutura de cada eletrodo no retângulo no canto inferior direito. Os oligômeros estão indicados no gráfico (1). A linha tracejada indica a energia de Fermi do ouro bulk obtida com B3LYP/LANL2DZ. 

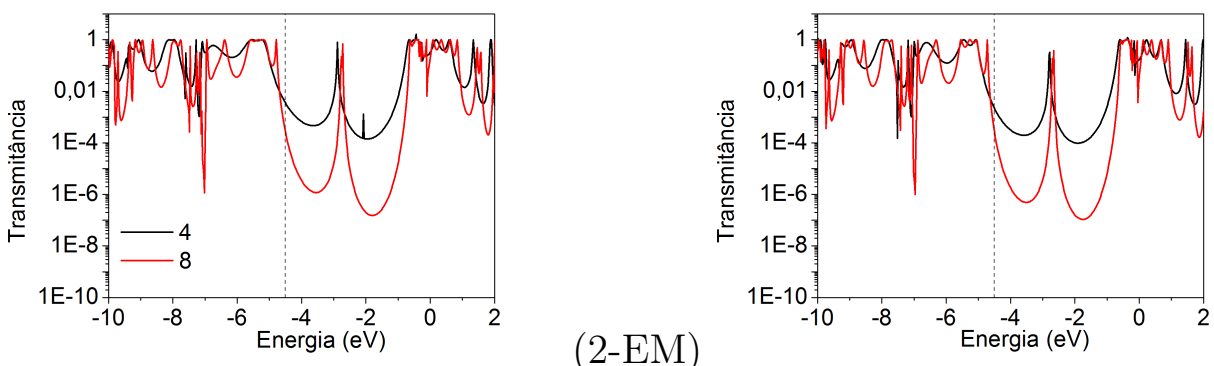

$(5-\mathrm{EM})$

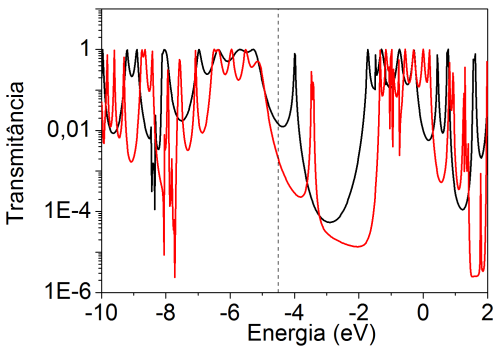

$(2-\mathrm{EM})$

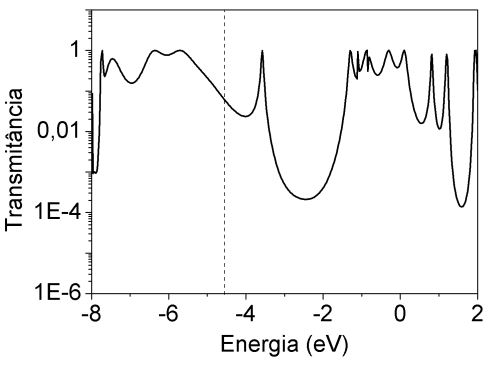

$(7-\mathrm{EM})$
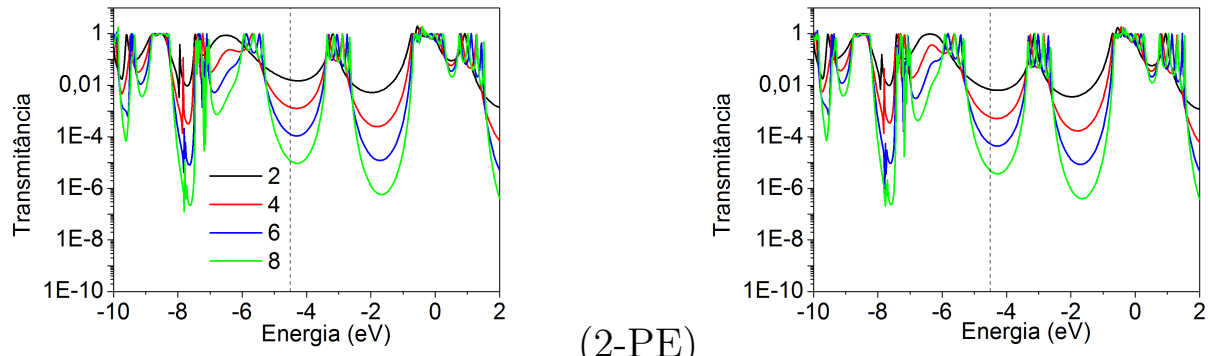

$(5-\mathrm{PE})$

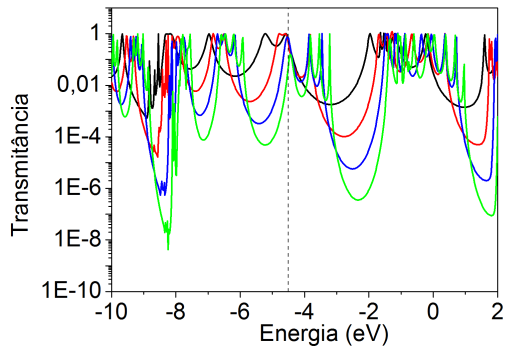

$(2-\mathrm{PE})$

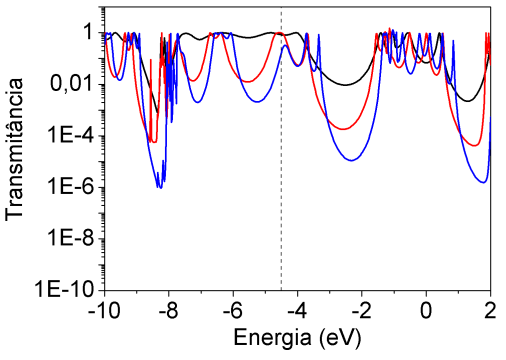

Figura 5.5: Transmitância da esmeraldina e pernigranilina obtida via DFT. Ao lado de cada gráfico estão indicados às formas de oxidação e o tipo de conexão com os eletrodos. Nos gráficos 2 (EM) e 2 (PE) estão indicados os oligômeros. A linha tracejada indica a energia de Fermi do ouro bulk obtida com B3LYP/LANL2DZ. 


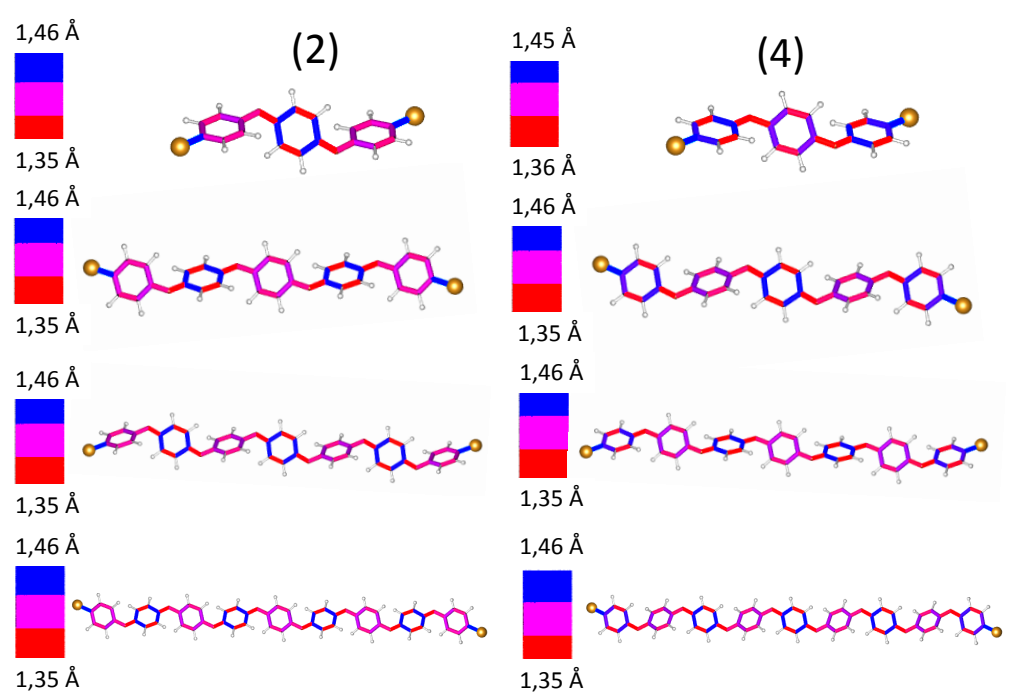

Figura 5.6: Comprimento de ligação entre os átomos das cadeias pernigranilina ligadas aos eletrodos (2) e (4), indicados na parte superior da figura. As cores em azul e vermelho indicam respectivamente as ligações longas e curtas.
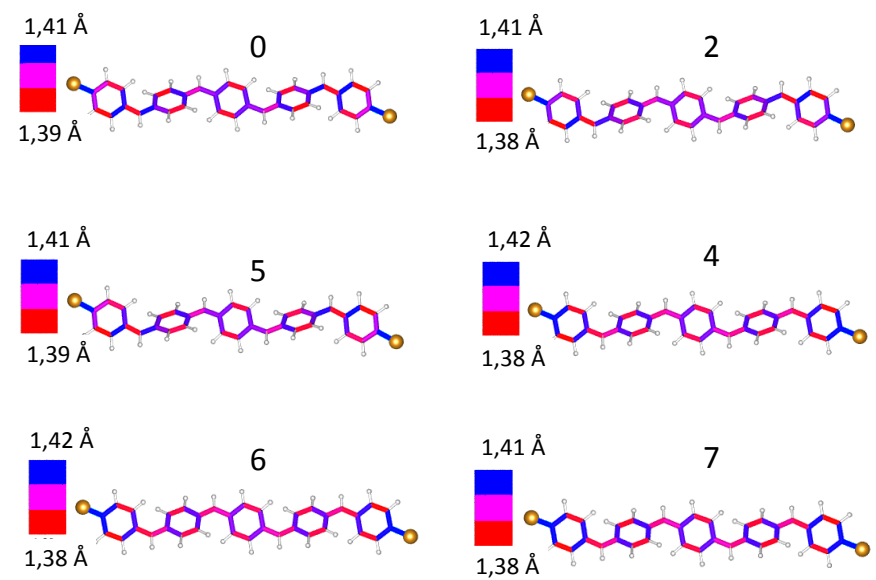

Figura 5.7: Comprimento de ligação entre os átomos do tetrâmero de LE livre (0) e conectado com os eletrodos $(2,5, \ldots$ e 7$)$. Os comprimentos de ligação maiores são indicados pela cor azul e os menores pela cor vermelha. 


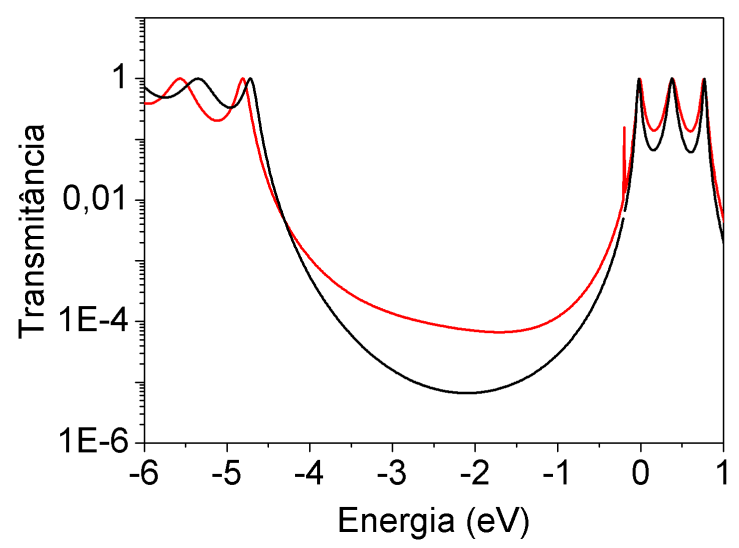

Figura 5.8: Transmitância do tetrâmero de LE calculada com o método tight-binding com os parâmetros que reproduzem as conexões bridge (curva em preto) e atop (curva em vermelho).

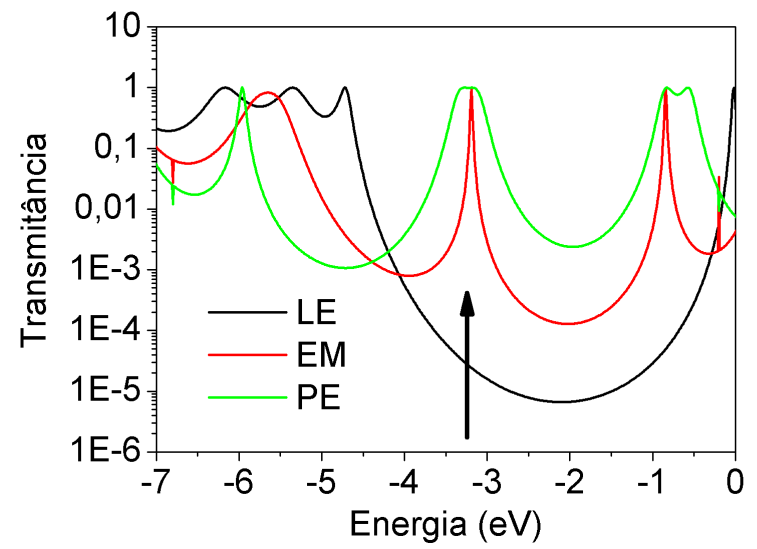

Figura 5.9: Transmitância calculada via tight-binding do tetrâmero das formas LE, EM e PE. A seta indica a posição dos níveis dos anéis quinóides. Na curva em verde, do tetrâmero de PE, a seta indica dois níveis de energia associados com os anéis quinóides, que estão próximos e quase sobrepostos. 
destacamos que na forma PE há a formação de um número maior de níveis associados aos anéis quinóides nos sistemas atop, que nos tipo bridge. Como já mencionado no capítulo anterior, em função da grande troca de carga com os eletrodos metálicos nos sistemas com conexão atop, a alternância de anéis quinóides e aromáticos é invertida com relação à forma isolada. Como a perda de elétrons é sentida mais intensamente nas extremidades, anéis quinóides são formados nestas regiões. Esta particularidade na geometria da PE é mostrada na figura 5.6.

\subsubsection{Transmitância alta e baixa obtidas com o método tight- binding}

Discutimos no capítulo anterior a intensidade das mudanças de comprimento de ligação das cadeias orgânicas nos sistemas estendidos. Esta análise torna-se mais completa com a identificação do tipo de alteração e o local onde as cadeias são mais afetadas. É importante determinar estes aspectos para reproduzir via tight-binding as diferenças entre as conexões bridge e atop, no cálculo da trasmitância. Na figura 5.7 estão indicados em azul e vermelho, respectivamente, os comprimentos de ligação longos e os curtos das cadeias de LE. Inspecionando a figura 5.7, verificamos que existe, de modo geral, uma região central que apresenta, principalmente, cores misturadas entre o vermelho e o azul, indicando comprimentos de ligação com um valor intermediário entre o máximo e o mínimo. As extremidades apresentam maior contraste entre as cores vermelha e azul, consistente com o caráter mais quinóide dos anéis, principalmente nos sistemas com conexão tipo atop. Na figura 5.8 as curvas de transmitância são obtidas com os parâmetros da cadeia isolada (curva em preto) e com os anéis das extremidades com uma fraca distorção quinóide(curva em vermelho). Com este resultado explicamos a origem dos sinais de condutância alto e baixo. Ou seja, a presença dos anéis quinóides causa um aumento na transmitância e dá origem a uma forma assimétrica do gap da transmitância, similarmente como obtido com o método DFT. 


\subsubsection{Transmitância das diversas formas de oligoanilinas obtidas com o método tight-binding}

Ao analisar a densidade de estados das formas oxidadas das oligoanilinas (Fig. 3.4), verificamos a 'formação' de níveis de energia em uma região de energia que coincide com o centro do gap HOMO-LUMO da forma LE. A origem destes níveis é associada com a perda de elétrons nas formas oxidadas (que induzem o aparecimento de anéis quinóides). Com dois elétrons a menos na forma esmeraldina (tetrâmero) ocorre a desocupação do nível HOMO da forma LE. Assim, como o número de níveis de energia permanece constante, o orbital LUMO da forma esmeraldina equivale ao nível HOMO da forma leucoesmeraldina. A mesma idéia pode ser aplicada no caso da pernigranilina. A estrutura geométrica das formas LE, EM e PE diferem entre si pela presença de anéis com distorção quinóide, cujas formações são induzidas pela perda dos elétrons. Nas formas oxidadas, para reproduzir os resultados ab-initio via tight-binding inserimos os parâmetros de hopping que tornam os anéis quinóides. A transmitância calculada com estes parâmetros é mostrada na figura 5.9. Os níveis associados com os anéis quinóides (indicados pela seta) encontram-se na região de energia próxima de $-3 \mathrm{eV}$, sendo que há apenas um na forma esmeraldina e dois na forma pernigranilina.

\subsection{Oligoanilinas sob Estiramento}

Antes de avaliarmos os resultados das oligoanilinas sob estiramento, uma questão relevante que devemos discutir é o quanto uma cadeia orgânica conectada pode ser estirada. Os experimentos de quebra de junção são realizados com a ponta de metal sendo erguida, e desta forma, o estiramento deve ser divido entre a cadeia orgânica e os átomos de ouro nas interfaces. Na cadeia mais amplamente estudada, o bezenoditiol, a distância de estiramento entre a ponta e o substrato metálico é de $3 \AA$ [51]. Um cálculo do benzenodimetanotiol sob estiramento conectado a eletrodos de ouro foi realizado, utilizando o funcional PBE e conjunto de base de ondas planas e um pseudopotencial [97], e fornece 
que este sistema, mesmo pequeno, é estirado de 2,3 A. Os autores também reportam que a a força para romper a ligação $\mathrm{S}-\mathrm{Au}$ é de 1,42 nN. A força necessária para romper uma junção de um octanoditiol é de $1,5 \mathrm{nN}$ [98], enquanto que para quebrar uma ligação de ouro, foi calculada (com dinâmica molecular) uma força de 1,8 nN [99]. Cadeias de oligotiofenos são nossos sistemas de referência, uma vez que não são reportados os valores da força necessária para romper o contato em oligoanilinas, apenas é informado o grau de estiramento (12 ̊), que compreende o estiramento da parte metálica e orgânica [100]. Os oligotiofenos com 3 e 4 unidades apresentam picos na força, aproximadamente, nos valores de 1,5, 3,0 e 4,5 $\mathrm{nN}$ (os valores são os mesmos para os dois oligômeros) [48]. As forças que analisamos são sobre os átomos de enxofre, obtidas do cálculo de otimização de geometria. Para o oligômero de 4 unidades, sob estiramento de $1 \AA$ a força vale 4,0 $\mathrm{nN}$ e $3,2 \mathrm{nN}$ quando conectado de forma atop e bridge, respectivamente. Ocorre um aumento grande na força, para o mesmo oligômero, quando o estiramento é dobrado. Os valores obtidos são 6,4 nN e 5,2 $\mathrm{nN}$ para as conexões bridge e atop, respectivamente. Os valores de força estão muito próximos daqueles obtidos experimentalmente, indicando que nossos resultados são consistentes com o estiramento sofrido pelas cadeias no momento da medida.

Os resultados da transmitância com as cadeias sob estiramento são discutidos na subseção a seguir para as formas LE e EM e em seguida, na próxima seção para a forma PE. Escolhemos as conexões 2 e 4 por apresentarem o comportamento típico das conexões bridge e atop.

\subsubsection{Leucoesmeraldinas e Esmeraldinas}

Ao estirar uma cadeia, dois aspectos relacionados às propriedades eletrônicas são afetados simultaneamente, que são: (1) Aumento do comprimento da cadeia e (2) diminuição do ângulo de torção entre os anéis. O primeiro aspecto, isoladamente, leva a uma redução na transmitância, por aumentar o tamanho da cadeia. O segundo causa uma melhora na conjugação, que pode levar a um aumento na transmitância. Assim, a competição entre 
estes dois aspectos leva a um comportamento aparentemente 'não linear' da transmitância em função do estiramento. A transmitância calculada do sistema 2 (bridge), das cadeias de LE e EM (Fig. 5.10), indica forte influência dos dois aspectos descritos anteriormente, onde inicialmente ocorre um aumento na transmitância quando a cadeia está estirada de $2 \AA$ e depois uma redução quando o estiramento é de $4 \AA$. Dois fatores estão diretamente ligados a este comportamento:(1) Diminuição do gap HOMO-LUMO e (2) a deslocalização do orbital LUMO no estiramento de $2 \AA$, como discutido no capítulo anterior. No sistema (4), entretanto, ocorre apenas uma leve redução na transmitância, comportamento que revela a forte influência do comprimento da cadeia na estrutura eletrônica. Para entender os resultados da transmitância avaliamos, na figura 5.11, a mudança da energia relativa, do comprimento de ligação, do ângulo de torção do anel central e da carga nos eletrodos do tetrâmero de leucoesmeraldina em função do estiramento. A forma que a energia aumenta com o estiramento é similar à mudança que ocorre no comprimento de ligação, enquanto que o ângulo de torção decresce de modo quase linear (Fig. 5.11 (a), (b) e (c)). Estes resultados indicam que o ângulo de torção altera-se de modo mais intenso com o estiramento que o comprimento de ligação, uma vez que o comprimento de ligação aumenta mais intensamente para os maiores valores de estiramento. Podemos então estabelecer o comportamento da cadeia sob estiramento: primeiro ocorre a redução no ângulo de torção e depois, com aumento do grau de estiramento, um forte aumento nos comprimentos de ligação ao longo da molécula. O comportamento das cadeias orgânicas é similar entre os sistemas 2 e 4 . A diferença reside no fato que o sistema 4 é mais plano que o sistema 2 quando as cadeias não estão estiradas, portanto, o ângulo de torção difere de um decrescimento linear( Fig. 5.11 (c)), indicando que o sistema 4 exige mais energia para tornar-se plano.

A análise da carga negativa acumulada nos eletrodos, revela que conforme aumenta o estiramento seu valor decai em ambos sistemas 2 e 4 . Entretanto, no sistema atop decresce de modo mais intenso que no bridge (Fig. 5.11(d)). Paralelamente a perda de carga no sistema atop leva a redução da distorção quinóide nos anéis das extremidades, fato que indica a diminuição da transmitância por tornar a estrutura eletrônica mais próxima a da 
cadeia isolada.

\subsubsection{Pernigranilinas}

As pernigranilinas, após a conexão atop com o eletrodo, sofrem uma mudança em sua estrutura geométrica, que produz um anel quinóide a mais que a sua forma isolada. Tal mudança é ocasionada pela perda de elétrons para o aglomerado de ouro. Na forma isolada da PE os anéis das extremidades são aromáticos e, na forma extendida com a configuração atop, a troca dos anéis quinóides por aromáticos permite que a cadeia possua ainda a alternância entre os tipos diferentes de anéis e ainda possibilita que esta possua mais um quinóide. Para cada anel quinóide há um nível de energia associado. No caso do sistema estendido com conexão atop, este nível é equivalente ao HOMO da cadeia isolada. Com isto, podemos concluir que a cadeia de pernigranilina conectada de forma atop pode acomodar em sua geometria a distorção causada pela perda de elétrons sem perder sua forma geométrica padrão. Algumas mudanças com relação a estrutura eletrônica isolada, naturalmente, ocorrem como por exemplo a origem do nível de energia associado com o anel quinóide adicional e o deslocamento do espectro de autovalores para menores energias. Estes aspectos estruturais das PE permitem que, independente da ligação com o eletrodo, apresentem o mesmo comportamento da transmitância em função do estiramento que as cadeias extendidas de LE e EM no acoplamento bridge. Estruturalmente podemos explicar o comportamento da transmitância através seus ângulos de torção: O ângulo de torção entre anéis aromáticos e quinóides é bastante similar nos sistemas bridge e atop destas cadeias estiradas, sendo de $11,84^{\circ}$ e $14,53^{\circ}$ para o estiramento de $2 \AA$ e $4 \AA$, respectivamente.

Os níveis de energia, juntamente com o INP são mostrados na figura 5.12. Não há forte mudança no valor do INP em função do estiramento. O orbital LUMO do sistema atop e HOMO do sistema bridge quase não apresentam alterações na participação dos estados das cadeias orgânicas em função do estiramento, nos quais ambos possuem participação superior a $80 \%$, sendo portanto estados deslocalizados. 


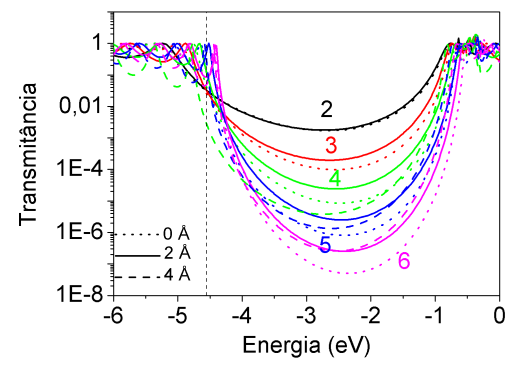

$(2-\mathrm{LE})$

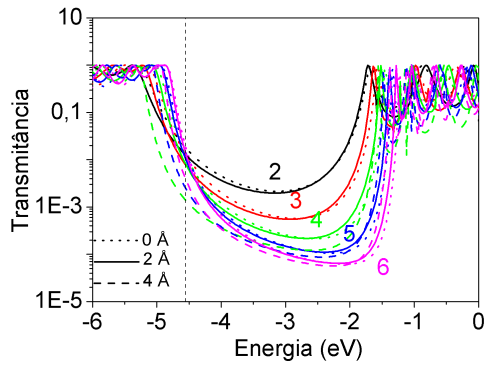

$(4-\mathrm{LE})$
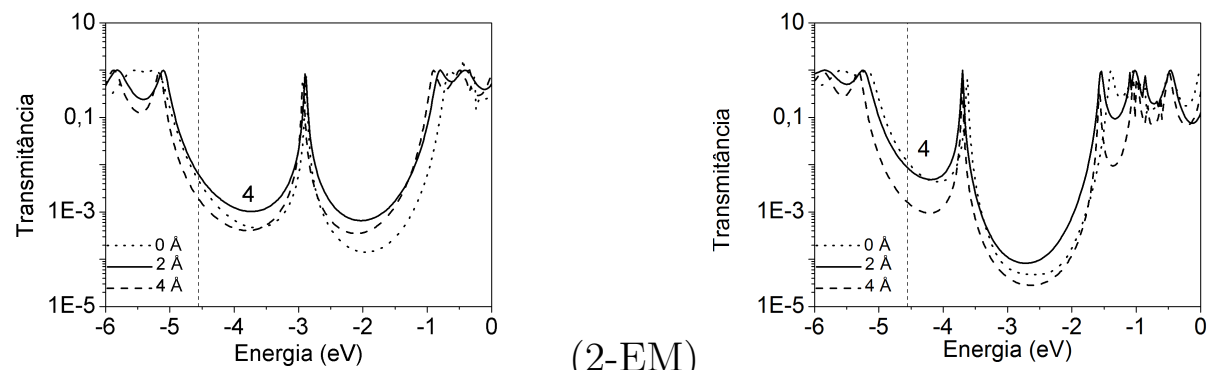

$(4-\mathrm{EM})$

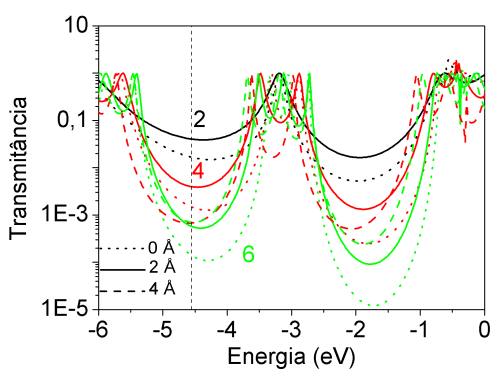

$(2-\mathrm{EM})$

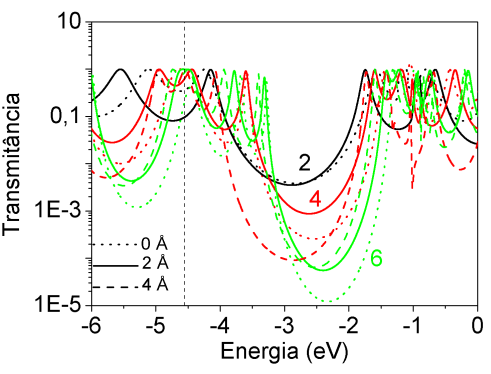

Figura 5.10: Transmitância das oligoanilinas sob estiramento. Os oligômeros e o tipo de conexão com os eletrodos estão indicados em cada gráfico. A linha tracejada indica a energia de Fermi do ouro bulk obtida com B3LYP/LANL2DZ. 

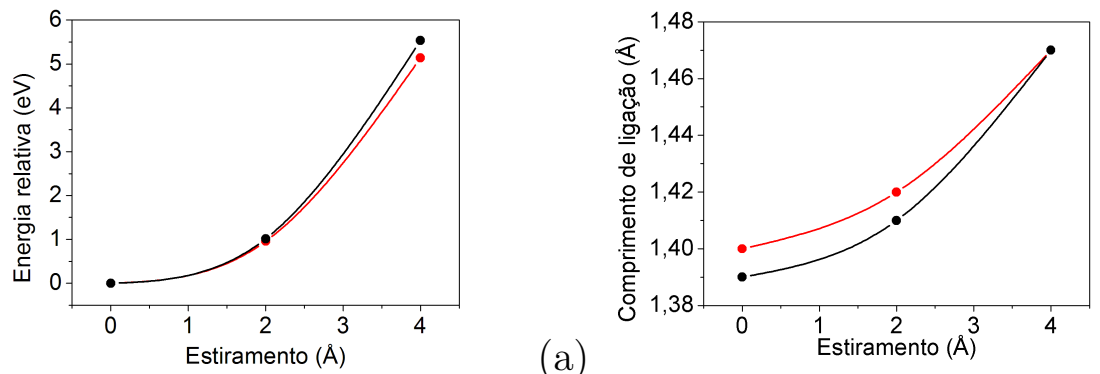

(a)

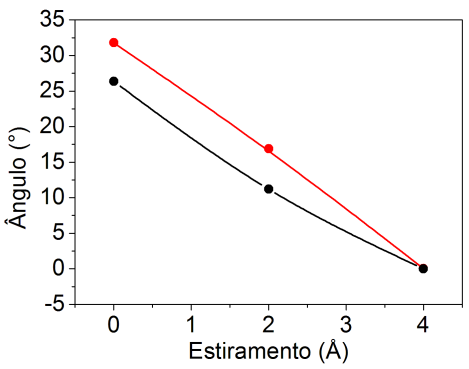

(c)

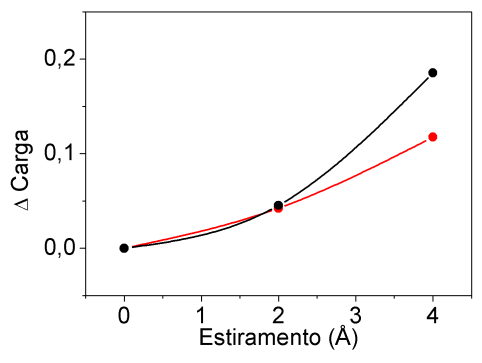

(d)

Figura 5.11: Variação da (a) energia, (b) comprimento de ligação, (c) ângulo de torção e (d) carga acumulada nos eletrodos em função do estiramento. Utilizamos o tetrâmero de LE como referência. O comprimento de ligação se refere ao $\mathrm{C}-\mathrm{N}$, sendo $\mathrm{C}$ o átomo de carbono na posição para do anel central. O ângulo de torção é o do anel central. As curvas em preto e vermelho referem-se, respectivamente, a sistema 4-atop e 2-bridge. 


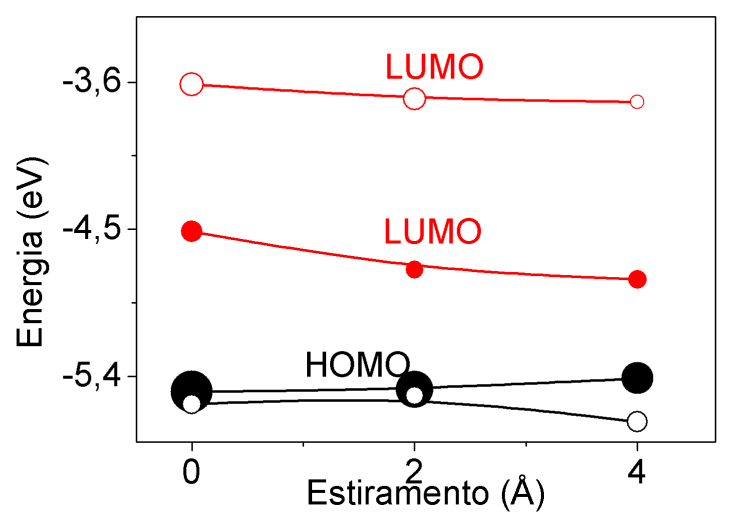

Figura 5.12: Níveis de energia dos orbitais HOMO e LUMO dos sistemas 2 (bridge) e 4 (atop) indicados pelos círculos vazios e preenchidos, respectivamente. As áreas dos círculos são proporcionais ao INP.

\subsection{Oligoanilinas sob ação de um Campo Elétrico}

As medidas de condutância das cadeias orgânicas são realizadas com a presença de um campo elétrico externo. Neste sentido, calculamos a estrutura eletrônica dos sistemas 2 e 4 sob ação de um campo elétrico aplicado no sentido do eixo longo da cadeia, com intensidade desde $5 \times 10^{8}$ até $15 \times 10^{8} \mathrm{~V} / \mathrm{m}$. A seguir discutimos o efeito do campo nas LE e EM, e na sequência seu efeito na PE.

\subsubsection{Leucoesmeraldinas e Esmeraldinas}

Os sistemas 2 e 4 apresentam comportamento distinto sob ação do campo elétrico, o primeiro apresenta aumento na transmitância em função do campo elétrico, enquanto que o segundo demonstra ser pouco sensível à intensidade do campo utilizada (Fig. 5.13).

No capítulo anterior vimos que o efeito do campo elétrico nos níveis do sistema 2 é o de deslocar o LUMO para menores energias e aumentar seu grau de deslocalização. No caso do sistema 4 o que obtivemos foi um valor quase constante do gap HOMOLUMO e aumento na localização dos orbitais. Na figura 5.14 mostramos que a evolução 
da porcentagem dos estados da cadeia orgânica nos níveis HOMO, LUMO em termos do campo elétrico aplicado é inversa entre os sistemas bridge e atop. O nível de energia LUMO apresenta maior participação dos estados moleculares no sistema bridge em função do campo, fato que explica o aumento da transmitância. Nos sistemas atop o LUMO torna-se mais localizado nos eletrodos, enquanto que o HOMO sofre um aumento na participação molecular em sua composição. O efeito combinado destes dois níveis leva à fraca influência da intensidade do campo na transmitância das leucoesmeraldinas e esmeraldinas na conexão atop.

\subsubsection{Pernigranilinas}

Os oligômeros de PE, independente da forma de conexão com os eletrodos, apresentam aumento da transmitância em função do campo elétrico. Apesar da troca de carga da PE após a conexão com os eletrodos atop, o aspecto geral desta classe de oligômeros permanece o mesmo, com a presença de anéis quinóides e aromáticos alternados. Esta característica da pernigranilina explica a semelhança da transmitância, para diferentes campos, das cadeias conectadas nas formas bridge e atop (Fig. 5.13). Além disto, sob ação do campo elétrico, os níveis de energia sofrem deslocamentos, que tornam o gap HOMO-LUMO bastante pequeno. Juntamente com este deslocamento, o nível HOMO do sistema estendido bridge mantém aproximadamente a mesma participação dos estados da cadeia, que o torna deslocalizado para todos os valores de campo(Fig. 5.15). Nos dois sistemas há um pequeno gap e a presença de um orbital deslocalizado, que favorecem o aumento da probabilidade de transmissão.

\subsection{Oligotiofenos}

Cálculos de transporte de oligotiofenos já foram reportados e apresentam resultados conflitantes, com o método DFT B3PW91 e base LANL2DZ os tiofenos possuem a transmitância cada vez maior com o tamanho do oligômero[101], enquanto que na referência 

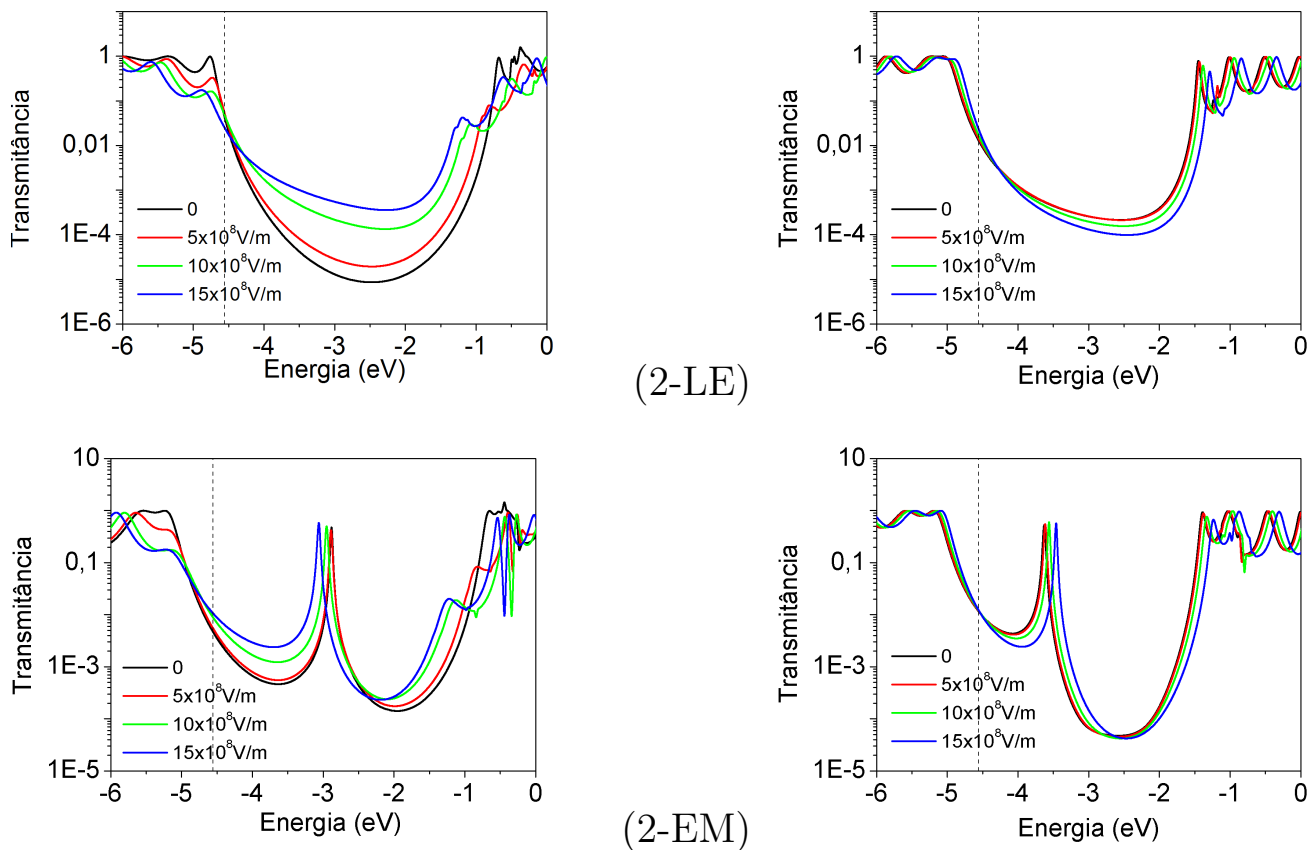

$(4-\mathrm{EM})$

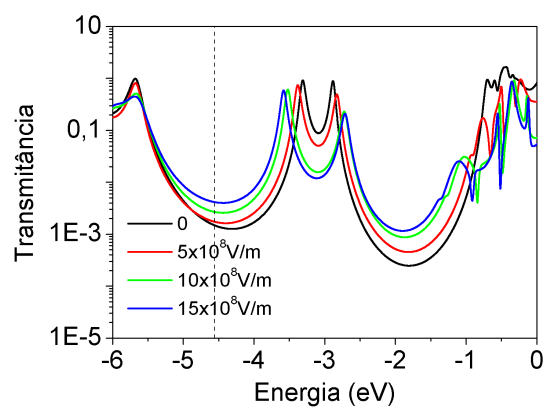

$(2-\mathrm{EM})$

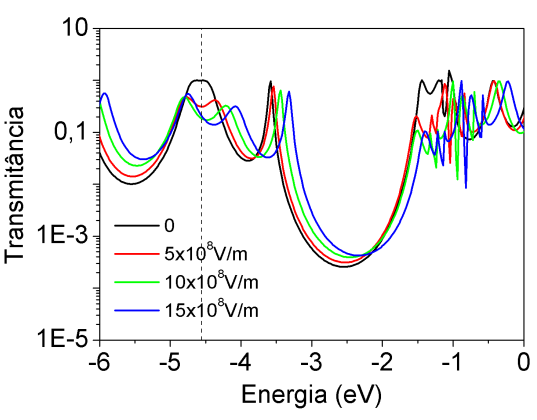

Figura 5.13: Transmitância do tetrâmero das anilinas sob ação de um campo elétrico externo. As formas de oxidação e tipo de conexão com os eletrodos são dados ao lado dos gráficos. A linha tracejada indica a energia de Fermi do ouro bulk obtida com B3LYP/LANL2DZ. 


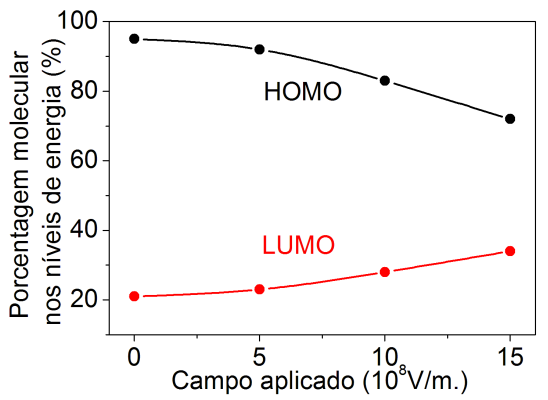

(2)(bridge)

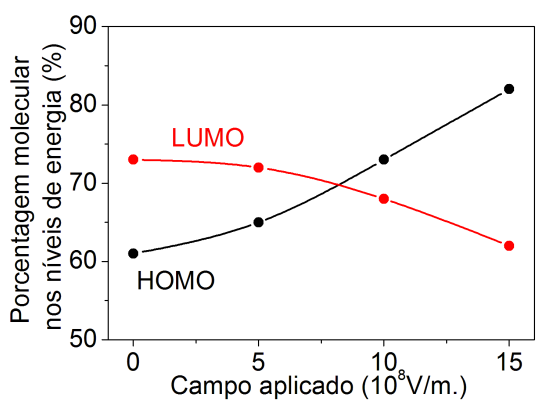

(4) (atop)

Figura 5.14: Participação dos orbitais do tetrâmero de LE no sistema metal-moléculametal sob ação do campo elétrico externo. O tipo de conexão é indicada ao lado do gráfico.
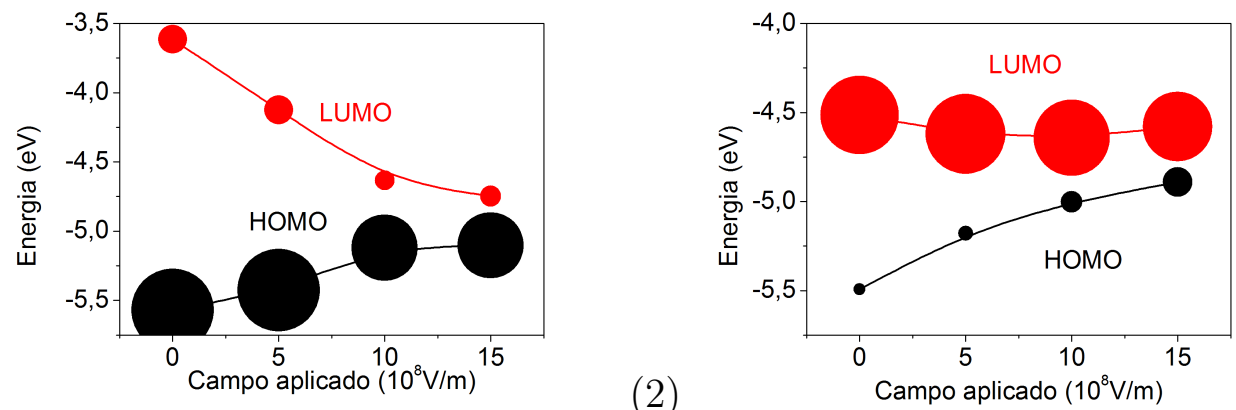

Figura 5.15: Participação dos orbitais do tetrâmero de PE no sistema metal-moléculametal sob ação do campo elétrico externo. O tipo de conexão é indicada ao lado do gráfico. A área do círculo é proporcional à porcentagem de estados da cadeia orgânica na composição do nível de energia. 
[94], calculos realizados com o método PW91 e ondas planas como função de base fornecem que a transmitância decai com o tamanho da cadeia. Em ambos os casos foi utilizada a forma de conexão hollow com o eletrodo. O primeiro reporte, que indica aumento da condutância com o tamanho da cadeia, é explicado pelo método escolhido. Neste trabalho os oligotiofenos apresentam um gap HOMO-LUMO muito pequeno, os valores para os oligômeros com 2, 3, 4 e 5 unidades são de 1,25, 1,01, 0,82 e 0,70 eV, respectivamente. Com o aumento da cadeia, o gap HOMO-LUMO diminui e os picos associados aos níveis de energia moleculares tornam-se cada vez mais estreitos, se o HOMO e o LUMO estiverem muito próximos entre si, a sobreposição dos picos na transmitância pode ser maior que o seu estreitamento, levando a um aumento da transmitância. Outro aspecto que não é muito bem descrito pelo método B3PW91 é a torção entre os anéis de tiofeno que fornece o valor de $180^{\circ}$, e discutimos no capítulo 3 que esta torção vale em torno de $157^{\circ}$. O segundo resultado, obtido com o funcional PW91 fornece um gap em torno de $2 \mathrm{eV}$ para o hexatiofeno, que é um valor muito próximo do experimental, indicando que o sistema molecular é bem descrito, bem como suas propriedades de transporte eletrônico.

Queremos investigar qual a possível origem da medida de condutância do trímero de tiofeno apresentar menor condutância que o tetrâmero[48], e estudaremos nas seções a seguir quais parâmetros presentes nos experimentos podem levar a esta observação.

Os oligotiofenos apresentam comportamento muito semelhante ao reportado para as oligoanilinas, entretanto, algumas diferenças devem ser ressaltadas.

Na figura 5.16 estão mostrados os gráficos da transmitância dos sistemas bridge e atop. De modo análogo ao obtido com as oligoanilianas, encontramos uma grande diferença na propriedade de transporte associada com a conexão com os eletrodos. Um aspecto muito importante da estrutura eletrônica e geometria dos oligotiofenos quando ligados de modo atop com os eletrodos é o fato de que estes sistemas apresentam uma distorção quinóide de seus anéis. Para estudar estes sistemas através do método tight-binding, primeiramente reproduzimos a densidade de estados dos elétrons $\pi$ calculado via DFT, figura 5.17(a). Uma vez que o sistema 4 apresenta uma distorção quinóide em sua geometria, calculamos a transmitância neste sistema utilizando os parâmetros obtidos para cadeia isolada mas 

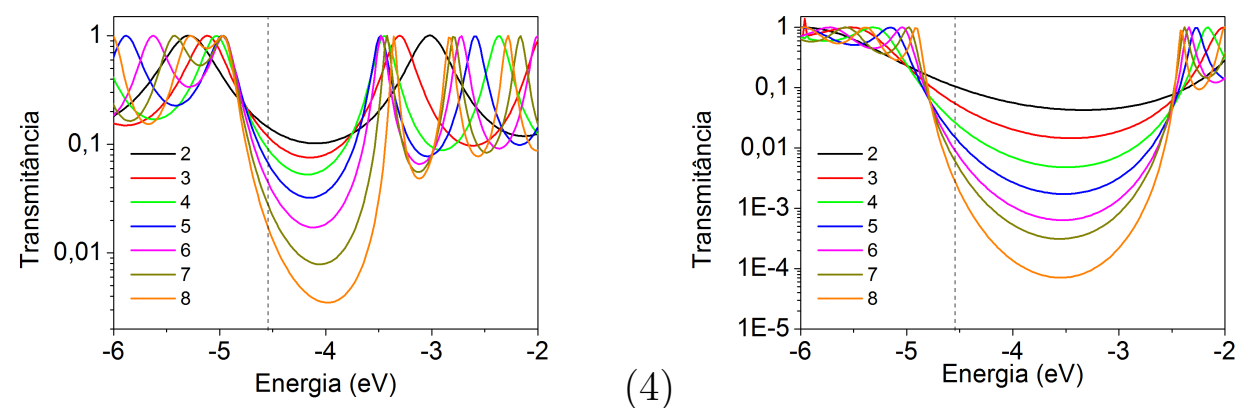

Figura 5.16: Transmitância dos oligotiofenos conectados de forma bridge e atop com os eletrodos. O tamanho dos oligômeros é indicado pelos números dentro dos gráficos. O tipo de conexão com o eletrodo está indicado ao lado, sendo (4) atop e (5) bridge. A linha tracejada indica a energia de Fermi do ouro bulk obtida com B3LYP/LANL2DZ.

trocamos a posição das ligações simples e duplas, como ocorre neste tipo de distorção. A transmitância calculada com o método tight-binding para o tetrâmero com as formas nãoquinóide e quinóide são mostrados na figura 5.17 (b), juntamente com as curvas obtidas via DFT dos sistemas bridge e atop. A boa correspondência entre estes resultados indica que: (1) os elétrons $\pi$ são determinantes nas propriedades eletrônicas destas cadeias e (2) a distorção quinóide é a origem do alto valor de transmitância nos sistemas conectados na forma atop.

\subsection{Oligotiofenos sob estiramento}

As curvas de transmitância dos oligotiofenos sob estiramento são mostradas na figura 5.18 , onde as cadeias orgânicas estão conectadas com os eletrodos nas configurações 2 (bridge) e 4 (atop). Os oligotiofenos apresentam a transmitância fortemente sensível ao estiramento quando comparamos com as oligoanilinas. A transmitância sofre uma grande redução independente do tipo de conexão com o eletrodo. Por conta disto sistemas bridge e atop covergem para valores similares de condutância. O gap entre os estados virtuais e ocupados também torna-se similar nos sistemas 2 e 4 quando o estiramento é de $2 \AA$. A 


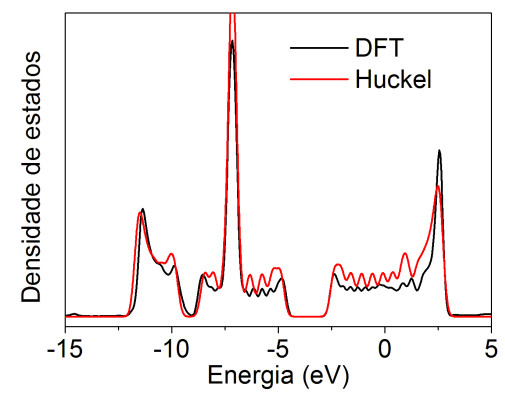

(a)

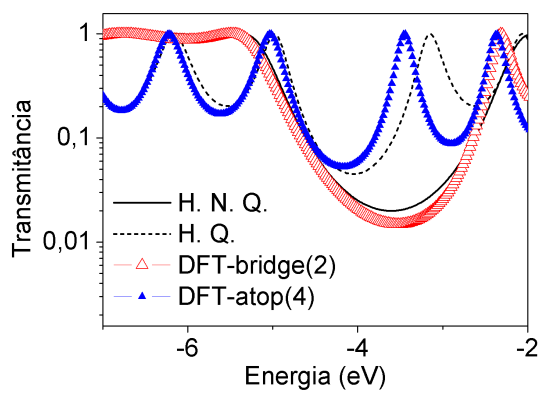

Figura 5.17: (a) Densidade de estados comparativa entre os métodos DFT e Hückel. (b) Transmitância calculada via DFT (Hückel) para as formas bridge (não quinóide-H. N. Q.) e atop (quinóide-H. Q.).

semelhança entre os sistemas bridge e atop deve-se à perda da característica quinóide que a cadeia orgânica dos tiofenos possuem quando conectados na forma atop. As mudanças estruturais do tetrâmero de tiofeno são mostradas na figura 5.19.

Os possíveis sinais de condutância alta e baixa destes sistemas podem ser perdidos em medidas experimentais pelo forte decaimento da transmitância sob estiramento. Ainda, induzido pelo estiramento, obtivemos curvas de transmitância similares para cadeias com diferentes comprimentos. Este resultado aponta para a quase ausência de um decaimento da condutância com o aumento da cadeia. Este resultado sugere que o comportamento incomum da condutância do trímero e do tetrâmero pode ser explicado pela proximidade entre seus valores de transmitância no máximo alongamento. 

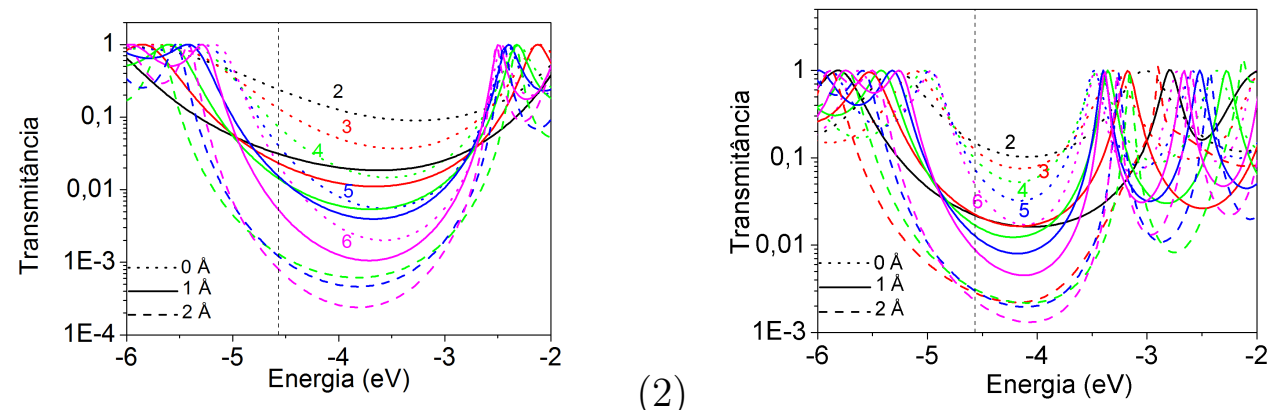

Figura 5.18: Transmitância dos oligotiofenos sob estiramento. O tamanho dos oligômeros está indicado pelos números $2,3, \ldots$, e 6 e a conexão pelos números (2) (bridge) e (4) (atop). A linha tracejada indica a energia de Fermi do ouro bulk obtida com B3LYP/LANL2DZ.

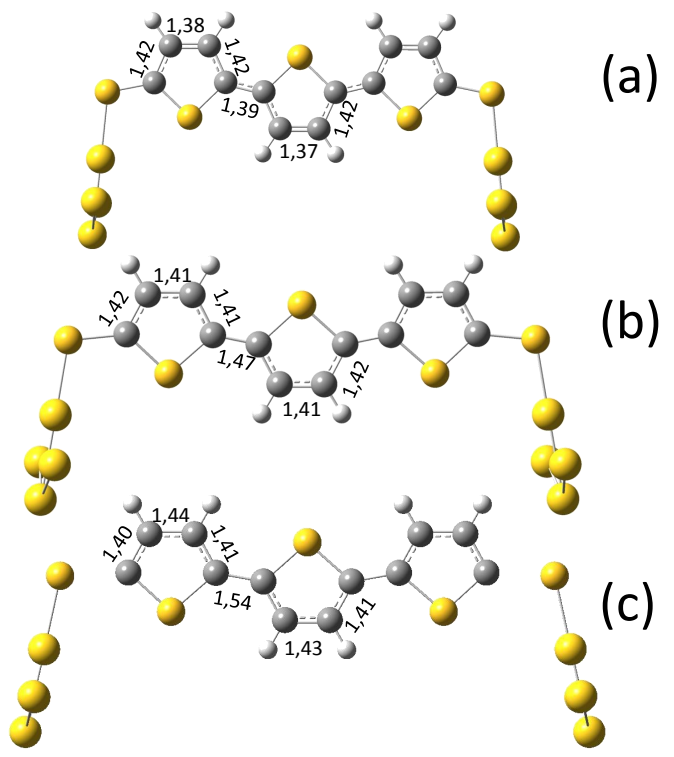

Figura 5.19: Comprimentos de ligação em angstroms $(\AA)$ do tetrâmero de tiofeno sob estiramento conectado ao eletrodo 4 (atop). O estiramento das cadeias é de (a) 0, (b) 1 e (c) 2 Å. Sob ação de um estiramento, uma transição quinóide-aromática é obtida. 


\section{Capítulo 6}

\section{Conclusão}

Neste trabalho estudamos as propriedades eletrônicas e estruturais de sistemas orgânicos conectados a eletrodos metálicos. Nosso foco principal reside no entendimento de alguns aspectos do transporte eletrônico em cadeias orgânicas, como o efeito do tamanho da cadeia orgânica, estiramento, estado de oxidação e campo elétrico externo.

As cadeias orgânicas investigadas apresentam, na forma de filmes, características de dispositivos ou sistemas condutores de elétrons. Há um grande interesse na aplicação de cadeias individuais como um dispositivo e o uso das oligoanilinas e oligotiofenos é motivado pelo amplo conhecimento de suas propriedades eletrônicas. Na condutância de apenas uma cadeia ligada a eletrodos metálicos, além de suas propriedades intrínsecas, a conexão com o metal pode desempenhar um papel fundamental no valor medido ou calculado. Diferentes valores de condutância são usualmente reportados nos experimentos de quebra de junção de cadeias conjugadas[46] e são associados às propriedades da interface metalcadeia. Para estudar a conexão orgânico-metal, utilizamos diferentes tipos de eletrodos, aos quais variamos a quantidade de átomos e o tipo de ligação entre estes e as cadeias orgânicas. Os oligômeros conectam-se aos metais através de um átomo de enxofre em cada extremidade nas formas bridge e atop. O estudo de diferentes conexões eletrodo-molécula é motivado pelo desconhecimento experimental da geometria do contato entre a cadeia orgânica e o eletrodo. 
Nossos cálculos mostraram que as formas de ligação entre as cadeias orgânicas e os eletrodos são determinantes nas propriedades de transporte eletrônico. As formas de acoplamento podem levar a cadeia a apresentar uma estrutura eletrônica mais condutora. Existem resultados na literatura que discutem sobre a observação da condutância alta e baixa estar associada com a configuração geométrica da região próxima da interface do metal. Cálculos da condutância de sistemas orgânicos conectados a eletrodos quase unidimensionais fornecem diferentes sinais de condutância para diferentes fios metálicos[102]. Neste estudo, é reportado que os diferentes valores de condutância dependem essencialmente da quantidade de estados na energia de Fermi de cada fio. Devemos também mencionar um resultado que mostra que quando uma cadeia orgânica conecta-se a uma superfície metálica com um adátomo (átomo posicionado sobre a superfície), a densidade de estados do átomo de enxofre sofre um aumento na região da energia de Fermi, contribuindo assim para o aumento da condutância[96]. Similarmente a estes resultados, obtivemos diferentes intensidades na condutância para sistemas conectados nas formas bridge e atop. Nossos resultados fornecem ainda que a diferença na conexão entre os sistemas bridge e atop pode estar no tipo de orbital de ouro que interage com a cadeia. Através da análise da contribuição dos orbitais do ouro nos autovalores da cadeia estendida, encontramos que sistemas com conexão atop apresentam uma contribuição maior de orbitais de simetria $s$ e $d$ nos níveis de fronteira, e sistemas de conexão bridge, dos orbitais tipo $p$. Orbitais do tipo $s$ são majoritários na energia de Fermi do ouro bulk e o alinhamento dos níveis moleculares com orbitais desta simetria podem levar um canal mais propício à troca de carga nesta configuração. As cadeias de modo geral sofrem mudanças no comprimento de ligação principalmente na interface molécula-metal. Pernigranilinas e oligotiofenos apresentam as mudanças mais notáveis. Os oligotiofenos apresentam uma distorção quinóide, e as cadeias pernigranilina sofrem uma mudança na alternância de seus anéis quinóides e aromáticos

Os oligotiofenos apresentam uma resposta muito incomum no que se refere a condutância em função do comprimento das cadeias, como obtido experimentalmente na referência[48]. A dependência usual da condutância em função do comprimento da cadeia 
é a diminuição exponencial com o tamanho da cadeia, mas experimentos indicam que os oligotiofenos apresentam um comportamento anômalo no que se refere ao trímero e tetrâmero, no qual a cadeia mais longa apresenta condutância maior que a mais curta. Nossos resultados indicam a presença de condutância alta e baixa quando os oligotiofenos estão conectados aos eletrodos atop e bridge, respectivamente. Entretanto, quando os sistemas são estirados obtemos uma redução muito grande da transmitância. No limite superior de estiramento, as diferenças entre as transmitâncias dos sistemas bridge e atop diminuem, bem como a diferença na transmitância de oligômeros de diversos tamanhos. Tal comportamento é explicado pela perda da característica quinóide dos tiofenos ligados de forma atop quando estirados. Nas oligoanilinas, o resultado do estiramento depende principalmente do tipo de conexão com o eletrodo e estado de oxidação. Nas cadeias de LE e EM conectadas aos eletrodos de forma brige bem como para as PE em ambos acoplamentos com o eletrodo, a transmitância sofre um aumento para valores iniciais de estiramento ( $2 \AA)$, que é associado à planarização da cadeia. Em seguida, uma vez que a cadeia encontra-se plana, um aumento no estiramento provoca um forte aumento nos comprimentos de ligação levando a um decaimento mais significativo da transmitância. As pernigranilinas apresentam o comportamento estrutural menos dependente do acoplamento com os eletrodos devido a sua capacidade de acomodar a perda de elétrons apenas por uma redistribuição dos anéis quinóides e aromáticos. Quando a conexão é do tipo atop as LE e EM apresentam um leve decaimento da transmitância com o aumento do estiramento, essas cadeias apresentam-se inicialmente mais planas, de tal modo que o estiramento provoca a delocalização dos orbitais.

Sob ação do campo elétrico externo, a transmitância das oligoanilinas apresenta um comportamento que depende tanto da forma de conexão com o metal, quanto do estado de oxidação. As LE e EM conectadas na forma bridge, bem como as PE em ambas conexões com os eletrodos apresentam aumento na transmitância em função do campo elétrico. Este comportamento, nas cadeias de EM e LE está associado com a diminuição do gap HOMO-LUMO e aumento da participação dos orbitais das cadeias orgânicas no LUMO. Nas PE o campo diminui o gap HOMO-LUMO, e o nível de energia HOMO(LUMO) 
apresenta-se deslocalizado na conexão bridge (atop) para todos os valores de campo.

Realizamos também a comparação de cálculos de transmitância cujos hamiltonianos são obtidos via DFT e tight-binding. Os elementos do hamiltoniano tight-binding são obtidos através de uma parametrização que fornece a densidade de estados da cadeia isolada similar à calculada com o método DFT. Há uma excelente semelhança da densidade de estados entre os dois métodos no caso dos oligotiofenos, que é explicado pela boa separabilidade $\sigma-\pi$ nestas cadeias. No caso das oligoanilinas obtivemos uma boa comparação quando levamos em conta alguns aspectos, tais como largura de banda, tamanho do gap e posição das singularidades. Através do método tight-binding conseguimos explicar todos os resultados obtidos via DFT. Nos oligotiofenos reproduzimos os estados de alta e baixa condutância apenas mudando os parâmetros do hamiltoniano de um sistema não quinóide para um quinóide, sendo que a distorção quinóide está associada com a condutância alta. Com as oligoanilinas conseguimos reproduzir a diferença da transmitância nas cadeias ligadas na forma bridge e atop, bem como nos diferentes estados de oxidação. O procedimento para obter estes resultados corresponde a inserção dos parâmetros nos elementos do hamiltoniano consistentes com as ligações duplas e simples, presentes nos anéis quinóides das diferentes formas de oxidação. Associamos o bom resultado geral obtido com o método tight-binding, quando comparamos com o DFT a alguns fatores: (1) Os elétrons $\pi$ são os principais responsáveis pelas características eletrônicas dos sistemas estudados, e (2) dado o fato de que a teoria de Landauer é de uma partícula, não possuindo portanto um termo de correlação entre os elétrons que vêm do eletrodo com os que estão na cadeia espalhadora, o resultado será extremamente dependente do hamiltoniano eletrônico. 


\section{Apêndice A}

\section{Método DFT}

No capitulo de metodologia mencionamos o uso da DFT no cálculo dos nossos sistemas, fizemos uma breve introdução deste método e citamos seus dois teoremas fundamentais. Entretanto, não discutimos sobre a forma do funcional da densidade e como ele é obtido. Nas seções a seguir, estes aspectos serão abordados, iniciando pelo funcional LDA (Local Density approximation) cujos termos são obtidos para um gás de elétrons livres. Exploraremos funcionais mais modernos, que utilizam como base em suas construções o funcional LDA.

\section{A.1 LDA}

Os teoremas da DFT garantem que existe um funcional que depende somente da densidade eletrônica e que fornece a energia do estado fundamental. Neste sentido uma busca pela forma do funcional se faz necessária. Até o momento, o que sabemos sobre o funcional é a forma da equação de Kohn-Sham[60]:

$$
E[\rho]=\int \nu(r) \rho(r) d^{3} r+\frac{1}{2} \iint \frac{\rho(r) \rho\left(r^{\prime}\right)}{\left|r-r^{\prime}\right|} d^{3} r d^{3} r^{\prime}+T_{0}[\rho]+E_{x c}[\rho]
$$

onde o primeiro termo representa a interação dos elétrons com um potencial externo; que pode ser devida, por exemplo, aos núcleos; o segundo termo refere-se a interação elétron- 
elétron e os dois termos finais representam respectivamente a energia cinética e de troca correlação. Já mencionamos que o termo de troca surge do princípio da exclusão de Pauli e a energia de correlação surge do fato de utilizarmos, por exemplo a energia cinética de um gás de elétrons não interagente.

Para obter a parte do funcional que corresponde a energia cinética e ao exchange, partimos do sistema multieletrônico mais simples que conhecemos, o gás de elétrons livres. Demonstraremos passo a passo a forma destes dois termos, iniciando pelo termo cinético. Para elétrons livres a energia cinética é obtida com a expressão:

$$
T=\frac{\hbar^{2} k^{2}}{2 m}
$$

onde $k$ é o momento do elétron, que possui a seguinte relação com a densidade eletrônica:

$$
\rho(k)=\frac{k^{3}}{3 \pi^{2}}
$$

Para obter a energia cinética de um sistema multieletrônico devemos tomar a somatória em todo o espaço $k$, lembrando que cada estado $k$ contém dois elétrons, assim:

$$
T=2 \sum_{k} \frac{\hbar^{2} k^{2}}{2 m}
$$

transformando a somatória em um integral obtemos:

$$
T=\frac{V}{(2 \pi)^{3}} \int_{k} \frac{\hbar^{2} k^{2}}{2 m} d^{3} k
$$

onde $V /(2 \pi)^{3}$ é o volume unitário no espaço $K$ que foi inserido para manter a dimensão correta da energia cinética. Para resolver a integral da equação A.5 que é feita em todo o volume do espaço dos momentos, utilizamos as coordenadas esféricas:

$$
T=\frac{V}{(2 \pi)^{3}} \int_{k_{0}}^{k_{f}} \frac{\hbar^{2} k^{2}}{2 m} 4 \pi k^{2} d k
$$

Resolvendo a integral obtemos:

$$
T=\frac{V}{2(\pi)^{2}} \frac{\hbar^{2} k_{f}^{5}}{10 m}
$$


Utilizando a expressão para $\rho$ dada na equação A.3 temos:

$$
T[\rho]=\frac{9 V h^{2}}{16 \pi m} \rho^{5 / 3}
$$

Este é o termo cinético para o funcional de Thomas-Fermi. O funcional foi aperfeiçoado com a inserção de um termo de exchange feita por Dirac. Para demonstrar sua forma, partimos da expressão de Hartree-Fock[60].

$$
\epsilon_{x}=-\sum_{j} \int d r^{3} \varphi_{i}^{*}(\vec{r}) \int d r^{\prime 3} \frac{e^{2}}{\left|\vec{r}-\vec{r}^{\prime}\right|} \varphi_{j}^{*}\left(\vec{r}^{\prime}\right) \varphi_{i}\left(\vec{r}^{\prime}\right) \varphi_{j}(\vec{r}) \delta_{S i S j}
$$

Na relação A.9 o termo $\delta_{S i S j}$ insere o cancelamento do termo de troca quando os elétrons possuem números de spin diferentes. Utilizando funções de onda plana $\varphi_{k}(r)=$ $\frac{1}{V^{1 / 2}} e^{i \vec{k} \cdot \vec{r}}$, obtemos:

$$
\epsilon_{x}=-\frac{1}{V^{2}} \sum_{j} \int d r^{3} e^{-i\left(\overrightarrow{k_{i}}\right) \cdot \vec{r}} \int d r^{\prime 3} \frac{e^{2}}{\left|\vec{r}-\overrightarrow{r^{\prime}}\right|} e^{i\left(\overrightarrow{k_{i}}-\overrightarrow{k_{j}}\right) \cdot \vec{r}^{\prime}} e^{i\left(\overrightarrow{k_{j}}\right) \cdot \vec{r}}
$$

Para resolver esta integral utilizamos a definição da função delta de Dirac $\delta(r)=$ $\int \frac{d x}{(2 \pi)^{3}} e^{i x r}$, e a relação $\nabla^{2} \frac{1}{\left|\vec{r}-\vec{r}^{\prime}\right|}=-4 \pi \delta\left(\vec{r}-\vec{r}^{\prime}\right)$ que nos fornece:

$$
-\frac{e^{2}}{\left|\vec{r}-\overrightarrow{r^{\prime}}\right|}=\int \frac{d \vec{x}}{(2 \pi)^{3}} e^{i \vec{x} \cdot\left(\vec{r}-\vec{r}^{\prime}\right)} \frac{4 \pi e^{2}}{x^{2}}
$$

Inserindo a expressão acima no termo de exchange da equação A.10 obtemos:

$$
\epsilon_{x}=\frac{1}{V^{2}} \sum_{j} \int d r^{3} e^{-i\left(\overrightarrow{k_{i}}\right) \cdot \vec{r}} \iint d r^{\prime 3} \frac{d \vec{x}}{(2 \pi)^{3}} e^{i \vec{x} \cdot \vec{r}} \frac{e^{2}}{\left|\vec{r}-\overrightarrow{r^{\prime}}\right|} e^{i\left(\overrightarrow{k_{i}}-\overrightarrow{k_{j}}-\vec{x}\right) \cdot \vec{r}^{\prime}} \frac{4 \pi e^{2}}{x^{2}} e^{i\left(\overrightarrow{k_{j}}\right) \cdot \vec{r}}
$$

Reescrevendo a equação acima e inserindo a variável $\vec{K}_{u}=\vec{K}_{i}-\vec{K}_{j}-\vec{x}$ obtemos:

$$
\epsilon_{x}=\frac{1}{V^{2}} \sum_{j} \int d r^{3} e^{-i\left(\overrightarrow{k_{i}}\right) \cdot \vec{r}} \iint d r^{\prime 3} \frac{d \vec{k}_{u}}{(2 \pi)^{3}} e^{i \vec{x} \cdot \vec{r}} e^{i \overrightarrow{k_{u} \cdot \vec{r}}} \frac{4 \pi e^{2}}{\left|\vec{k}_{i}-\vec{k}_{j}-\vec{k}_{u}\right|^{2}} e^{i\left(\overrightarrow{k_{j}}\right) \cdot \vec{r}}
$$

explicitando a delta da variável $\overrightarrow{k_{u}}$ : 


$$
\epsilon_{x}=-\frac{1}{V^{2}} \sum_{j} \int d r^{3} e^{-i\left(\overrightarrow{k_{i}}\right) \cdot \vec{r}} \delta\left(\vec{k}_{u}\right) e^{i \vec{x} \cdot \vec{r}} \frac{4 \pi e^{2}}{\left|\vec{k}_{i}-\vec{k}_{j}-\vec{k}_{u}\right|^{2}} e^{i\left(\overrightarrow{k_{j}}\right) \cdot \vec{r}}
$$

resolvendo a delta,

$$
\epsilon_{x}=-\frac{1}{V^{2}} \sum_{j} \int d r^{3} e^{-i\left(\overrightarrow{k_{i}}\right) \cdot \vec{r}} e^{i \vec{x} \cdot \vec{r}} \frac{4 \pi e^{2}}{\left|\vec{k}_{i}-\vec{k}_{j}\right|^{2}} e^{i\left(\overrightarrow{k_{j}}\right) \cdot \vec{r}}
$$

Substituindo $\vec{x}$ na expresão acima obtemos:

$$
\epsilon_{x}=-\frac{1}{V^{2}} \sum_{j} \int d r^{3} e^{-i\left(\overrightarrow{k_{i}}\right) \cdot \vec{r}} e^{i\left(\overrightarrow{k_{i}}-\overrightarrow{k_{j}}\right) \cdot \vec{r}} \frac{4 \pi e^{2}}{\left|\overrightarrow{k_{i}}-\overrightarrow{k_{j}}\right|^{2}} e^{i\left(\overrightarrow{k_{j}}\right) \cdot \vec{r}}
$$

Resolvendo a integral em $r$ obtemos:

$$
\epsilon_{x}=-\frac{1}{V} \sum_{j} \frac{4 \pi e^{2}}{\left|\vec{k}_{i}-\vec{k}_{j}\right|^{2}}
$$

A somatória em $k_{j}$ será transformada numa integral, do mesmo modo como feito para a energia cinética, resultando em:

$$
\epsilon_{x} / V=-\frac{3}{4} e^{2}\left(\frac{3}{\pi}\right)^{1 / 3} \rho^{4 / 3}
$$

Embora os termos do LDA sejam obtidos para sistemas eletrônicos com densidade uniforme, ele pode ser aplicado para sistemas atômicos e moleculares. Neste funcional cada elemento infinitesimal de volume comporta-se localmente como um gás uniforme, sendo diferente o valor da densidade para cada ponto do espaço. A seguir discutiremos como inserir nos funcionais a variação da densidade eletrônica através do gradiente de $\rho$.

\section{A.2 Funcionais GGA}

O aperfeiçoamento mais imediato da forma dos funcionais da DFT é a inserção da dependência do gradiente da densidade nos termos do funcional (exchange e correlação). Na aproximação do GGA (Generalized gradient approximations), a forma mais comum de inserir o $\nabla \rho$ é feita com a função de realce $F$, que será discutida nas seções a seguir. Os 
termos de exchange e correlação que utilizam $F(\nabla \rho)$ são ditos semilocais. Porém, além das aproximações locais (LDA) e semilocais (GGA) ainda existem os funcionais híbridos, como o B3LYP, que combina a utilização de termos de exchange semilocais e de HF. O funcional B3LYP apresenta a seguinte composição:

$$
E_{X C}=a_{0} E_{X}^{L S D A}+\left(1-a_{0}\right) E_{X}^{e x a t o}+a_{X} \Delta E_{X}^{B 88}+a_{c} E_{c}^{L Y P}+\left(1-a_{c}\right) E_{c}^{L S D A}
$$

Como já mencionado no capítulo 2, os termos da equação A.19 representam: $E_{X, C}^{L S D A}$ as energias de troca e correlação obtidos com o gás de elétrons livres, $E_{X}^{\text {exato }}$ a energia de troca exata (Hartree-Fock) e o termo $\Delta E_{X}^{B 88}$ [62] é uma correção de gradiente feita para o exchange, do gás de elétrons livres e $E_{c}^{L Y P}$ é o termo de correlação com correção de gradiente de Lee et al [63]. Os parâmetros $a, b$ e $c$ são obtidos com os átomos e moléculas da base de dados G1[53].

Discutiremos nas seções a seguir as formas dos termos de exchange de Becke e correlação de LYP.

\section{A.2.1 O termo de Exchange}

O termo de exchange de Becke foi desenvolvido apartir de sucessivas melhoras do funcional de exchange GGA mais simples, o $X \alpha \beta$, que insere a dependencia de $\nabla \rho$ através de uma análise dimensional:

$$
E_{x}^{L G C}=E_{X}^{L D A}-\beta \sum_{\sigma} \int \frac{\left(\nabla \rho_{\sigma}\right)^{2}}{\rho_{\sigma}^{4 / 3}} d^{3} r
$$

Partindo de A.20, Becke propõe o termo de exchange:

$$
E_{x}^{S E}=E_{X}^{L D A}-\beta \sum_{\sigma} \int \rho_{\sigma}^{4 / 3} \frac{\chi_{\sigma}^{2}}{1+\gamma \chi_{\sigma}^{2}} d^{3} r
$$

$\operatorname{com} \chi_{\sigma}=\frac{\left|\nabla \rho_{\sigma}\right|}{\rho_{\sigma}^{4 / 3}}$. Esta expressão que corrige alguns defeitos do funcional $X \alpha \beta$, é obtida de modo semi-empírico para se ajustar ao exchange de Hartree-Fock. 
O passo seguinte para o aperfeiçoamento do exchange de Becke consiste em reproduzir o comportamento da energia de exchange de HF nos limites em que $r \rightarrow \infty$.

$$
\lim _{r \rightarrow \infty} U_{X}^{\sigma}=-\frac{1}{r}
$$

que está relacionado com a densidade eletrônica através da relação:

$$
E_{X}=\frac{1}{2} \sum_{\sigma} \int \rho U_{X}^{\sigma} d^{3} r
$$

$$
\lim _{r \rightarrow \infty} \rho_{\sigma}=-e^{-a_{\sigma} r}
$$

A expressão de Becke que atende aos requisitos acima é a seguinte:

$$
E_{X}^{L D A}-\beta \sum_{\sigma} \int \rho_{\sigma}^{4 / 3} \frac{\chi_{\sigma}^{2}}{\left(1+6 \beta \chi_{\sigma} \sinh ^{-1} \chi_{\sigma}\right)} d^{3} r
$$

Os detalhes do desenvolvimento deste funcional podem ser obtidos na referencia [62].

\section{A.2.2 O termo de correlação}

O outro termo importante do funcional B3LYP é a correlação de Lee Yang e Parr[63], que utiliza a fórmula de Colle-Salvetti, derivada da matriz densidade do método de HF e calculada apartir da equação:

$$
E_{c}=\langle\psi|\hat{H}| \psi\rangle-\left\langle\psi^{H F}|\hat{H}| \psi^{H F}\right\rangle
$$

onde $\psi^{H F}$ é o determinante de slater para os elétrons no estado fundamental e $\psi$ a solução exata . A função de onde multieletrônica de HF é conhecida e na aproximação de ColleSalvetti, a solução $\psi$ exata é dada por:

$$
\psi^{C S}=\psi^{H F} \times \prod_{i>j}\left[1-\varphi\left(r_{i}, r_{j}\right)\right]
$$

onde 


$$
\varphi\left(r_{i}, r_{j}\right)=\exp \left[-\beta^{2}(R) u^{2}\right]\{\Phi(R)(1+u / 2)\}
$$

com

$$
\Phi\left(r_{i}, r_{j}\right)=\sqrt{\pi} \beta(R) /[1+\sqrt{\pi} \beta(R)]
$$

Onde $\varphi$ é o fator de correlação de Jastrow, com $u=\left|r^{\prime}-r\right|, R=\left(r+r^{\prime}\right) / 2$ e $\beta(R)=q \rho^{1 / 3}(R)$, com $q=2.29$ obtidos do ajuste da correlação exata obtida com o átomo de Hélio.

A demonstração da fórmula de Colle-Salveti pode ser obtida na referência[103].

\section{A.2.3 O funcional PBE}

Este é um funcional não empírico derivado de uma simplicação do PW91 [104]. Diferentemente dos termos de exchange e correlação discutidos anteriormente, no funcional PBE estes não apresentam uma forte argumentação física na sua obtenção. Os autores propuseram uma função de realce que leva corretamente a comportamentos assintóticos dos termos de troca e correlação nos limites em que $\nabla \rho$ apresenta forte ou fraca variação. Além disso os termos de troca e correlação apresentam um bom comportamento matemático, como a ausência de singularidades em alguns limites assintóticos[61]. 


\section{Apêndice B}

\section{Função de Green}

Neste apêndice discutiremos alguns aspectos relacionados à função de Green e ao cálculo da transmitância. Para isto, utilizaremos o poliacetileno, como eletrodo e sua unidade monomérica como contato. Neste teste, a função de Green do reservatório de elétrons é obtida sem o uso da aproximação $W B L$. O mesmo código computacional empregado ao longo da tese, no estudo das cadeias orgânicas, é empregado aqui. Dado que o resultado da transmitância em sistemas como este é conhecido (como discutido no capítulo 1), é uma ótima validação do funcionamento do código, e ainda podemos discutir como um sistema infinito não necessariamente periódico pode ser estudado.

\section{B.1 Teste com o poliacetileno}

O poliacetileno é um polímero orgânico que possui dois átomos de carbono na sua unidade fundamental, neste apêndice, calcularemos a probabilidade de um elétron atravessar uma região equivalente a sua unidade monomérica. Os elétrons que serão espalhados são originados do polímero. Um esquema de sua estrutura e do arranjo eletrodo-contatoeletrodo é mostrado na figura B.1. Para o estudo deste sistema não podemos utilizar a aproximação $W B L$, porque a densidade de estados não é constante em função da energia. Assim, utilizaremos a função de Green dos eletrodos sem fazer aproximações. Entretanto, 


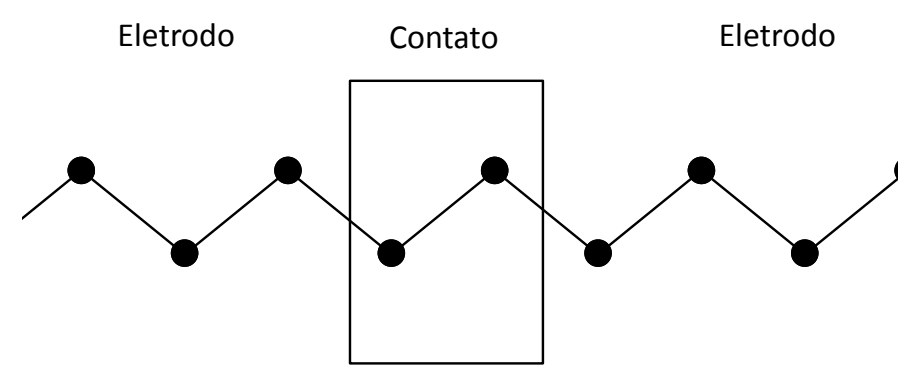

Figura B.1: Esquema do arranjo eletrodo-contato eletrodo do poliacetileno.

é impossível obter a matriz inversa de um sistema molecular de dimensão infinita, felizmente não necessitamos calcular todos os elementos, uma vez que o contato interage apenas com alguns átomos do eletrodo e o sistema não precisa ser infinito, apenas muito grande. Para esclarecer, vamos escrever o hamiltoniano de todo o sistema.

$$
\left(\begin{array}{ccccccc}
H L_{1,1} & \cdots & H L_{1, N} & 0 & 0 & \cdots & 0 \\
\vdots & \ddots & \vdots & \vdots & \vdots & \ddots & \vdots \\
H L_{N, 1} & \cdots & H L_{N, N} & \gamma_{L} & 0 & \cdots & 0 \\
0 & \cdots & \gamma_{L} & H M & \gamma_{R} & \cdots & 0 \\
0 & \cdots & 0 & \gamma_{R} & H R_{1,1} & \cdots & H R_{1, N} \\
\vdots & \ddots & \vdots & \vdots & \vdots & \ddots & \vdots \\
0 & \cdots & 0 & 0 & H R_{N, 1} & \cdots & H R_{N, N}
\end{array}\right)
$$

De modo geral, os elementos desta matriz são blocos matriciais. Neste sistema, onde os eletrodos são idênticos ao contato ocorre um transporte muito próximo de $100 \%$ balístico. Deste modo, esperamos que ocorra a formação de platôs da transmitância, com altura igual ao número de estados com aquela energia. De modo breve, obteremos a transmitância deste sistema. Calculando os termos $\Sigma_{L, R}$ : 


$$
\Sigma_{L}=H_{M L} g_{L} H_{L M}=\left(\begin{array}{lll}
0 & \cdots & \gamma_{L}
\end{array}\right)\left(\begin{array}{ccc}
g_{1,1}^{L} & \cdots & g_{1, N}^{L} \\
\vdots & \cdots & \vdots \\
g_{N, 1}^{L} & \cdots & g_{N, N}^{L}
\end{array}\right)\left(\begin{array}{c}
0 \\
\vdots \\
\gamma_{L}
\end{array}\right)
$$

Assim, $\Sigma_{L}$ assume o valor:

$$
\Sigma_{L}=\gamma_{L} g_{N, N}^{L} \gamma_{L}
$$

similarmente,

$$
\Sigma_{R}=\gamma_{R} g_{1,1}^{R} \gamma_{R}
$$

onde a matriz $g^{L, R}$ é a função de Green dos eletrodos e os índices $L$ e $R$ indicam o eletrodo à esquerda e à direita, respectivamente.

Utilizando as definições de $\Gamma=-2 \operatorname{Imag} \Sigma$, obtemos:

$$
T(E)=\Gamma_{L}\left(E-H M-\gamma_{L} g_{N, N}^{L} \gamma_{L}-\gamma_{R} g_{1,1}^{R} \gamma_{R}\right)^{-1} \Gamma_{R}
$$

Como mencionado anteriormente, não podemos utilizar a aproximação WBL, que considera a função de Green do eletrodo proporcional a densidade de estados. Neste sentido, o uso da função de Green $(g)$ sem aproximações se faz necessário. Existem dois aspectos que nos facilita o cálculo de $g$. O primeiro é que não precisamos calcular todos os seus elementos, o segundo se deve à forma tridiagonal do hamiltoniano do eletrodo. A relação entre o hamiltoniano e sua função de Green é dada a seguir:

$$
\left(\begin{array}{ccccc}
E-\alpha & \beta & 0 & \cdots & 0 \\
\beta^{T} & E-\alpha & \beta & \cdots & 0 \\
0 & \beta^{T} & E-\alpha & \beta & \cdots \\
\vdots & \vdots & \vdots & \vdots & \vdots
\end{array}\right)\left(\begin{array}{ccc}
g_{1,1} & \cdots & g_{1, N} \\
\vdots & \ddots & \vdots \\
g_{N, 1} & \cdots & g_{N, N}
\end{array}\right)=\left(\begin{array}{ccc}
1 & \cdots & 0 \\
\vdots & \ddots & \vdots \\
0 & \cdots & 1
\end{array}\right)
$$

Para obter o bloco de matriz $g_{N, N}$ multiplicamos todas as linhas do hamiltoniano apenas pela última coluna, para obter o conjunto de equações: 


$$
\begin{gathered}
(E-\alpha) g_{1, N}+\beta g_{2, N}+0+\cdots+0=0 \\
\beta^{T} g_{1, N}+(E-\alpha) g_{2, N}+\beta g_{3, N}+\cdots=0 \\
\vdots \\
0+\cdots+0+\beta^{T} g_{N-1, N}+(E-\alpha) g_{N, N}=1
\end{gathered}
$$

que organizados na forma matricial:

$$
\left(\begin{array}{ccccccc}
E-\alpha & \beta & 0 & 0 & 0 & \cdots & 0 \\
\beta^{T} & E-\alpha & \beta & 0 & 0 & \cdots & 0 \\
0 & \beta^{T} & E-\alpha & \beta & 0 & \cdots & 0 \\
\vdots & \vdots & \vdots & \vdots & \ddots & \vdots & \vdots \\
0 & \cdots & 0 & 0 & \beta^{T} & E-\alpha & 1
\end{array}\right)
$$

Ao escalonar a matriz acima, e torna-la triangular inferior, obtemos:

$$
\left(\begin{array}{ccccccc}
U_{1} & \beta & 0 & 0 & 0 & \cdots & 0 \\
0 & U_{2} & \beta & 0 & 0 & \cdots & 0 \\
0 & 0 & U_{3} & \beta & 0 & \cdots & 0 \\
\vdots & \vdots & \vdots & \vdots & \ddots & \vdots & \vdots \\
0 & \cdots & 0 & 0 & 0 & U_{N} & 1
\end{array}\right)
$$

Assim o elemento $g_{N, N}=U_{N}^{-1}$, para obter os elementos $U_{i}$ utilizamos a relação de recorrência:

$$
U_{i}=E-\alpha-\beta^{T} U_{i-1}^{-1} \beta
$$

$\operatorname{com} i=2,3, \ldots \mathrm{e}$

$$
U_{1}=E-\alpha
$$

O procedimento descrito acima fornece o bloco matricial da função de Green do eletrodo à esquerda $\left(g_{N, N}\right)$. Para o bloco matricial $g_{1,1}$, que é o termo necessário para à conexão a esquerda, fazemos o mesmo procedimento para obter $g_{N, N}$, mas multiplicando 
as linhas do hamiltoniano pela primeira coluna da função de Green, e obtemos a seguinte matriz:

$$
\left(\begin{array}{ccccccc}
E-\alpha & \beta & 0 & 0 & 0 & \cdots & 1 \\
\beta^{T} & E-\alpha & \beta & 0 & 0 & \cdots & 0 \\
0 & \beta^{T} & E-\alpha & \beta & 0 & \cdots & 0 \\
\vdots & \vdots & \vdots & \vdots & \ddots & \vdots & \vdots \\
0 & \cdots & 0 & 0 & \beta^{T} & E-\alpha & 0
\end{array}\right)
$$

Rearranjando os elementos dessa matriz obtemos:

$$
\left(\begin{array}{ccccccc}
E-\alpha & \beta^{T} & 0 & 0 & 0 & \cdots & 0 \\
\beta & E-\alpha & \beta^{T} & 0 & 0 & \cdots & 0 \\
0 & \beta & E-\alpha & \beta^{T} & 0 & \cdots & 0 \\
\vdots & \vdots & \vdots & \vdots & \ddots & \vdots & \vdots \\
0 & \cdots & 0 & 0 & \beta & E-\alpha & 1
\end{array}\right)
$$

Como consequencia de rearranjar os elementos blocos matriciais, $\beta$ e $\beta^{T}$ são permutados com relação a posição original do hamiltoniano. Portanto, após o escalonamento, os elementos da diagonal principal são obtidos com a relação:

$$
U_{i}=E-\alpha-\beta U_{i-1}^{-1} \beta^{T}
$$

$\operatorname{com} i=2,3, \ldots \mathrm{e}$

$$
U_{1}=E-\alpha
$$

e o elemento $g_{1,1}=U_{N}^{-1}$

O resultado mostrado na figura B.2 foi obtido utilizando o método descrito neste apêndice. A transmitância do poliacetileno apresenta uma excelente correlação com a densidade de estados e com a estrutura de bandas. 


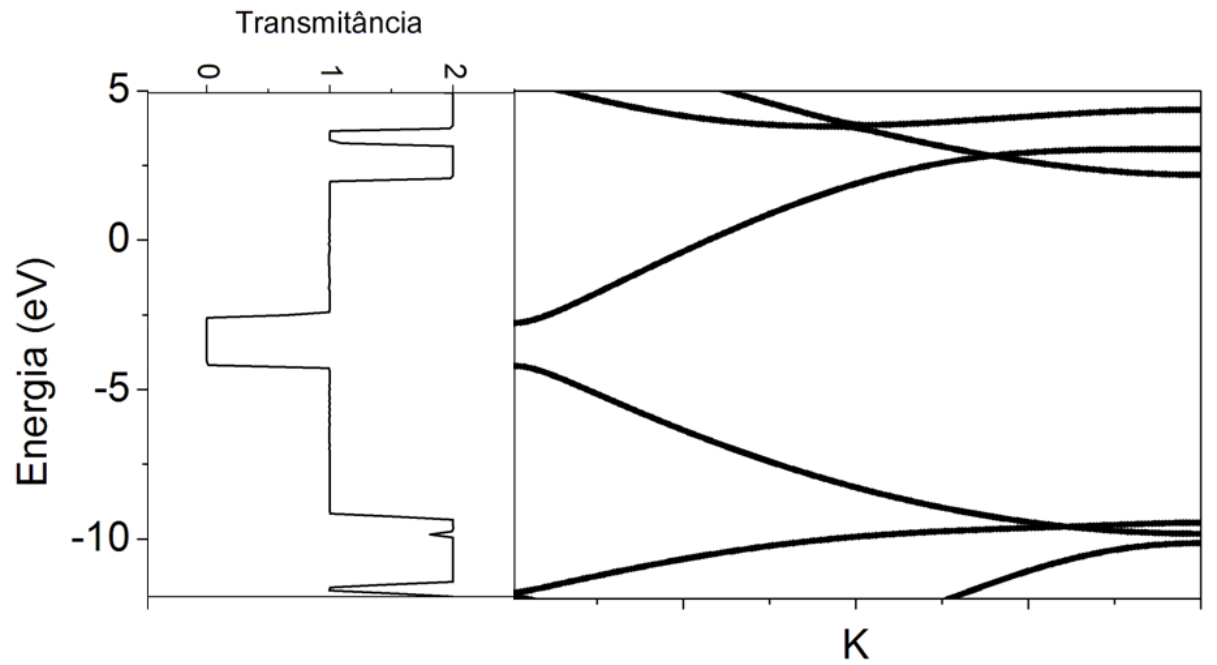

Figura B.2: Transmitância do poliacetileno, comparada com a estrutura de bandas. 


\section{Referências Bibliográficas}

[1] Samanta, M. P., Tian, W., e Datta, S. Phys. Rev. B 53, R7626-R7629 (1996).

[2] Seminario, J. M., De La Cruz, C., e Derosa, P. A. J. Am. Chem. Soc. 123, 56165617 (2001).

[3] Derosa, P. A. e Seminario, J. M. J. Phys. Chem. B 105, 471-481 (2001).

[4] Liu, Q. et al. ACS Nano 3, 3861-3868 (2009).

[5] Zhou, J., Chen, F., e Xu, B. J. Am. Chem. Soc. 131, 10439-10446 (2009).

[6] Salomon, A. et al. Adv. Mater. 15, 1881-1890 (2003).

[7] Lindsay, S. M. e Ratner, M. A. Adv. mater. 19, 23-31 (2007).

[8] Nitzan, A. e Ratner, M. Science 300, 1384-1389 (2003).

[9] Novaes, F. D., da Silva, A. J. R., e Fazzio, A. Braz. J. of Phys. 36, 799-807 (2006).

[10] Abadir, G. B., Walus, K., e Pulfrey, D. L. J. Comp. Elect. 8, 1-9 (2009).

[11] Kienle, D., Cerda, J. I., e Ghosh, A. W. J. Appl. Phys. 100, 043714 (2006).

[12] Nardelli, M. B. Phys. Rev. B 60, 7828-7833 (1999).

[13] Chen, F. et al. Annu. Rev. Chem 58, 535-64 (2007).

[14] Liu, H. et al. J. Chem. Phys. 130, 244501 (2009). 
[15] Tian, W. et al. J.Chem Phys. 109, 2874-2882 (1998).

[16] Seminario, J. M., Zacarias, A. G., e Derosa, P. A. J. Chem Phys. 116, 1671-1683 (2002).

[17] Datta, S. e Tian, W. Phys. Rev. Lett. 79, 2530-2533 (1997).

[18] Bardeen, J. Phys. Rev. 71, 717-727 (1947).

[19] Yao, J. et al. Nano Lett. 10, 4105-4110 (2010).

[20] Lundstrom, M. Appl. Phys. 299, 210-211 (2003).

[21] Chiang, C. K. et al. Phys. Rev. Lett. 39, 1098-1101 (1977).

[22] Gruner, G. J. Matter. Chem. 16, 3533-3539 (2006).

[23] Saran, N. et al. J. Am. Chem. Soc. 16, 4462-4463 (2004).

[24] Baughman, R. H., Zakhidov, A. A., e Heer, W. A. Science 297, 787-792 (2002).

[25] Tang, S. and. Zhang, J. Int. J. Quantum Chem. 111, 2089-2098 (2011).

[26] Horowitz, G., Fichou, D., Peng, X., e Garnier, F. Synth. Met. 41, 1127-1130 (1991).

[27] Mastragostino, M. et al. Electrochim. Acta 38, 135-140 (1993).

[28] Lin, Y. et al. Science 332, 1294-1296 (2011).

[29] Ranjbartoreh, A. R. et al. J. of Appl. Phys. 109, 014306 (2011).

[30] Patrone, L., Soullier, J., e Martin, P. Phys. Statu Solidi B 247, 1867-1870 (2010).

[31] Donhauser, Z. J. et al. Science 292, 2303-2307 (2001).

[32] Ramachadran, G. K. et al. Science 300, 1413-1416 (2003).

[33] Moreland, J. e Ekin, J. W. J. Appl. Phys. 58, 3888-3895 (1985). 
[34] Xu, B. e Tao, N. J. Science 301, 1221-1223 (2003).

[35] Chen, F., Zhifeng, H., e Tao, N. J. Appl. Phys. Let. 91, 162106 (2007).

[36] Slowinski, K. et al. J. Am. Chem. Soc. 118, 4709-4710 (1996).

[37] Slowinski, K. et al. J. Am. Chem. Soc. 119, 11910-11919 (1997).

[38] Mishchenko, A. et al. Nano Lett. 10, 156-163 (2010).

[39] Tilke, A. T. Prog. Quant. Elec. 25, 97-138 (2001).

[40] Durrani, Z. A. K. Physica E: Low-dimensional Systems and Nanostructures 17, $572-578$ (2003).

[41] Aviram, A. e Ratner, M. Chem. Phys. Lett. 29, 277-283 (1974).

[42] Aviram, A. J. Am. Chem. Soc. 53, 5687-5692 (1988).

[43] Dulić, D. et al. Phys. Rev. Let. 91, 207402 (2003).

[44] Huang, J., Li, Q., e Ren, H. J. Chem. Phys 127, 094705 (2007).

[45] Yamada, R., Kumazawa, H., Noutoshi, T., Tanaka, S., e Tada, H. Nano Lett. 8, 1237-1240 (2008).

[46] He, J., Chen, F., Lindsay, S., e Nuckolls, C. Appl. Phys. Lett. 90, 072112 (2007).

[47] Lee, M. H., Speyer, G., e Sankey, O. F. J. of Phys.: Condens. Matter 19, 1-16 (2007).

[48] Xu, B. Q. et al. Nano Lett. 5, 1491-1495 (2005).

[49] Basch, H. e Ratner, M. A. J. of Chem. Phys. 123, 234704 (2005).

[50] Krüger, D., Fuchs, H., Rousseau, R., Marx, D., e Parrinello, M. Phys. Rev. Lett. 89, $186402(2002)$. 
[51] Xiao, X., Xu, B., e Tao, N. J. Nano Lett. 4, 267-271 (2004).

[52] Frisch, M. J. et al. Gaussian 03. Pittsburgh PA, (2003).

[53] Becke, A. D. J. Chem. Phys. 98, 5648-5652 (1993).

[54] Hay, P. J. e Wadt, W. R. J. Chem. Phys. 82, 299-310 (1985).

[55] Datta, S. Quantum transport, Atom to transistor. Cambridge, Cambridge, New York, Melbourne, Cape town, Singapore, São Paulo, (2005).

[56] Herrman, C. et al. J. Chem. Phys. 132, 024103 (2010).

[57] Szabo, A. e Ostlund, N. S. Modern Quantum Chemistry: Introduction to Advanced Electronic Structure Theory. Dover Publications, inc., 31 East 2nd Street, Mineola, N.Y. 11501, (1996).

[58] Hohenberg, P. e Kohn, W. Phys. Rev. 136, B864-B871 (1964).

[59] Kohn, W. e Sham, L. J. Phys. Rev. 140, A1133-A1138 (1965).

[60] Vianna, J. D. M., Fazzio, A., e Canuto, S. Teoria Quântica de Moléculas and Sólidos. Livraria da Física, São Paulo, (2004).

[61] Perdew, J. P., Burke, K., e Ernzerhof, M. Phys. Rev. Lett. 77, 3865-3868 (1996).

[62] Becke, A. D. Phys. Rev. A 38, 3098 - 3100 (1988).

[63] Lee, C., Yang, W., e Parr, R. G. Phys. Rev. B 37, 785-789 (1988).

[64] Capelle, K. Braz. J. of Phys. 36, 1318-1343 (2006).

[65] dos Santos, M. C. Polímeros condutores: Técnicas de Cálculo da Estrutura Eletrônica. PhD thesis, Universidade Federal de Pernambuco.

[66] Nita, M., Aldea, A., e Zittartz, J. J. Phys.: Condens. Matter 19, 1-7 (2007).

[67] Wei, Z. e Faul, C. F. J. Macromol. Rapid Commun. 29, 280-292 (2008). 
[68] Lim, S. L. e Tan, L. J. Chem. Phys. 112(23), 10648-10658 june (2000).

[69] Baughman, R. H., Wolf, J. F., Eckhardt, H., e Shacklette, L. W. Synth. Met. 25, 121-137 (1988).

[70] Karpfen, A., Choi, C. H., e Kertesz, M. J. Phys. Chem. A 101, 7426-7433 (1997).

[71] Kaneto, K., Yoshino, K., e Inuishi, Y. Solid State Commun. 46, 389-391 (1983).

[72] Samdal, S., Samuelsen, E. J., e Volden, H. V. Synth. Met. 59, 259-265 (1993).

[73] Almenningen, A., Bastiansen, O., e Svendas, P. Acta Chem. Scandinavica 12, 16711674 (1958).

[74] Pickholz, M. e dos Santos, M. C. J. Mol. Struct. 717, 99-106 (2005).

[75] Raya, A. J. Phys. Chem. A 101, 7426-7433 (1997).

[76] Li, X. et al. J. Chem. Phys. 126, 1-7 May (2007).

[77] Huber, K. P. e Herzberg, G. Constants of Diatomic Molecules. Van Nostrand Reinhold, New York, (1979).

[78] Hu, Q., Reuter, K., e Scheffler, M. Phys. Rev. Lett. 98, 176103 (2007).

[79] Dell'Angela, M. et al. Nano Let. 10, 2470-2474 (2010).

[80] Scott, J. C. J. Vac. Sci. Technol. 21, 521-531 (2003).

[81] Xue, Y., Datta, S., e Ratner, M. A. J. of Chem. Phys. 115, 4292-4299 (2001).

[82] Fabiano, E. et al. J. Chem. Phys 131, 234101 (2009).

[83] Dovesi, R. et al. Crystal 03. http://www.crystal.unito.it, (2003).

[84] Kergueris, C. et al. Phys. Rev. B. 59, 505-512 (1999).

[85] Stokbro, K. et al. Comp. Mat. Science 27, 151-160 (2003). 
[86] Sotelo, J. C., Yan, L., e Seminario, J. M. Phys. Rev. A 75, 022511 (2007).

[87] Solomon, G. C. et al. Chem. Phys. Chem. 10, 257-264 (2009).

[88] Markussen, S., Stadler, R., e Thygesen, K. S. Nano Lett. 10, 4260-4265 (2010).

[89] Chen, F., Nuckolls, C., e Lindsay, S. Chem. Phys. 324, 236-243 (2006).

[90] Choi, S. H., Kim, B., e Frisbie, D. Science 320, 1482-1486 (2008).

[91] Yamada, R., Kumazawa, H., Tanaka, S., e Tada, H. Appl. Phys. Express 2, 0250 $02(2009)$.

[92] Cai, L. et al. Nano Lett. 5, 2365-2372 (2005).

[93] Ning, Z. et al. Phys. Rev. B 72, 155403 (2005).

[94] Peng, G. et al. J. Phys. Chem 113, 20967-20973 (2009).

[95] Kondo, M. et al. J. Phys. Chem. A 108, 9143-9149 (2004).

[96] Tomfohr e Sankey, O. F. J. Chem. Phys. 120, 1542-1554 (2004).

[97] Hoft, R. C. et al. J. Phys.: Condens. Matter 20, 1-9 (2008).

[98] Xu, B., Xiao, X., e Tao, N. J. Am. Chem. Soc. 125, 16164-16165 (2003).

[99] da Silva, E. Z., da Silva, A. J. R., e Fazzio, A. Phys. Rev. Lett. 87, 256102 (2001).

[100] Chen, F. et al. Nano Lett. 5, 503-506 (2005).

[101] Zhou, X. Y. et al. Phys. Rev. B 75, 245407 (2004).

[102] Luzhbin, D. A. e Kaun, C.-C. Phys. Rev. B 81, 035424 (2010).

[103] Tao, J. et al. Phys. Rev. A 63, 032513 (2001).

[104] Levy, M. e Perdew, J. P. Phys. Rev. B 48, 638-645 (1993). 


\section{Lista de Tabelas}

3.1 Comparações estruturais entre os diveros métodos teóricos e experimentais da LE. Os valores experimentais foram obtidos com os sais de $\mathrm{ClO}_{4}^{-}$e $B F_{4}^{-}$(com comprimentos de ligação entre parênteses na tabela) de LE. Os índices dos átomos estão indicados na figura 3.2. Os comprimentos de ligação são dados em angstroms $(\AA)$. . . . . . . . . . . . . . . . . . . 40

3.2 Comparações estruturais entre os diveros métodos teóricos e experimentais da EM. Os índices dos átomos estão indicados na figura 3.2. Os comprimentos de ligação são dados em angstroms $(\AA)$. . . . . . . . . . . . . . . . 41

3.3 Parâmetros estruturais calculados e experimentais do dímero (2T) e tetrâmero (4T) de tiofeno. Os comprimentos de ligação são dados em angstroms $(\AA) . \quad 45$

3.4 Comparações estruturais entre os diversos métodos teóricos para um eletrodo de dois átomos de ouro. . . . . . . . . . . . . . . . . . . . . . . 47

3.5 Comparações estruturais e eletrônicas entre os métodos DFT para o eletrodo 7 com 14 átomos de ouro. Os átomos estão indicados na figura 3.9. Os comprimentos de ligação são dados em $\operatorname{angstrons}(\AA)$. . . . . . . . . . . . 48 


\section{Lista de Figuras}

1.1 (a) Exemplo de uma cadeia conectada a eletrodos que possuem como célula unitária a mesma estrutura da cadeia espalhadora. (b) Resultado da transmitância e estrutura de bandas (ver Apêndice B) . . . . . . . . . . . . . 7

1.2 Estrutura padrão do sistema metal-molécula-metal. . . . . . . . . . . . 8

1.3 Representação esquemática do aparato de medida de condutância que emprega o método MCJB. . . . . . . . . . . . . . . . . . 10

1.4 Representação esquemática da medida de condutância baseada no método STM(AFM)-BJ. Brevemente, em cada etapa temos: (I) as moléculas estão depositadas sobre o substrato metálico, enquanto a ponta encontra-se distante da superfície metálica, (II) a seguir a ponta de STM é descida até formar uma ligação com a superfície, (III) que é erguida até romper a ligação Au-Au. (IV) Eventualmente cadeias orgânicas podem ocupar a região recém quebrada entre os metáis. . . . . . . . . . . . . . . . . . 12 
1.5 Diodo usual em comparação com o modelo molecular proposto por Aviram. O diodo está representado na parte superior, com os átomos de silício indicados pela cor amarela e os dopantes com as cores vermelha $(\mathrm{P})$ e azul (N). À esquerda está a região P (com excesso de buracos), no centro a região de depleção (igual quantidade de buracos e elétrons) e à direita a região N (com mais elétrons que buracos). Na parte inferior está o modelo molecular, com a região com maior eletroafinidade à esquerda, no centro a região isolante, com átomos de carbono que ligam-se de forma $\sigma$, e à direita a região com pouca eletroafinidade. As setas abaixo da cadeia orgânica indicam a direção de um campo elétrico aplicado, onde apenas na direção indicada de verde ocorre o transporte de elétrons, pois quando estes chegam ao diodo pelo lado N "empurram" os elétrons em excesso para o lado $\mathrm{P}$, fechando circuito. Note que quando a direção do campo está indicada pela seta vermelha os elétrons que chegam pelo lado $\mathrm{P}$ param na região de depleção, devido a uma barreira criada pelo excesso de elétrons. . . . . . . . 14

1.6 Tipos de ligações que podem ser feitas entre os eletrodos metálicos e as moléculas orgânicas. Em amarelo estão representados os átomos do eletrodo, em laranja o átomo de enxofre e em cinza os átomos da molécula orgânica. . . . . . . . . . . . . . . . . . . . . 17

2.1 Esquema de um sistema molecular conectado a eletrodos metálicos. Os índices L, M e R indicam o eletrodo esquerdo, a cadeia central e o eletrodo direito, respectivamente. . . . . . . . . . . . . . . . 21

2.2 Esquema de um sistema linear formado por 3 átomos. . . . . . . . . . . . . 28

2.3 Esquema de um sistema linear formado por 4 átomos, que após renormalização dá origem a um sistema formado por apenas dois átomos. . . . . . . 29

3.1 Polianilinas nos estados de oxidação (a) Pernigranilina (PE), (b) Esmeral-

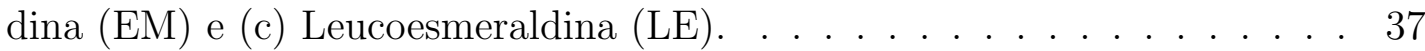


3.2 Tetrâmero de Leucoesmeraldina (a), Esmeraldina (b) e Pernigranilina (c) com grupos SH ligados nas extremidades. . . . . . . . . . . . . 37

3.3 Evolução do gap HOMO-LUMO dos oligômeros de LE (a) e PE (b). Dada a proporção de 3 anéis aromáticos e um quinóide na forma EM, calculamos apenas dois pontos: tetrâmero e octâmero, cujos gaps HOMO-LUMO calculados são de 2,25 eV e 2,01 eV, respectivamente, obtidos com B3LYP/6-

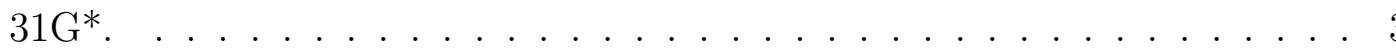

3.4 Densidade de estados dos tetrâmeros de (a) leucoesmeraldina, (b)esmeraldina e (c) pernigranilina com o grupo SH nas extremidades. As curvas em preto e vermelho representam respectivamente os estados ocupados e os virtuais.

3.5 Orbitais de fronteira HOMO e LUMO dos tetrâmeros de (a) LE, (b) EM e (c) PE. Os orbitais LUMO apresentam-se localizados principalmente sobre os anés quinóides nas estruturas oxidadas. . . . . . . . . . . . . . . 42

3.6 Estrutura esquemática do bitiofeno (superior) e quatertiofeno (inferior). . . 44

3.7 Evolução do gap HOMO-LUMO dos oligômeros de tiofeno. . . . . . . . . . . 44

3.8 Esquema do arranjo entre os eletrodos e a cadeia orgânica (dímero de tiofeno). Os retângulos vermelhos indicam a região dos modelos de eletrodos utilizados. . . . . . . . . . . . . . . . . . . 48

3.9 Eletrodos utilizados neste trabalho e suas diferentes formas de conexão com o átomo de enxofre das cadeias orgânicas. . . . . . . . . . . . . . . . 49

4.1 Variação da carga e comprimento de ligação do tetrâmero de leucoesmeraldina após conexão com eletrodos de ouro. O tipo de conexão com o eletrodo é indicada pelos números 1,2 ,.. e 7 na parte superior de cada gráfico. As geometrias dos contatos são mostradas à direita. Os índices dos átomos e das ligações no oligômero estão indicados na cadeia do topo da figura. . . . . . . . . . . . . . . . . . . 5 
4.2 Orbitais de Kohn-Sham do tetrâmero de Leucoesmeraldina. Estão indicados o número de participação (INP) e a contribuição dos orbitais dos átomos da cadeia. Os índices 1,2.. e 7 indicam o eletrodo, cujas formas de conexão bridge e atop são indicadas respectivamente pelas cores preta e

4.3 Densidade de estados projetada calculadas com o tetrâmero de LE. As curvas em preto, vermelho e verde indicam, respectivamente, a densidade de estados total, a densidade projetada na base atômica da cadeia orgânica e a densidade projetada na base atômica do ouro. Os eletrodos estão indicados pelos números $1,2, .$. e 6 . . . . . . . . . . . . . . . . . . 5

4.4 Carga acumulada nos eletrodos de ouro conectados de forma (a) atop e (b) bridge aos oligômeros.

4.5 Densidade de estados dos sistemas isolados e estendidos. No gráfico superior, a densidade de estados do eletrodo (5) é indicada em azul (spin $\alpha)$ e vermelho $(\operatorname{spin} \beta)$, a DOS do eletrodo no sistema estendido é indicado pela cor amarelo-escuro. No gráfico inferior, o sistema (7) é explorado, a DOS do eletrodo isolado é indicado em azul e no sistema estendido em amarelo. Em ambos os casos a densidade de estados da cadeia orgânica é indicada em preto quando isolada e de verde no sistema estendido. Os níveis de energia seguem o mesmo código de cores para a densidade de estados, e adicionalmente são inseridos em laranja as indicações dos níveis de fronteira do sistema estendido. . . . . . . . . . . . . . . . . . . 59

4.6 Participação dos orbitais $s, p$ e $d$ do ouro nos níveis de energia do sistema estendido. Em preto, vermelho e verde indicamos, respectivamente, os orbitais $s, p$ e $d$. O sistema estendido está indicado pelos índices (2), (4),

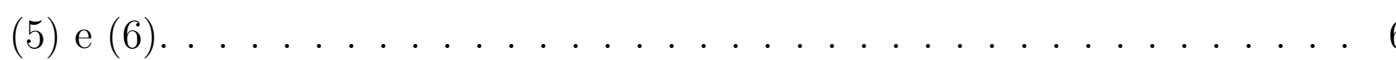


4.7 Variação dos níveis de fronteira do tetrâmero de lecoesmeraldina sob ação de campo elétrico externo. Em (a) são mostrados os níveis do sistema de conexão 2 e em (b) do sistema 4. Cada círculo possui a área proporcional ao INP. . . . . . . . . . . . . . . . . . . . . . . . 61

4.8 Variação dos níveis de energia, sob estiramento, do tetrâmero de leucoesmeraldina conectado com os eletrodos na forma (a)2(bridge) e (b)4(atop). . 62

4.9 Níveis de energia das configurações eletrodo-tetrâmero-eletrodo. Os orbitais de Kohn-Sham HOMO e LUMO são representados por H e L e os eletrodos são indicados pelos números 1,2, .. e 6 . . . . . . . . . . . . . 65

4.10 Comparação entre os orbitais dos sistemas 1,2 e $4 . \quad \ldots . \ldots .65$

5.1 Densidade de estados obtidas com o método tight-binding e com o método DFT do octâmero de LE. No método DFT é feita uma projeção da DOS total nos orbitais $P z \ldots \ldots \ldots \ldots$. . . . . . . . . . 69

5.2 Parâmetros em eV utilizados no hamiltoniano tight-binding da leucoesmeraldina. Os átomos de carbono ocupam os vértices da figura e o átomo de nitrogênio está indicado pelo círculo azul. . . . . . . . . . . . . . . . . . 69

5.3 Transmitância dos oligômeros dímero (2), trímero (3) e tetrâmero (4) de LE obtido via método tight-binding e DFT (apenas o tetrâmero, mostrado na curva dos círculos verdes). No cálculo realizado com o método DFT a conexão com o eletrodo é do tipo bridge (2) . . . . . . . . . . . . . . . . . . 70

5.4 Transmitância dos oligômeros de leucoesmeraldina obtida via DFT. A forma de conexão com os eletrodos está indicada ao lado de cada gráfico, bem como a estrutura de cada eletrodo no retângulo no canto inferior direito. Os oligômeros estão indicados no gráfico (1). A linha tracejada indica a energia de Fermi do ouro bulk obtida com B3LYP/LANL2DZ. . . . . . . . 73 
5.5 Transmitância da esmeraldina e pernigranilina obtida via DFT. Ao lado de cada gráfico estão indicados às formas de oxidação e o tipo de conexão com os eletrodos. Nos gráficos 2 (EM) e 2 (PE) estão indicados os oligômeros. A linha tracejada indica a energia de Fermi do ouro bulk obtida com B3LYP/LANL2DZ. . . . . . . . . . . . . . . . . . . 74

5.6 Comprimento de ligação entre os átomos das cadeias pernigranilina ligadas aos eletrodos (2) e (4), indicados na parte superior da figura. As cores em azul e vermelho indicam respectivamente as ligações longas e curtas. . . . . 75

5.7 Comprimento de ligação entre os átomos do tetrâmero de LE livre (0) e conectado com os eletrodos $(2,5, \ldots$ e 7$)$. Os comprimentos de ligação maiores são indicados pela cor azul e os menores pela cor vermelha. . . . . 75

5.8 Transmitância do tetrâmero de LE calculada com o método tight-binding com os parâmetros que reproduzem as conexões bridge (curva em preto) e atop (curva em vermelho). . . . . . . . . . . . . . . 76

5.9 Transmitância calculada via tight-binding do tetrâmero das formas LE, EM e PE. A seta indica a posição dos níveis dos anéis quinóides. Na curva em verde, do tetrâmero de PE, a seta indica dois níveis de energia associados com os anéis quinóides, que estão próximos e quase sobrepostos. . . . . . . 76

5.10 Transmitância das oligoanilinas sob estiramento. Os oligômeros e o tipo de conexão com os eletrodos estão indicados em cada gráfico. A linha tracejada indica a energia de Fermi do ouro bulk obtida com B3LYP/LANL2DZ. . . 82

5.11 Variação da (a) energia, (b) comprimento de ligação, (c) ângulo de torção e (d) carga acumulada nos eletrodos em função do estiramento. Utilizamos o tetrâmero de LE como referência. O comprimento de ligação se refere ao $\mathrm{C}-\mathrm{N}$, sendo $\mathrm{C}$ o átomo de carbono na posição para do anel central. O ângulo de torção é o do anel central. As curvas em preto e vermelho referem-se, respectivamente, a sistema 4-atop e 2-bridge. . . . . . . . . 83 
5.12 Níveis de energia dos orbitais HOMO e LUMO dos sistemas 2 (bridge) e 4 (atop) indicados pelos círculos vazios e preenchidos, respectivamente. As áreas dos círculos são proporcionais ao INP. . . . . . . . . . . . . . . . . . 84

5.13 Transmitância do tetrâmero das anilinas sob ação de um campo elétrico externo. As formas de oxidação e tipo de conexão com os eletrodos são dados ao lado dos gráficos. A linha tracejada indica a energia de Fermi do ouro bulk obtida com B3LYP/LANL2DZ. . . . . . . . . . . . . . . 86

5.14 Participação dos orbitais do tetrâmero de LE no sistema metal-moléculametal sob ação do campo elétrico externo. O tipo de conexão é indicada ao lado do gráfico. . . . . . . . . . . . . . . . . . . . . .

5.15 Participação dos orbitais do tetrâmero de PE no sistema metal-moléculametal sob ação do campo elétrico externo. O tipo de conexão é indicada ao lado do gráfico. A área do círculo é proporcional à porcentagem de estados da cadeia orgânica na composição do nível de energia. . . . . . . . . . . . . 87

5.16 Transmitância dos oligotiofenos conectados de forma bridge e atop com os eletrodos. O tamanho dos oligômeros é indicado pelos números dentro dos gráficos. O tipo de conexão com o eletrodo está indicado ao lado, sendo (4) atop e (2) bridge. A linha tracejada indica a energia de Fermi do ouro bulk obtida com B3LYP/LANL2DZ. . . . . . . . . . . . . . . 89

5.17 (a) Densidade de estados comparativa entre os métodos DFT e Hückel. (b) Transmitância calculada via DFT (Hückel) para as formas bridge (não quinóide-H. N. Q.) e atop (quinóide-H. Q.). . . . . . . . . . . . . . . . . . 90

5.18 Transmitância dos oligotiofenos sob estiramento. O tamanho dos oligômeros está indicado pelos números $2,3, \ldots$, e 6 e a conexão pelos números (2) (bridge) e (4) (atop). A linha tracejada indica a energia de Fermi do ouro bulk obtida com B3LYP/LANL2DZ. . . . . . . . . . . . . . . . . . . 9 
5.19 Comprimentos de ligação em $\operatorname{angstroms}(\AA)$ do tetrâmero de tiofeno sob estiramento conectado ao eletrodo 4 (atop). O estiramento das cadeias é de (a) 0, (b) 1 e (c) 2 A. Sob ação de um estiramento, uma transição quinóide-aromática é obtida. . . . . . . . . . . . . . . . . . . . . 91

B.1 Esquema do arranjo eletrodo-contato eletrodo do poliacetileno. . . . . . . . 104

B.2 Transmitância do poliacetileno, comparada com a estrutura de bandas. . 108 